Metodologia de Controle Adaptativo de Ganho para Amplificadores Ópticos em Redes WDM Dinâmicas

Uiara Celine de Moura 



\title{
Metodologia de Controle Adaptativo de Ganho para Amplificadores Ópticos em Redes WDM Dinâmicas
}

\author{
Uiara Celine de Moura
}

Orientador: Prof. Dr. Amílcar Careli César

Dissertação de mestrado apresentada à Escola de Engenharia de São Carlos, da Universidade de São Paulo, como parte dos requisitos para obtenção do título de Mestre em Ciências, Programa de Engenharia Elétrica - Área de concentração: Telecomunicações.

USP - São Carlos

Abril/2014

Trata-se da versão corrigida da dissertação. A versão original se encontra disponivel na EESC/USP que aloja o Programa de Pós-Graduação de Engenharia Elétrica. 
AUTORIZO A REPRODUÇÃO TOTAL OU PARCIAL DESTE TRABALHO, POR QUALQUER MEIO CONVENCIONAL OU ELETRÔNICO, PARA FINS DE ESTUDO E PESQUISA, DESDE QUE CITADA A FONTE.

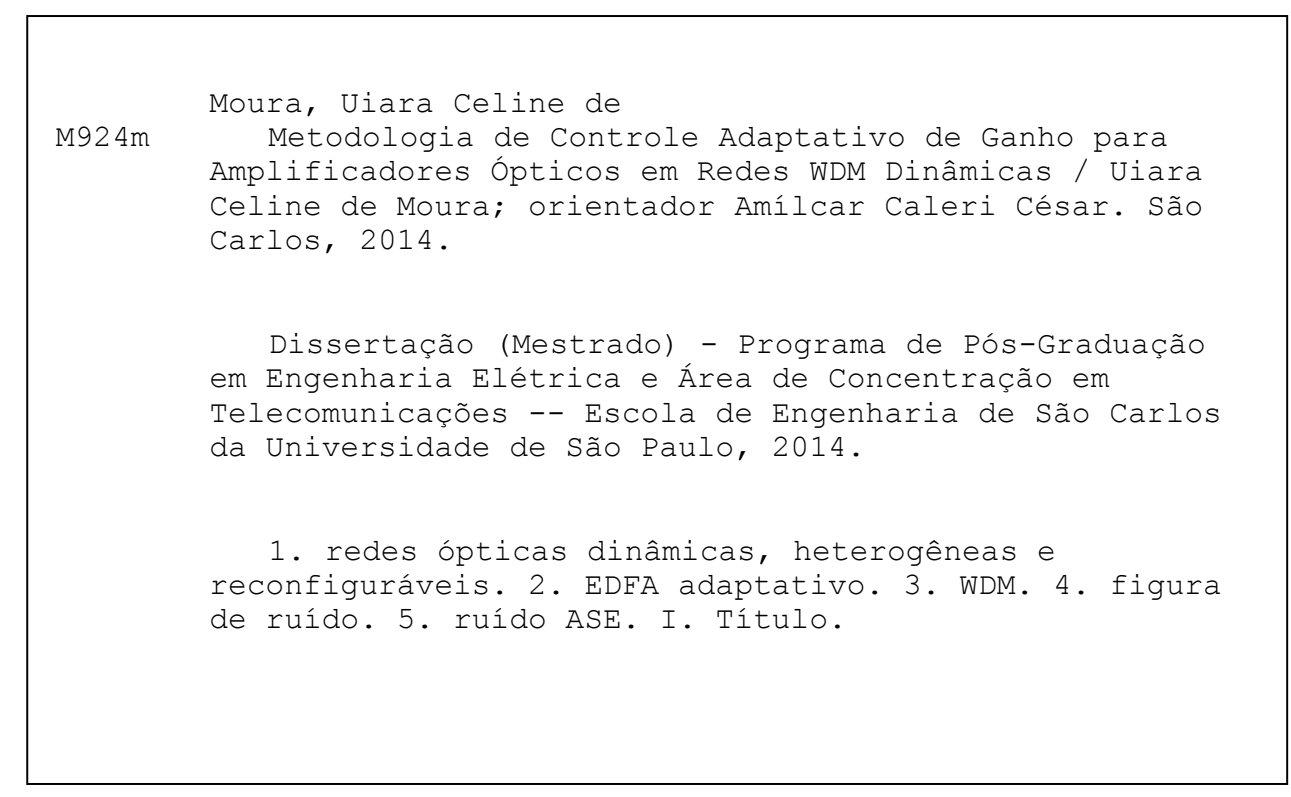




\section{FOLHA DE JULGAMENTO}

Candidata: Engenheira UIARA CELINE DE MOURA.

Título da dissertação: "Metodologia de controle adaptativo de ganho para amplificadores ópticos em redes WDM dinâmicas".

Data da defesa: 15/04/2014

Comissão Julgadora:

Prof. Titular Amílcar Careli César (Orientador)

(Escola de Engenharia de São Carlos/EESC)

Prof. Dr. Carlos Alberto De Francisco

(Universidade Federal de São Carlos/UFSCar)

Prof. Dr. Joaquim Ferreira Martins Filho

(Universidade Federal de Pernambuco/UFPE)
Resultado:
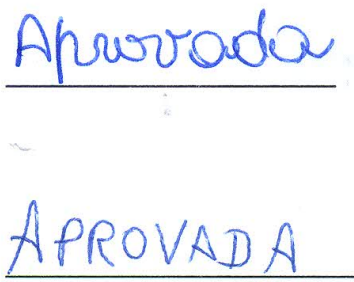

ARROVADA

Coordenador do Programa de Pós-Graduação em Engenharia Elétrica e Presidente da Comissão de Pós-Graduação:

Prof. Titular Denis Vinicius Coury 


\section{Agradecimentos}

Primeiramente, ao meu pai, Valter, que sempre acreditou em mim e é meu exemplo. À minha mãe, Nadja que, muito paciente, ficava ao meu lado enquanto eu, nervosa, fazia minhas tarefas de casa. À minha irmã, Maiara, pelo carinho e amizade.

Ao meu marido, Sérgio Henrique, meu apoio nos momentos mais difíceis.

Ao meu orientador, professor Amílcar, por toda paciência, ensinamento e apoio desde a graduação.

A Júlio por acreditar em mim e dar-me oportunidade de fazer parte da equipe do CPqD e a Juliano pela confiança e pela ajuda ao longo desses três anos de trabalho em equipe.

A Eduardo, aluno do professor Amílcar, pela ajuda neste trabalho.

A todos os meus colegas e amigos de trabalho que estão ou estiveram sempre ao meu lado, ouvindo, ensinando e de alguma forma, me apoiando na conclusão este trabalho.

Aos amigos que encontrei ao longo do caminho e continuam comigo até hoje.

Aos meus amigos de infância que, mesmo distantes, estão no meu coração.

À tia Helena. 


\section{Resumo}

MOURA, U. C. Metodologia de Controle Adaptativo de Ganho para Amplificadores Ópticos em Redes WDM Dinâmicas. 2014. Dissertação (Mestrado) - Escola de Engenharia de São Carlos, Universidade de São Paulo, São Carlos, 2014.

Para suportar as novas aplicações heterogêneas e dinâmicas, como a TV digital interativa, os vídeos sob demanda e a computação em nuvem, as redes ópticas WDM (wavelength division multiplexing) estão passando por uma grande mudança. Estão deixando de ser estáticas para se tornarem reconfiguráveis. Assim, elas devem suportar diferentes taxas e formatos de modulação, que podem variar com o tempo, tornando-as heterogêneas tanto no que se refere aos tipos de serviços, quanto às tecnologias de transmissão. Assim, novos desafios para controlar e administrar estas redes estão surgindo e soluções cognitivas estão começando a ser estudadas. Uma das premissas de uma solução cognitiva é a adaptabilidade. Neste cenário, este trabalho propõe uma metodologia de controle adaptativo de ganho para amplificadores ópticos em redes WDM dinâmicas. Tal metodologia baseia-se em uma máscara de potência com informações sobre o desempenho óptico do amplificador em termos de figura de ruído e "planicidade" espectral de ganho, ajustando seu ponto de operação visando um compromisso entre estes parâmetros. Esta metodologia foi aplicada em um problema de roteamento e alocação de comprimento de onda para algumas topologias de redes com 4, 6, 10 e 15 nós e considerando uma restrição de qualidade de serviço, relacionada à OSNR do sinal, para realização da conexão. Os resultados mostram uma redução na probabilidade de bloqueio total com a aplicação da metodologia proposta em relação a um cenário sem a metodologia de $80 \%$ para abaixo de $20 \%$ em alguns casos.

Palavras chave: redes ópticas dinâmicas, heterogêneas e reconfiguráveis, EDFA adaptativo, WDM, figura de ruído, ruído ASE. 


\section{Abstract}

MOURA, U. C. Adaptive Gain Control Methodology for Optical Amplifiers in Dynamic WDM Networks. 2014. Dissertation (Master's Degree) - Engineering School of Sao Carlos, University of Sao Paulo, Sao Carlos, 2014.

To support new dynamic and heterogeneous applications such as interactive digital TV, video on demand and cloud computing, WDM (wavelength division multiplexing) optical networks are undergoing significant changes. They are changing from static to reconfigurable networks. Thus, they need to support different data rates and modulation formats, which can varie along the time, leading to a heterogeneous network with respect not only to different services, but also to different transmission technology. Therefore, new network control and management challenges are arising and cognitive solutions are being studied. One of the cognitive solution premises is adaptability. In this scenario, this work propose an adaptive gain control methodology for optical amplifiers in WDM dynamic optical networks. Such methodology is based on a power mask with information about the amplifier optical performance in terms of noise figure and gain flatness, adjusting its operating point aiming to the best trade off between these parameters. This methodology was applied to a routing and wavelength assignment problem to some network topology with 4,6 , 10 and 15 nodes and considering a quality of service constraint, due to the signal OSNR, to accomplish the connection. Results show blocking probability reduction from $80 \%$ to bellow $20 \%$ for some cases from a scenario without the methodology to one with it.

Keywords: dynamic, heterogeneous and reconfigurable optical networks, adaptive EDFA, WDM, noise figure, ASE noise. 


\section{Sumário}

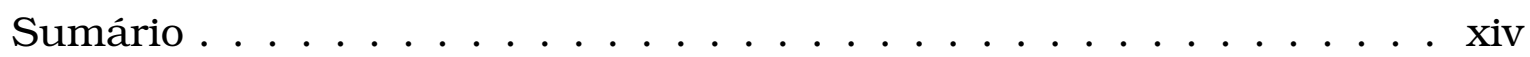

Lista de Figuras . . . . . . . . . . . . . . . xxi

Lista de Abreviaturas . . . . . . . . . . . . . . xxiv

1 Introdução 1

2 Amplificadores Ópticos $\quad 7$

2.1 Amplificadores a fibra dopada com érbio (EDFA) $\ldots \ldots \ldots$

2.2 Máscara de potência de amplificadores ópticos . . . . . . . . 11

3 Metodologia de Controle Adaptativo de Ganho em Amplificadores Ópticos $\quad 13$

3.1 Caracterização . . . . . . . . . . . . . . . . 13

3.1.1 Etapa experimental . . . . . . . . . . . . . . 14

3.1.2 Etapa de tratamento dos dados experimentais . . . . . . . 17

3.1 .3 Resultado da caracterização . . . . . . . . . . . . . 18

3.2 Metodologia . . . . . . . . . . . . . . . . . . . . 19

3.2 .1 Função qualidade . . . . . . . . . . . . . . . . 19

3.2 .2 Seleção e ajuste de ganho . . . . . . . . . . . . . . 21

3.2 .3 Peso dos parâmetros . . . . . . . . . . . . . . . . 22

4 Roteamento e Atribuição de Comprimento de Onda (RWA) 25

5 Aplicação da Metodologia $\quad 31$

5.1 Descrição . . . . . . . . . . . . . . . . . 32

5.2 Primeiro caso: sem a metodologia adaptativa . . . . . . . . . 39

5.3 Segundo caso: com a metodologia adaptativa . . . . . . . . . . 43

5.4 Validação da simulação . . . . . . . . . . . . . . . . 45

5.5 Escolha dos limiares . . . . . . . . . . . . . . . . . 47

5.6 Resultados . . . . . . . . . . . . . . . . 51 
6 Conclusões e trabalhos futuros

Referências

A Modelagem do tráfego da rede

B Passo a passo de cada evento

C OSNR por conexão

D Figura de ruido por conexão

E Probabilidade de bloqueio $x$ carga com restrição de NF

F Probabilidade de bloqueio $x$ carga com restrição de NF para rede com 20 canais

G Artigos sobre esta pesquisa 


\section{Lista de Figuras}

1.1 Crescimento do tráfego nas redes ópticas como uma função do tempo, histórico e previsão [2]. . . . . . . . . . . . . . 2

2.1 Circuito óptico do amplificador a fibra dopada com érbio. . . . . 8

2.2 Níveis de energia de um íon érbio na sílica. . . . . . . . . . 9

2.3 Curva de ganho em função do comprimento de onda para o EDFA. 10

2.4 Região definida como máscara de potência de um amplificador

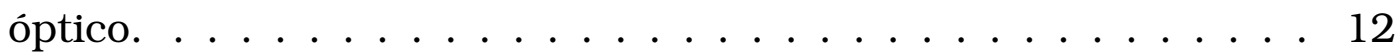

3.1 Montagem experimental do caracterizador de amplificadores. WSS se refere á chave seletora de comprimento de onda e OSA é o analisador de espectro óptico. . . . . . . . . . . . . 15

3.2 Máscaras de potência com informações de (a) Figura de ruído, (b) "Planicidade" espectral de ganho, (c) Precisão de controle de ganho e (d) medidas dos espectros de entrada e saída exemplificando as medidas de "planicidade" espectral de ganho e OSNR. 18

3.3 Espaço de objetivos (figura de ruído versus "planicidade") para Pin $=-15 \mathrm{dBm}$ com a representação dos parâmetros usados para calcular a função de qualidade: distância $d_{i}$ e ângulo $\theta_{i}$. A barra de cores mapeia os valores de ganho. . . . . . . . 20

3.4 Máscara de potência com os valores absolutos da função qualidade. . . . . . . . . . . . . . . . 20

3.5 Espaço de objetivos para Pin $=-15 \mathrm{dBm}$ com o ponto de operação escolhido: Ganho $(\mathrm{G})=19 \mathrm{~dB}$ por apresentar a menor distância à origem. . . . . . . . . . . . . . . 21

3.6 Espaço de objetivos para Pin $=-15 \mathrm{dBm}$ e máscara da função qualidade para diferentes valores de pesos para a "planicidade" espectral de ganho: (a) e (b) $G F_{W}=1$, (c) e (d) $G F_{W}=0,5$ e (e) e (f) $G F_{W}=0,25 . \ldots \ldots \ldots \ldots \ldots \ldots \ldots \ldots \ldots$ 
4.1 Rede óptica WDM com conexões em comprimento de onda. . . . 26

5.1 Rede de quatro nós utilizada para desenvolver a simulação. WSS são as chaves seletoras de comprimentos de onda. . . . . . 35

5.2 Máscara de potência do amplificador de potência - Amp 1 do enlace. (a) sem e (b) com a metodologia adaptativa. Destaque em azul para os possíveis pontos de operação dada as suas potências de entrada com carregamento variando do mínimo ao máximo. . . . . . . . . . . . . . . .

5.3 Máscara de potência do pré-amplificador - Amp 2 do enlace. (a) sem e (b) com a metodologia adaptativa. Destaque em azul para os possíveis pontos de operação dada as suas potências de entrada com carregamento variando do mínimo ao máximo. . . 38

5.4 Rede de seis nós utilizada na simulação. . . . . . . . . . . . . 38

5.5 Cascata de amplificadores com componentes de perdas. . . . . . 40

5.6 Topologia de enlace utilizado nas redes simuladas. . . . . . . . . 41

5.7 Enlace visto como uma caixa preta para cálculo do fator de ruído do caminho. . . . . . . . . . . . . . . 41

5.8 Caminho utilizado para validação dos cálculos de figura de ruído e OSNR. .....................

5.9 Probabilidade de bloqueio versus carga para as topologias de rede de (a) quatro, (b) seis, (c) dez e (d) quinze nós para algumas condições de canais disponíveis sem restrições e sem a utilização da metodologia adaptativa. . . . . . . . . . . . . . .

5.10 OSNR na recepção de cada conexão para os caminhos de ida e volta para uma rede de seis nós: (a) sem AdGC e carga de 50 erlangs, (b) com AdGC e carga de 50 erlangs, (c) sem AdGc e carga de 200 erlangs e (d) com AdGC e carga de 200 erlangs. Curva em azul corresponde à evolução do número de canais presentes na rede em função do tempo de chegada e a linha em vermelho é o limiar escolhido.

5.11 OSNR na recepção de cada conexão para os caminhos de ida e volta para uma rede de quinze nós: (a) sem AdGC e carga de 50 erlangs, (b) com AdGC e carga de 50 erlangs, (c) sem AdGc e carga de 200 erlangs e (d) com AdGC e carga de 200 erlangs. Curva em azul corresponde à evolução do número de canais presentes na rede em função do tempo de chegada e a linha em vermelho é o limiar escolhido. . . . . . . . . . . . . . .

5.12 Número de conexões presentes na rede de quinze nós ao longo de todo tempo de alocações e desalocações com uma carga de (a) 50 erlangs e (b) 200 erlangs e sem a metodologia adaptativa. 
5.13 Probabilidade de bloqueio versus carga para a topologia de seis nós com restrição de OSNR (limiar de $27 \mathrm{~dB}$ ) com e sem a metodologia adaptativa (AdGC) . . . . . . . . . . . . . . 53

5.14 Probabilidade de bloqueio total versus carga para: (a) topologia de quatro nós com restrição de OSNR (limiar de $26 \mathrm{~dB}$ ), (b) topologia de dez nós com restrição de OSNR (limiar de $26 \mathrm{~dB}$ ) e (c) topologia de quinze nós com restrição de OSNR (limiar de 24 dB). Todas com e sem a metodologia adaptativa (AdGC) . . . . . 54

5.15 Probabilidade de bloqueio total versus carga para a topologia de seis nós com restrição de OSNR (limiar de $27 \mathrm{~dB}$ ) com 20 canais disponíveis na rede com e sem a metodologia adaptativa (AdGC). 56

5.16 Probabilidade de bloqueio total versus carga para todas as topologia com restrição de OSNR (limiar de 26,32 dB) com 20 canais disponiveis na rede com e sem a metodologia adaptativa (AdGC). 57

A.1 Geração de tráfego da rede. . . . . . . . . . . . . . . . 68

C.1 OSNR na recepção de cada conexão para os caminhos de ida e volta para uma rede de quatro nós sem AdGC e carga de 50 erlangs. Curva em azul corresponde à evolução do número de canais presentes na rede em função do tempo de chegada e a linha em vermelho é o limiar escolhido. . . . . . . . . . . . . 79

C.2 OSNR na recepção de cada conexão para os caminhos de ida e volta para uma rede de quatro nós com AdGC e carga de 50 erlangs. Curva em azul corresponde à evolução do número de canais presentes na rede em função do tempo de chegada e a linha em vermelho é o limiar escolhido. . . . . . . . . . . . . 80

C.3 OSNR na recepção de cada conexão para os caminhos de ida e volta para uma rede de quatro nós sem AdGC e carga de 200 erlangs. Curva em azul corresponde à evolução do número de canais presentes na rede em função do tempo de chegada e a linha em vermelho é o limiar escolhido. . . . . . . . . . . . . . 80

C.4 OSNR na recepção de cada conexão para os caminhos de ida e volta para uma rede de quatro nós com AdGC e carga de 200 erlangs. Curva em azul corresponde à evolução do número de canais presentes na rede em função do tempo de chegada e a linha em vermelho é o limiar escolhido. . . . . . . . . . . . .81 
C.5 OSNR na recepção de cada conexão para os caminhos de ida e volta para uma rede de dez nós sem AdGC e carga de 50 erlangs. Curva em azul corresponde à evolução do número de canais presentes na rede em função do tempo de chegada e a linha em vermelho é o limiar escolhido. . . . . . . . . . . . . . .

C.6 OSNR na recepção de cada conexão para os caminhos de ida e volta para uma rede de dez nós com AdGC e carga de 50 erlangs. Curva em azul corresponde à evolução do número de canais presentes na rede em função do tempo de chegada e a linha em vermelho é o limiar escolhido. . . . . . . . . . . .

C.7 OSNR na recepção de cada conexão para os caminhos de ida e volta para uma rede de dez nós sem AdGC e carga de 200 erlangs. Curva em azul corresponde à evolução do número de canais presentes na rede em função do tempo de chegada e a linha em vermelho é o limiar escolhido. . . . . . . . . . . .

C.8 OSNR na recepção de cada conexão para os caminhos de ida e volta para uma rede de dez nós com AdGC e carga de 200 erlangs. Curva em azul corresponde à evolução do número de canais presentes na rede em função do tempo de chegada e a linha em vermelho é o limiar escolhido. . . . . . . . . . . . .

D.1 Figura de ruído de cada conexão para os caminhos de ida e volta para uma rede de quatro nós sem AdGC e carga de 50 erlangs. Curva em azul corresponde à evolução do número de canais presentes na rede em função do tempo de chegada e a linha em vermelho é o limiar escolhido. . . . . . . . . . . . .

D.2 Figura de ruído de cada conexão para os caminhos de ida e volta para uma rede de quatro nós com AdGC e carga de 50 erlangs. Curva em azul corresponde à evolução do número de canais presentes na rede em função do tempo de chegada e a linha em vermelho é o limiar escolhido. . . . . . . . . . . 86

D.3 Figura de ruído de cada conexão para os caminhos de ida e volta para uma rede de quatro nós sem AdGC e carga de 200 erlangs. Curva em azul corresponde à evolução do número de canais presentes na rede em função do tempo de chegada e a linha em vermelho é o limiar escolhido. . . . . . . . . . . . . 86

D.4 Figura de ruído de cada conexão para os caminhos de ida e volta para uma rede de quatro nós com AdGC e carga de 200 erlangs. Curva em azul corresponde à evolução do número de canais presentes na rede em função do tempo de chegada e a linha em vermelho é o limiar escolhido. . . . . . . . . . . . 
D.5 Figura de ruído de cada conexão na saída dos caminhos de ida e volta para uma rede de seis nós sem AdGC e carga de 50 erlangs. Curva em azul corresponde à evolução do número de canais presentes na rede em função do tempo de chegada e a linha em vermelho é o limiar escolhido. . . . . . . . . . . . . .

D.6 Figura de ruído de cada conexão na saída dos caminhos de ida e volta para uma rede de seis nós co AdGC e carga de 50 erlangs. Curva em azul corresponde à evolução do número de canais presentes na rede em função do tempo de chegada e a linha em vermelho é o limiar escolhido.

D.7 Figura de ruído de cada conexão na saída dos caminhos de ida e volta para uma rede de seis nós sem AdGC e carga de 200 erlangs. Curva em azul corresponde à evolução do número de canais presentes na rede em função do tempo de chegada e a linha em vermelho é o limiar escolhido. . . . . . . . . . . . . .

D.8 Figura de ruído de cada conexão na saída dos caminhos de ida e volta para uma rede de seis nós com AdGC e carga de 200 erlangs. Curva em azul corresponde à evolução do número de canais presentes na rede em função do tempo de chegada e a linha em vermelho é o limiar escolhido. . . . . . . . . . . . . .

D.9 Figura de ruído de cada conexão para os caminhos de ida e volta para uma rede de dez nós sem AdGC e carga de 50 erlangs. Curva em azul corresponde à evolução do número de canais presentes na rede em função do tempo de chegada e a linha em vermelho é o limiar escolhido. . . . . . . . . . . . . . . . . 89

D.10 Figura de ruído de cada conexão para os caminhos de ida e volta para uma rede de dez nós com AdGC e carga de 50 erlangs. Curva em azul corresponde à evolução do número de canais presentes na rede em função do tempo de chegada e a linha em vermelho é o limiar escolhido. . . . . . . . . . . . . . . . 990

D.11 Figura de ruído de cada conexão para os caminhos de ida e volta para uma rede de dez nós sem AdGC e carga de 200 erlangs. Curva em azul corresponde à evolução do número de canais presentes na rede em função do tempo de chegada e a linha em vermelho é o limiar escolhido. . . . . . . . . . . . . . . . 990

D.12 Figura de ruído de cada conexão para os caminhos de ida e volta para uma rede de dez nós com AdGC e carga de 200 erlangs. Curva em azul corresponde à evolução do número de canais presentes na rede em função do tempo de chegada e a linha em vermelho é o limiar escolhido. 
D.13 Figura de ruído de cada conexão na saída dos caminhos de ida e volta para uma rede de quinze nós sem AdGC e carga de 50 erlangs. Curva em azul corresponde à evolução do número de canais presentes na rede em função do tempo de chegada e a linha em vermelho é o limiar escolhido. . . . . . . . . . . . .

D.14 Figura de ruído de cada conexão na saída dos caminhos de ida e volta para uma rede de quinze nós com AdGC e carga de 50 erlangs. Curva em azul corresponde à evolução do número de canais presentes na rede em função do tempo de chegada e a linha em vermelho é o limiar escolhido. . . . . . . . . . . . . . . 92

D.15 Figura de ruído de cada conexão na saída dos caminhos de ida e volta para uma rede de quinze nós sem AdGC e carga de 200 erlangs. Curva em azul corresponde à evolução do número de canais presentes na rede em função do tempo de chegada e a linha em vermelho é o limiar escolhido. . . . . . . . . . . .

D.16 Figura de ruído de cada conexão na saída dos caminhos de ida e volta para uma rede de quinze nós com AdGC e carga de 200 erlangs. Curva em azul corresponde à evolução do número de canais presentes na rede em função do tempo de chegada e a linha em vermelho é o limiar escolhido. . . . . . . . . . . . . .

E.1 Probabilidade de bloqueio versus carga para a topologia de quatro nós com restrição de NF (limiar de 20 dB). . . . . . . . . . . 95

E.2 Probabilidade de bloqueio total versus carga para a topologia de seis nós com restrição de NF (limiar de 19 dB). . . . . . . . . . . 95

E.3 Probabilidade de bloqueio total versus carga para a topologia de dez nós com restrição de NF (limiar de 20 dB). . . . . . . . . . . 96

E.4 Probabilidade de bloqueio total versus carga para a topologia de dez nós com restrição de NF (limiar de 22 dB). . . . . . . . . . . 96

F.1 Probabilidade de bloqueio total versus carga para a topologia de quatro nós com restrição de OSNR (limiar de 26 dB) com 20 canais disponíveis na rede. . . . . . . . . . . . . .

F.2 Probabilidade de bloqueio total versus carga para a topologia de dez nós com restrição de OSNR (limiar de 26 dB) com 20 canais disponiveis na rede. . . . . . . . . . . . . .

F.3 Probabilidade de bloqueio total versus carga para a topologia de quinze nós com restrição de OSNR (limiar de 24 dB) com 20 canais disponíveis na rede. . . . . . . . . . . . . 
F.4 Probabilidade de bloqueio total versus carga para a topologia de seis nós com restrição de NF (limiar de $19 \mathrm{~dB}$ ) com 20 canais disponíveis na rede. . . . . . . . . . . . . . . . . 99

F.5 Probabilidade de bloqueio total versus carga para a topologia de quatro nós com restrição de NF (limiar de 20 dB) com 20 canais disponíveis na rede. . . . . . . . . . . . . . . . . . 99

F.6 Probabilidade de bloqueio total versus carga para a topologia de dez nós com restrição de NF (limiar de $20 \mathrm{~dB}$ ) com 20 canais disponiveis na rede. . . . . . . . . . . . . . 100

F.7 Probabilidade de bloqueio total versus carga para a topologia de quinze nós com restrição de NF (limiar de $22 \mathrm{~dB}$ ) com 20 canais disponiveis na rede. . . . . . . . . . . . 100 
Xxii 


\section{Lista de Abreviaturas}

ASE amplified spontaneous emission

BER bit error rate

CD chromatic dispersion

DWDM dense wavelength division multiplexing

EDFA erbium-doped fiber amplifier

FF first-fit

FWM four-wave mixing

LCP least-congested-path

LU least-used

MU most-used

NP non-deterministic polynomial time

OEO óptico-elétrico-óptico

OIM optical impairment monitoring

OSA optical spectrum analyzer

OSNR optical signal noise ratio

PDL polarization dependent loss

PLI-RWA physical layer impairment - RWA

PLIC-RWA physical layer impairment constrained - RWA

PLIA-RWA physical layer impairment aware - RWA 
PMD polarization mode dispersion

RWA routing and wavelength assignment

$\mathbf{R Z}$ return-to-zero

SBS spontaneous Brillouin scattering

SCP shortest-cost-path

SP short-path

SPM self-phase modulation

SRS spontaneous Raman scattering

VOA variable optical attenuator

WDM wavelength division multiplexing

WSS wavelength selective switch

XPM cross-phase nodulation 


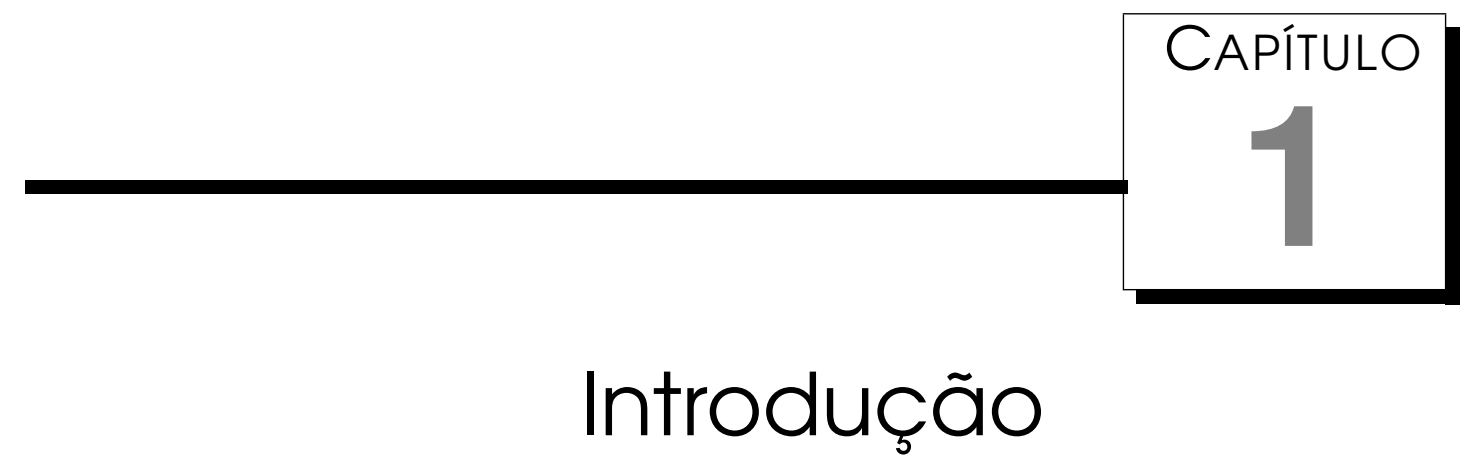

As redes de comunicações ópticas começaram a ser implantadas no mundo a partir da década de 80 e, com a evolução das técnicas de fabricação de fibras ópticas de baixa perda (em torno de $0,2 \mathrm{~dB} / \mathrm{km}$ na região de $1,55 \mu \mathrm{m}$ ) [1], continuam sendo um importante meio de comunicação devido à sua alta capacidade de transmissão.

Desde a época de sua implantação até os dias de hoje, as redes ópticas têm experimentado um incrível aumento no tráfego de dados, principalmente após o surgimento da internet nos anos 90, como pode ser visto na Figura 1.1 [2]. Esta figura apresenta a evolução histórica e a previsão para o tráfego de dados nas redes ópticas em função do tempo, tanto em termos de pesquisa, quanto comercial.

Atualmente, as redes ópticas implantadas funcionam de forma praticamente estática e são construídas para operar com especificações bem definidas, como níveis de potência óptica ou relação sinal ruído óptica. Uma variação de um destes parâmetros pode causar a queda de toda a rede [3]. Além disso, uma rede estática, mesmo com alta capacidade, não é suficiente para suportar as demandas das novas aplicações dinâmicas como os vídeos sob demanda, computação em nuvem e a TV digital interativa. Dessa forma, uma nova geração de redes ópticas WDM (wavelength division multiplexing) reconfiguráveis e dinâmicas começa a aparecer para atender estas necessidades [4].

Um dos primeiros passos para as redes ópticas se tornarem dinâmicas foi a redução no uso de conversores óptico-elétrico-óptico (OEO) nos nós de chaveamento e amplificação, tornando-as mais flexíveis. Estes conversores são responsáveis pela regeneração do sinal no que diz respeito à amplitude, ao 


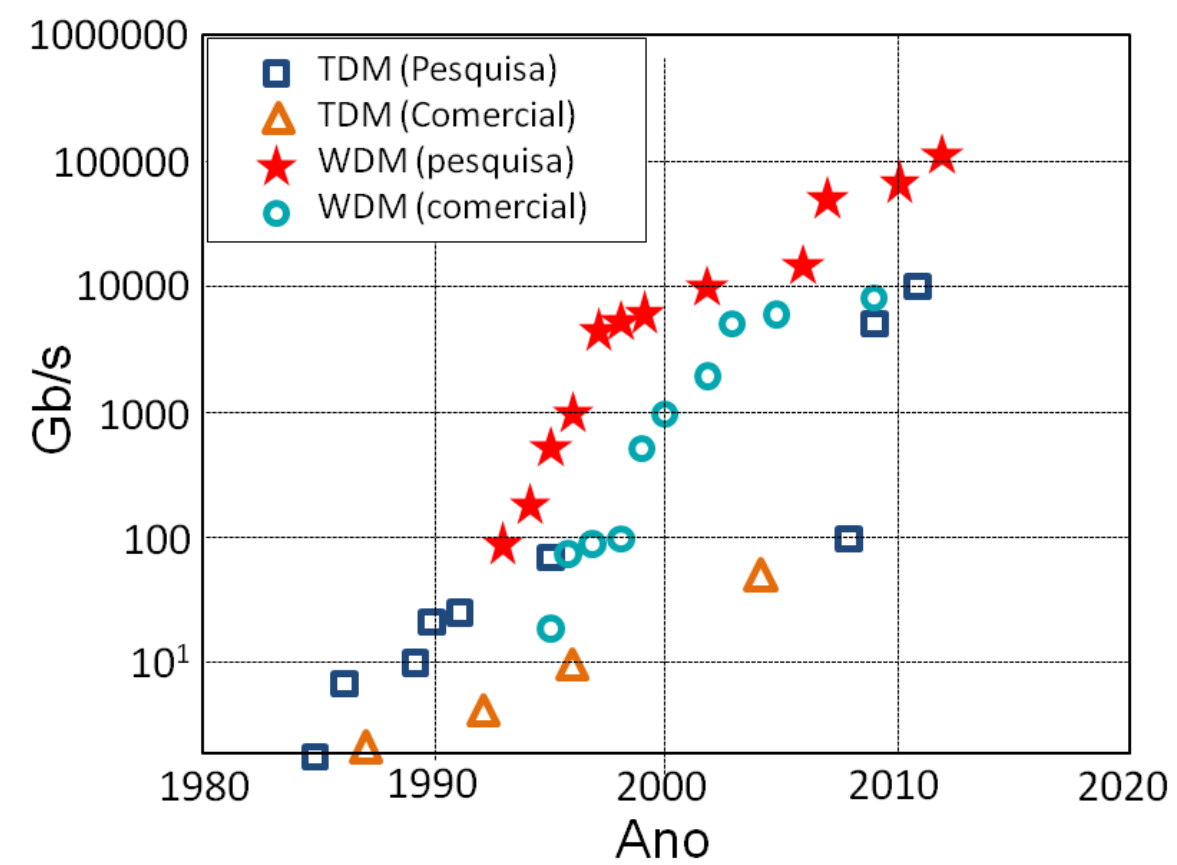

Figura 1.1: Crescimento do tráfego nas redes ópticas como uma função do tempo, histórico e previsão [2].

formato e à temporização, permitindo alcançar longas distâncias. Em contrapartida, tal equipamento de processamento eletrônico é custoso devido ao consumo de energia, à dissipação de calor e ao espaço ocupado nas estações, além da dependência com a taxa de transmissão e com o formato de modulação do sinal [4], tornando a rede inflexível em relação a alterações destes parâmetros.

Assim, as redes estão deixando de ser opacas (nas quais o sinal passa por um conversor OEO em cada processo de chaveamento) e translúcidas (ainda com alguns conversores $\mathrm{OEO}$ ) para se tornarem totalmente ópticas (redes transparentes), onde todo processo de chaveamento e amplificação é realizado no domínio óptico [4].

No entanto, esta longa permanência do sinal no domínio óptico em uma rede óptica transparente faz com que algumas penalidades da camada física, como adição de ruído, dispersão cromática, dispersão por modo de polarização e efeitos não lineares, prejudiquem a qualidade do sinal. Estas degradações afetam a intensidade do sinal bem como suas propriedades temporais, espectrais e de polarização [4], e causam o aumento da taxa de erro de bit (bit error rate, BER) do sinal, podendo chegar a níveis não aceitáveis para recepção [5].

Além de se tornarem dinâmicas no sentido de suportar diferentes carregamentos de canais e diferentes taxas e formatos de modulação variando no tempo, as redes estão se tornando heterogêneas, tanto no que se refere aos tipos de serviços, quanto às tecnologias de transmissão. Um grande desafio destas novas redes dinâmicas e heterogêneas é como controlar e administrar 
eficientemente os recursos de forma a manter a qualidade de serviço requerida [6].

Propostas interessantes surgiram para solucionar estes novos problemas. Porém, antes desses problemas serem detectados, já em 2001, [7] menciona que o controle automático de ganho, presente nos amplificadores ópticos, já é uma forma de adaptação. Até onde se sabe, ele é o primeiro a apresentar uma forma mais ampla da aplicação do conceito de adaptação em amplificadores ópticos, na qual eles podem ajustar seu estado de operação automaticamente de modo a suprir às necessidades de aplicações do sistema.

As redes sem fio começaram a utilizar processos cognitivos como uma solução para os problemas de controle e administração das futuras redes complexas, heterogêneas e com requisitos de confiabilidade [8], [9]. Como tais necessidades são semelhantes às das redes ópticas, as redes cognitivas passaram a ser vistas como um novo paradigma para também solucionar a crescente complexidade das redes ópticas [10]. Ainda em [10], é apresentado como uma rede óptica pode evoluir desde ser ciente, adaptativa até cognitiva. A cognição é definida por três atributos: consciência (percebendo as condições atuais), adaptação (planejando, decidindo e atuando baseado nas condições atuais) e capacidade de aprendizado através das adaptações. Este conhecimento é utilizado para futuras decisões, sempre considerando objetivos fim-a-fim da rede. Exemplos de tais objetivos fim-a-fim são a redução das penalidades durante a transmissão que garantem a manutenção da relação sinal ruído óptica (optical signal to noise ratio, OSNR) acima do limite relacionado à qualidade de serviço requerida.

Em [11], as redes cognitivas também são vistas como soluções para suportar a evolução das redes ópticas. Tanto [10] quanto [11] apresentam sugestões de arquiteturas de redes cognitivas. Tais sugestões incluem módulos adicionais nos nós das redes ópticas para suportar cognição, permitindo adaptações dinâmicas de parâmetros físicos da rede, como formatos de modulação ou taxas de transmissão [10], ou suportando serviço de banda adaptativa em nível de comprimentos de onda e sub comprimentos de onda [11].

Ainda sobre processos cognitivos, [12] e [13] apresentam uma proposta alternativa de predição da qualidade de transmissão dos caminhos ópticos baseado em cognição, explorando experiências passadas. Já [6], além de discutir os fundamentos de cognição, com aplicação em redes ópticas, descreve algumas arquiteturas de redes cognitivas encontradas até então na literatura.

Processos adaptativos estão sempre presentes nas soluções cognitivas apresentadas. Porém, eles são encontrados apenas em transmissores/receptores, ou ao longo dos nós da rede para alterar formatos de modulação, taxa de transmissão e alocação de banda. Exemplos desses processos adaptativos 
podem ser vistos em [14], onde o mínimo recurso espectral, em termos de fatias do espectro, é alocado de forma adaptativa, de acordo com as condições físicas do caminho óptico fim-a-fim. Neste cenário, formatos de modulação e largura de banda dos filtros são utilizados como parâmetros para determinar os recursos espectrais a serem alocados no caminho óptico. Ou em [15], onde um transmissor óptico flexível que pode alterar tanto a taxa de símbolos quanto o formato de modulação é proposto, juntamente com um receptor flexível, baseado em detecção coerente e capaz de realizar medidas de BER do sinal óptico em diferentes formatos de modulação. Essas medidas de BER são utilizadas por um controlador para determinar automaticamente o formato de modulação, a taxa de bits e as rotas de caminhos ópticos adequados.

Até onde se sabe, não foram encontradas propostas atuais que tratassem do processo adaptativo em amplificadores visando a melhora do seu próprio desempenho e do desempenho do sistema fim-a-fim.

Para o amplificador adaptativo proposto em [7], é necessário definir o nível do sinal de entrada do amplificador, que auxilia na determinação de quais parâmetros serão otimizados: ganho e figura de ruído caso a potência de entrada seja baixa (pequenos sinais, pré-amplificador), potência de saída e ganho se a potência de entrada for alta (saturação, amplificadores de potência) ou um balanceamento destes parâmetros para potência de entrada intermediária. Assim, nesta proposta, é necessário conhecer os fatores que afetam o desempenho dos amplificadores, como ganho e figura de ruído, para construir um amplificador adaptativo. Deve-se obter as relações desses fatores previamente e descobrir sob quais condições e quais parâmetros precisam ser otimizados, sendo possivel desenvolver um programa auto-adaptativo que, de acordo com um dado sinal de entrada, controla as variáveis relacionadas para suprir demandas diferentes do sistema.

Ainda em [7], o amplificador adaptativo é exemplificado a partir de um amplificador a fibra dopada com érbio (erbium doped fiber amplifier, EDFA) de dois estágios, sendo o primeiro responsável por otimizar o parâmetro de ruído enquanto o segundo otimiza o ganho. Além disso, um filtro sintonizável é utilizado para otimizar o desempenho de banda, isto é, a "planicidade" espectral de ganho. Esta topologia de amplificação (EDFA) é utilizada em [7] para investigar a possibilidade de realização do amplificador adaptativo, que é restrito ao EDFA de dois estágios, não abrangendo outras tecnologias (Raman ou híbrido: EDFA + Raman) e topologias (um, dois ou mais estágios) de amplificação. Além disso, [7] não apresenta resultados sistêmicos da aplicação do amplificador adaptativo em uma rede óptica.

Visando propor uma solução que possa evoluir para um amplificador cognitivo, é necessário haver uma metodologia adaptativa que possa ser aplicada, 
igualmente, para todos os amplificadores de uma rede, tanto nos já existentes, quanto em novas plataformas de amplificação, sem que seja necessária a construção de novos amplificadores apenas para suprir esta necessidade. Tal metodologia não pode ser restrita nem à tecnologia utilizada para amplificação (EDFA, Raman, etc.) e nem à topologia (um ou mais estágios de amplificação).

Neste trabalho, é apresentada uma metodologia de controle adaptativo de ganho para amplificadores ópticos que busca o melhor ponto de operação e o altera, em termos de ganho ajustado, em redes WDM dinâmicas. Esta metodologia será aplicada em conjunto com o roteamento e atribuição de comprimento de onda em uma rede WDM dinâmica. O objetivo é obter uma redução da probabilidade de bloqueio com a aplicação da metodologia quando restrições referentes à qualidade de serviço em termos de OSNR ou figura de ruído são consideradas.

A metodologia de controle adaptativo de ganho visa um melhor compromisso entre os parâmetros de figura de ruído e "planicidade" espectral de ganho do dispositivo amplificador. Assim, o amplificador óptico pode se adaptar, de acordo com a sua atual potência de entrada, visando a mínima degradação das características do sinal óptico e melhora do desempenho da rede fim-afim.

A metodologia de adaptação proposta neste trabalho poderá ser aplicada para qualquer tecnologia de amplificação: à fibra dopada com terra rara, por efeito Raman, por efeito Brillouin, amplificadores paramétricos, semicondutores ou até mesmo uma plataforma de amplificação híbrida, composta de duas ou mais tecnologias de amplificação, além de poder apresentar qualquer topologia: um, dois ou mais estágios de amplificação com os componentes ópticos necessários. A única exigência é que o amplificador disponha de algum mecanismo de controle automático de ganho, para que seu ponto de operação, em termos de ganho ajustado, possa ser alterado.

Sendo a adaptação um dos pré-requisitos para a cognição [6], este pode ser considerado o primeiro passo para construção de um dispositivo cognitivo que tem a capacidade de atuar diretamente na rede óptica, influenciando nos parâmetros de recepção do sinal.

No contexto de redes ópticas WDM chaveadas por circuito, onde a metodologia proposta neste trabalho será aplicada, existe o problema de roteamento e atribuição de comprimento de onda (routing and wavelength assignment, RWA), que consiste em encontrar o caminho óptico e atribuir comprimentos de onda entre o nó origem e o destino. Para reduzir o tempo computacional, este problema pode ser dividido em dois, o problema de roteamento e o de atribuição de comprimento de onda [16]. Existem vários algoritmos que tratam cada um separadamente, como será descrito no Capítulo 4. 
Nas redes transparentes, dado que o sinal permanece no caminho óptico ao longo de todo o caminho, é importante considerar as penalidades da camada física durante o RWA. Estas penalidades podem ser consideradas como restrições para as decisões do RWA ou as decisões do RWA podem ser feitas já considerando as penalidades [4]. Com relação as formas de incorporar as penalidades aos algoritmos de RWA, existem duas formas. A primeira utiliza modelos analíticos de estimação e a segunda utiliza resultados simulados, experimentais ou técnicas de monitoramento em tempo real [4].

Neste trabalho, o RWA será simulado em quatro topologias de redes com 4, 6, 10 e 15 nós, com e sem a metodologia de controle adaptativo de ganho e considerando as penalidades em termos de figura de ruído ou OSNR após a escolha do caminho. Assim, se o caminho não atender às especificações de qualidade de serviço em termos de ONSR ou figura de ruído, a conexão será bloqueada. Dessa forma, espera-se que, com a utilização da metodologia, sejam obtidas probabilidades de bloqueio menores.

Os próximos capítulos são divididos da seguinte forma: o Capítulo 2 mostra um resumo sobre a tecnologia de amplificação óptica mais comum nas redes ópticas atuais: os EDFAs, apresentando o conceito de máscara de potência. Em seguida, o Capítulo 3 apresenta a metodologia adaptativa, descrevendo o passo a passo para a sua implementação, iniciando com a caracterização prévia do amplificador óptico até a forma de seleção e ajuste do ponto de operação. O Capítulo 4 apresenta os conceitos básicos de RWA, para facilitar o entendimento do Capítulo 5, que apresenta a simulação realizada para validar a metodologia proposta neste trabalho. E, finalmente, o Capítulo 6 fala sobre as conclusões e trabalhos futuros. 


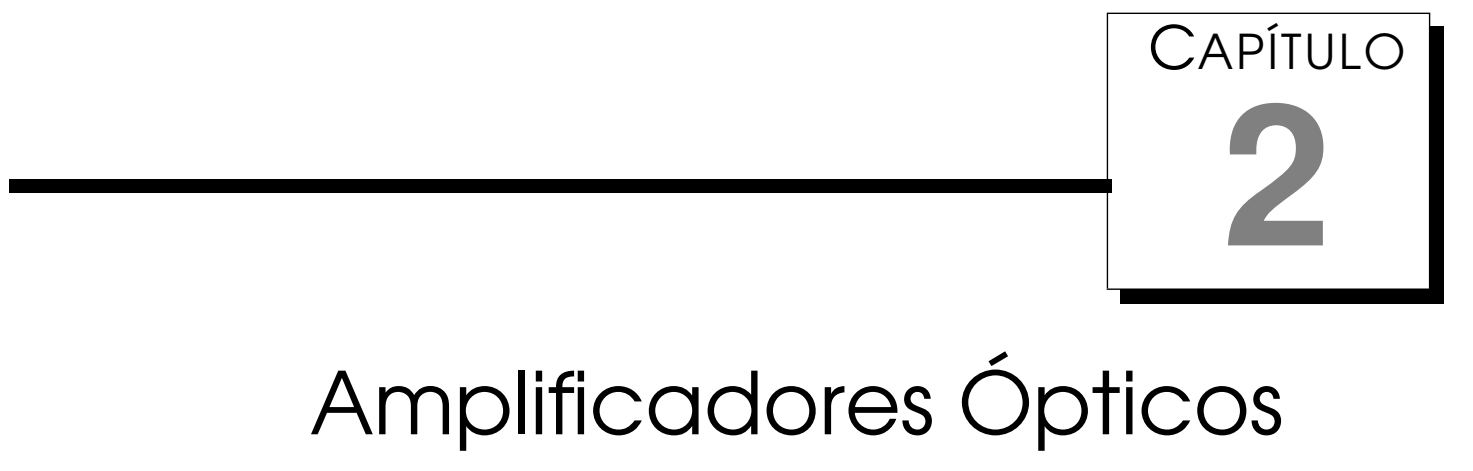

Nos sistemas de comunicações ópticas, o sinal óptico sofre atenuação ao passar pela fibra óptica e por dispositivos como multiplexadores e acopladores. Essas perdas acumuladas ao longo dos enlaces fazem o sinal ficar tão fraco que não é possível detectá-lo. Antes que isso aconteça, é necessário amplificálo [17].

Antes do aparecimento dos amplificadores ópticos, esse papel era desempenhado pelos regeneradores. Tais dispositivos convertiam o sinal óptico para o domínio elétrico e o regeneravam (reformatando, retemporizando e reamplificando). Novamente no domínio óptico, o sinal estava pronto para percorrer mais um enlace.

Porém, os regeneradores apresentam algumas desvantagens. Existe uma dependência com a taxa de bits e o formato de modulação. Além disso, para regenerar um sinal WDM composto por vários comprimentos de onda, é necessário demultiplexar o sinal e utilizar um dispositivo para cada comprimento de onda. Dessa forma, não há flexibilidade. Em caso de uma atualização na rede, como aumento de taxa, os regeneradores devem ser substituídos. Assim, tais regeneradores eram complexos e caros para serem utilizados em sistemas WDM [1].

Com o desenvolvimento dos amplificadores ópticos, a partir década de 80 e já amplamente utilizados na década de 90 [1], o processo de amplificação passou a ser realizado totalmente no domínio óptico, sendo assim transparente à taxa de bits e ao formato de modulação. Além disso, por possuírem uma larga banda de operação, podem amplificar vários canais simultaneamente, tornando possível a grande utilização dos sistemas WDM.

Porém, os amplificadores ópticos não são dispositivos perfeitos. Os ampli- 
ficadores a fibra dopada com érbio, por exemplo, introduzem ruído (amplified spontaneous emission, ASE) ao sinal amplificado. Esse ruído é acumulado à medida que o sinal passa por consecutivos amplificadores [17], causando redução na OSNR do sinal. Outros amplificadores, como os amplificadores a semicondutor, podem ser sensíveis à polarização do sinal ou causar crosstalk (diafonia) entre os canais WDM, como é o caso dos amplificadores Raman [17].

A sessão a seguir descreve em linhas gerais o funcionamento do EDFA, a tecnologia de amplificação mais utilizada nas redes ópticas WDM.

\subsection{Amplificadores a fibra dopada com érbio (EDFA)}

Estes amplificadores são constituídos por um segmento de fibra óptica com o núcleo dopado com átomos ionizados de érbio $\left(\mathrm{Er}^{3+}\right)$. Para uma melhor eficiência na transferência de energia entre o bombeio e o sinal, esta fibra óptica é bombeada por lasers de 980 ou $1480 \mathrm{~nm}$, cujo desenvolvimento foi motivado pelos EDFAs [1]. Um acoplador de comprimentos de onda é utilizado para reunir o sinal de bombeio com o sinal óptico a ser amplificado. Outro acoplador é utilizado para separar o sinal amplificado do sinal de bombeio residual. O isolador na entrada é utilizado para que a ASE gerada na fibra dopada com érbio não siga para entrada do amplificador e interfira nos dispositivos prévios. Já o isolador na saída previne que reflexões de sinais ou ruídos ocorridos após o amplificador interfiram no processo de amplificação. A Figura 2.1, adaptada de [17], apresenta a estrutura interna do EDFA.

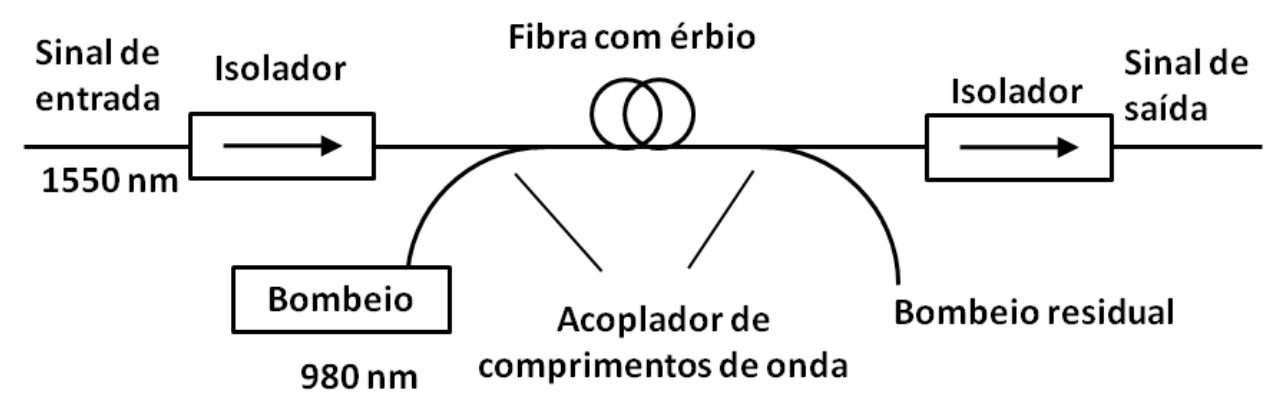

Figura 2.1: Circuito óptico do amplificador a fibra dopada com érbio.

Antes de abordar seu princípio de operação, é preciso entender a distribuição dos níveis de energia dos íons érbio na sílica. Cada nível, que aparece como uma linha discreta em um íon isolado, é dividido em vários níveis (constituindo uma banda de energia) quando esses íons são introduzidos na sílica [17], devido à sua natureza amorfa [1]. Olhando esta estrutura macroscopicamente, observa-se um espalhamento do nível de energia, transformandose em uma banda de energia contínua. Esse espalhamento é importante, pois aumenta o número de comprimentos de onda que podem ser amplificados, ou 
seja, aumenta a janela de amplificação [17].

Por outro lado, em cada banda de energia, os elétrons com seus níveis de energia diferentemente separados distribuem-se de maneira não uniforme na respectiva banda, tornando possivel a amplificação simultânea de vários comprimentos de onda.

Assim, a partir do conceito de banda de energia é possível amplificar não só uma frequência, mas um intervalo que satisfaça $\Delta E=h f_{C}$ onde $\Delta E$ é a diferença entre alguma energia na banda $E_{1}$ e alguma energia na banda $E_{2}$, para o caso de duas bandas e $f_{c}$ é a frequência do sinal a ser amplificado. Para os íons de érbio na sílica, a faixa de frequência de sinal que pode ser amplificado corresponde aos comprimentos de onda de 1525 a $1570 \mathrm{~nm}$, que é uma das janelas de baixa atenuação para fibra óptica padrão que os sistemas de comunicações ópticas utilizam (banda C da grade ITU-T) [17].

O principio de operação do EDFA baseia-se no processo de emissão estimulada em sistemas de três bandas de energia, que são exibidos na Figura 2.2, adaptada de [17].

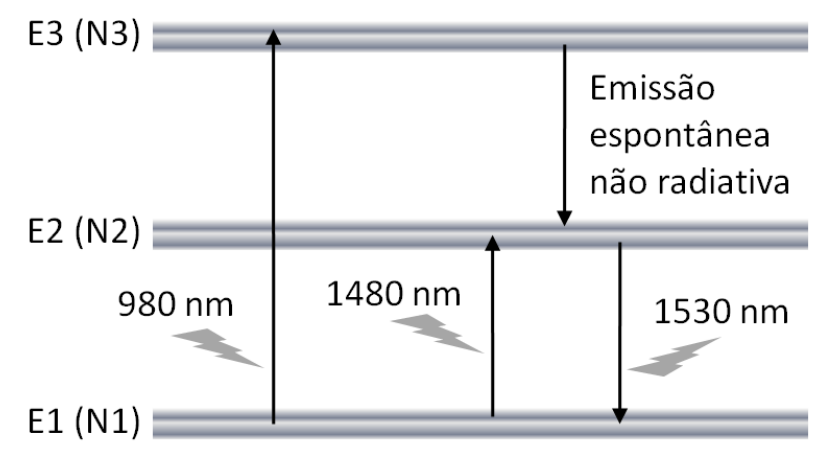

Figura 2.2: Níveis de energia de um íon érbio na sílica.

O íon de érbio em sílica apresenta muito mais bandas de energia, mas para o processo de amplificação são utilizados apenas os apresentados na Figura 2.2 .

No equilíbrio térmico, as populações dos níveis $E_{1}, E_{2}$ e $E_{3}$ apresentam a seguinte relação: $N_{1}>N_{2}>N_{3}$, onde $N_{x}$ é a população de elétrons no nível $E_{x}$. A inversão $N_{2}>N_{1}$ é obtida por meio de uma combinação de emissão espontânea e absorção. Observando a Figura 2.2, ao introduzir um bombeio de $980 \mathrm{~nm}$, cuja frequência $f$ satisfaz a relação $h f=E_{3}-E_{1}$, haverá absorção dos fótons do bombeio, uma vez que $N_{1}>N_{3}$, e transição de elétrons do nível $E_{1}$ ao nível $E_{3}$. Em seguida, os elétrons no nível $E_{3}$ irão cair para o nível $E_{2}$ por emissão espontânea não radiativa, com tempo de vida $\tau_{32}=1 \mu \mathrm{s}$. A emissão espontânea do nível $E_{2}$ para $E_{1}$ apresenta um tempo de vida $\tau_{21}=10$ $m s$, muito mais demorado que $\tau_{32}$ e, por este motivo, o nível $E_{2}$ é denominado metaestável. Além disso, se a potência de bombeio é muito alta, os íons que 
passam do nível $E_{2}$ para o $E_{1}$ por emissão espontânea rapidamente voltarão para o nível $E_{3}$ para decair para o nível $E_{2}$ novamente. Como resultado, tem-se uma maior população no nível $E_{2}$ que no nível $E_{1}\left(N_{2}>N_{1}\right)$, concluindo assim o processo de inversão de população [17].

Não há eficiência em bombear para níveis maiores que $E_{3}$, pois é necessária maior potência de bombeio para o mesmo ganho com bombeio em $980 \mathrm{~nm}$. É possivel realizar o bombeio em $1480 \mathrm{~nm}$ como pode ser visto na Figura 2.2, com transição de elétrons diretamente do nível $E_{1}$ para o nível $E_{2}$. Mas, nesse caso, a inversão de população conseguida é menor. Quanto menor a inversão de população, maior a figura de ruído do amplificador. Por outro lado, há disponibilidade de lasers de maior potência em 1480 nm. Assim, para amplificadores que necessitam de maior potência na saída, o bombeio em $1480 \mathrm{~nm}$ é preferido [17].

Outra vantagem do bombeio em $1480 \mathrm{~nm}$ é a possibilidade de bombeio remoto, uma vez que os sinais neste comprimento de onda sofrem pouca atenuação nas fibras ópticas que transportam o sinal óptico [17]. O bombeio remoto evita componentes ativos ao longo de enlaces críticos de difícil acesso, como em oceanos.

O ganho em função do comprimento de onda do EDFA pode ser visto na Figura 2.3, onde é possível observar que o ganho não é plano. Consequentemente, cada comprimento de onda apresenta um ganho diferente. Este perfil não plano de ganho é consequência da distribuição não uniforme da população no nível $E_{2}$.

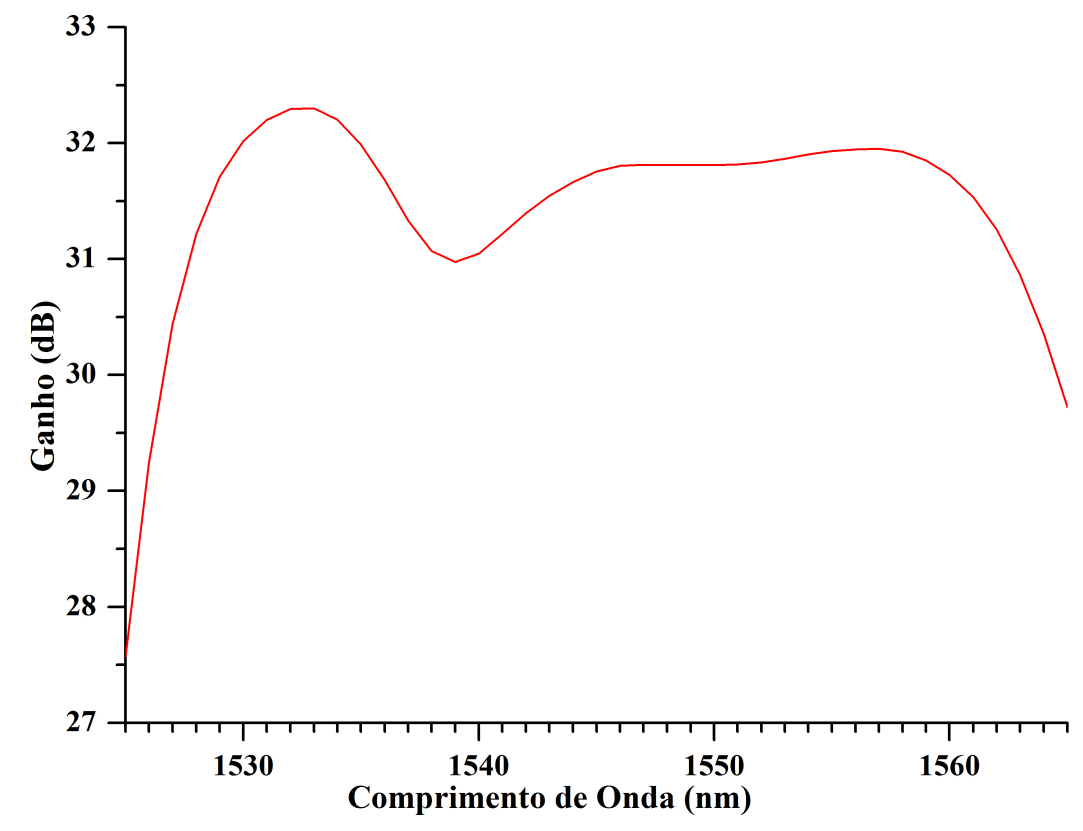

Figura 2.3: Curva de ganho em função do comprimento de onda para o EDFA.

Por outro lado, o processo de emissão estimulada amplifica também os fotóns emitidos espontaneamente, que não apresentam relação alguma com 
o sinal a ser amplificado em termos de sentido de propagação e polarização, sendo considerado apenas ruído (ASE). Assim, na medida em que amplifica, o EDFA também adiciona ruído ao sinal. Este ruído é acumulado quando o sinal atravessa uma cascata de amplificadores e é um limitador do alcance do sinal, pois há degradação da OSNR.

Para minimizar o efeito do ganho não uniforme para os canais, a adição de filtros que atenuam mais os canais em torno de $1530 \mathrm{~nm}$, onde o ganho é maior, pode ajudar a tornar a curva de ganho mais plana. Além disso, busca-se projetar amplificadores determinando o melhor comprimento de fibra dopada com érbio e o posicionamento dos componentes ópticos, de modo que a adição de ruído seja reduzida.

Por fim, uma das principais vantagens dos EDFAs é a disponibilidade de lasers de bombeio confiáveis, compactos e de alta potência. Por serem dispositivos simples e totalmente ópticos apresentam facilidade na inserção e remoção do sinal óptico. Além disso, são independentes da polarização da luz e não introduzem crosstalk entre os canais WDM.

\subsection{Máscara de potência de amplificadores ópticos}

Como reflexo da transição entre as redes estática e dinâmica, observase uma mudança na forma de projetar os amplificadores ópticos que farão parte dessa nova rede [18]. Como em uma rede dinâmica o número de canais (ou carregamento de canais) pode variar de forma dinâmica e imprevisivel, é necessário que o amplificador óptico opere de forma satisfatória em uma faixa de potência de entrada que corresponde a diferentes valores de carregamento de canais.

Outra necessidade é a de operar em diferentes valores de ganho, permitindo assim que uma variação da potência de entrada, quando não causada pela adição ou remoção de canais, possa ser compensada pelo ajuste no ganho.

Esta região de operação do amplificador, definida pela potência de entrada e ganho, sob a qual seu bom desempenho é garantido, foi definida como a máscara de potência do amplificador [19]. Alguns fabricantes já consideram o desempenho de seus amplificadores dentro de uma máscara de potência predefinida [20], sob a qual os parâmetros de figura de ruído, "planicidade" espectral de ganho e precisão de controle automático de ganho são conhecidos e há garantia de que permanecerão dentro de uma determinada faixa.

Uma ilustração da máscara de potência de um amplificador pode ser vista na Figura 2.4. Ela pode ser definida em termos dos ganhos máximos e mínimos e das potências máxima de saída e mínima de entrada.

Na Figura 2.4, o aumento ou redução na potência de entrada pode ser con- 


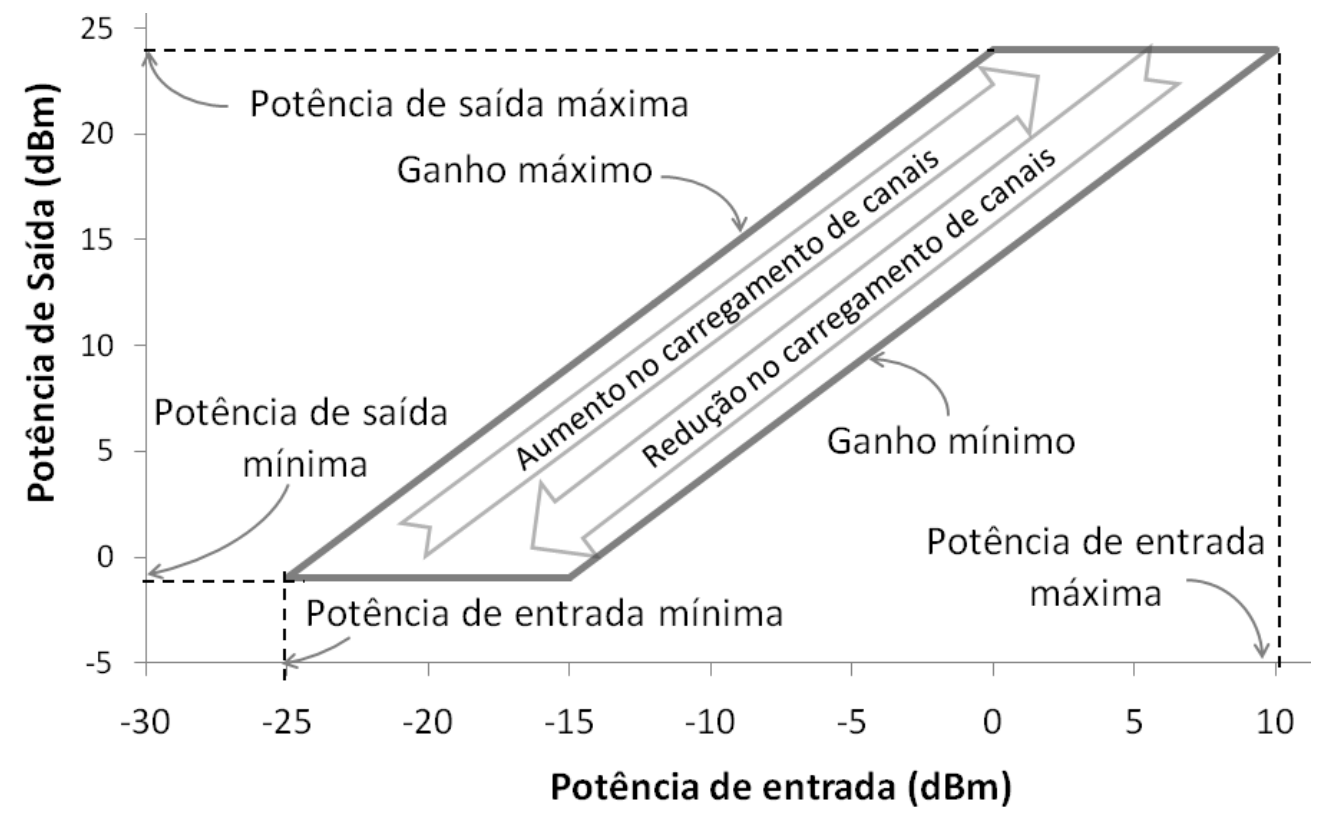

Figura 2.4: Região definida como máscara de potência de um amplificador óptico.

sequência das alterações no carregamento de canais, como indicado na figura, ou devido a alguma penalidade que possa causar mudanças nos valores das potências dos canais, como uma degradação de uma chave óptica, por exemplo. Estas mudanças na potência de entrada leva o amplificador a operar em um ponto de operação diferente em relação à figura e ruído e "planicidade" espectral de ganho e é indesejável que este novo ponto de operação apresente um desempenho pior.

Assim, com o objetivo de buscar sempre o melhor ponto de operação do amplificador, dada uma potência de entrada, as máscaras de potência, com informações de figura de ruído e "planicidade" espectral de ganho, serão utilizadas na metodologia adaptativa proposta neste trabalho e descrita no próximo capítulo. 


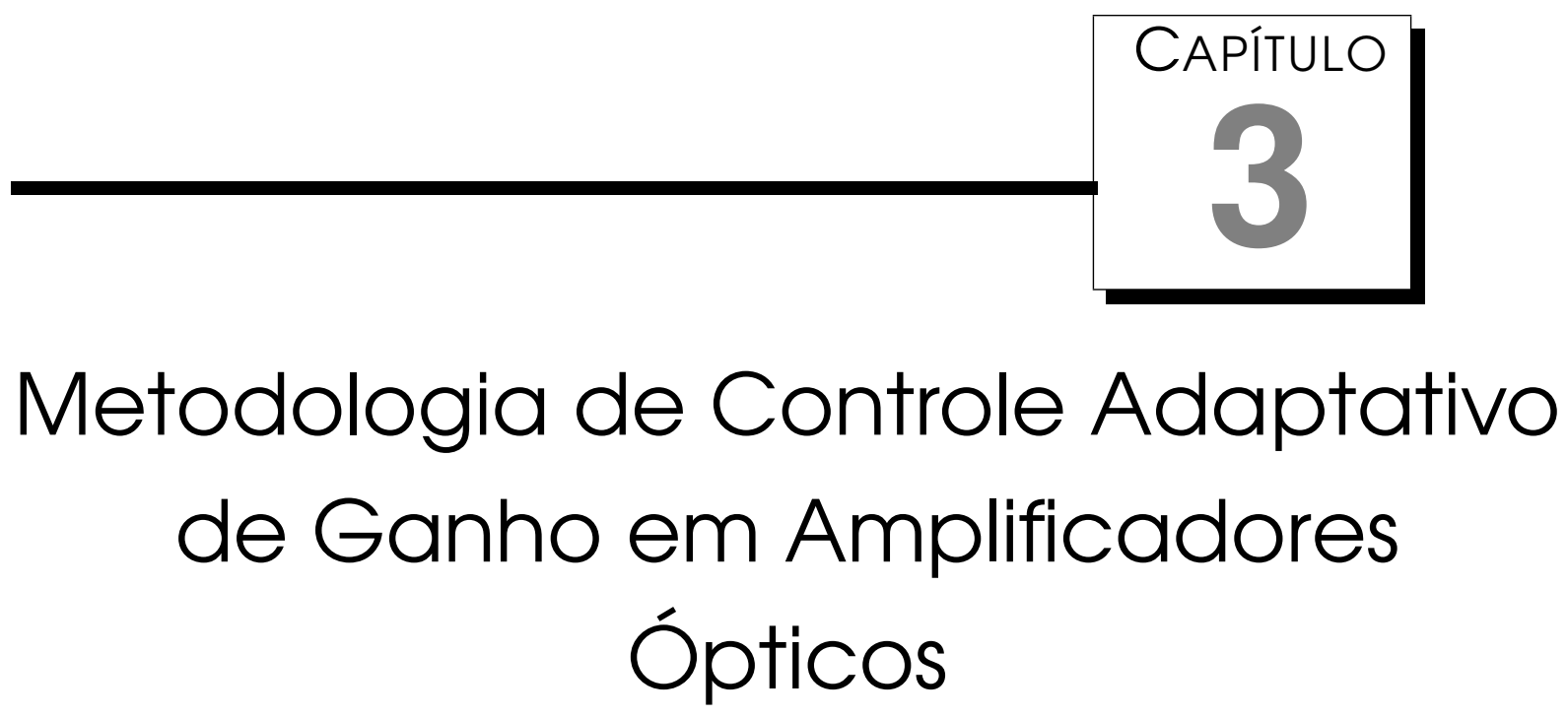

A metodologia de ajuste do ponto de operação de amplificadores ópticos, em termos de ganho ajustado, proposta neste trabalho é baseada em duas premissas dos sistemas cognitivos: ser ciente e adaptativa [6, 10]. Neste contexto, ser ciente significa ter conhecimento dos parâmetros dinâmicos da rede em tempo real a partir da realização de monitoramentos. Já a premissa de adaptação corresponde às ações de planejar, decidir e agir de acordo com as medidas atuais.

Dessa forma, o amplificador adaptativo escolhe e ajusta seu ponto de operação. Tal escolha se baseia no melhor custo-benefício entre duas figuras de mérito muito importantes para amplificadores: a figura de ruído e a "planicidade" espectral de ganho. Além disso, este processo é baseado em uma caracterização prévia, descrita a seguir, do amplificador óptico em questão, a qual busca obter o desempenho do amplificador dentro de máscara de potência em termos destas duas figuras de mérito.

\subsection{Caracterização}

Tendo como objetivo a obtenção do desempenho do amplificador dentro da máscara de potência, apresentada na seção 2.2 , um caracterizador automatizado de amplificadores ópticos foi apresentado em [21]. 
Esta ferramenta consiste em variar a potência de entrada para cada valor de ganho, obtendo-se os valores de potência de saída correspondentes. Os espectros dos sinais de entrada e saída também são capturados e utilizados para calcular os valores de figura de ruído de cada canal e a "planicidade" espectral do ganho. Todo esse processo é feito de forma automatizada, uma vez que a obtenção desses dados de forma manual poderia se tornar muito lenta e trabalhosa.

Além dos parâmetros de figura de ruído, "planicidade" espectral de ganho e precisão de controle de ganho, também é possível conhecer o comportamento/desempenho do amplificador em termos de parâmetros dos lasers: corrente, potência óptica, tensão direta ou temperatura, bastando, para isso, capturar tais valores para cada ponto de operação durante o processo de caracterização.

Apesar dos amplificadores caracterizados em [21] consistirem apenas de EDFAs, em [22] o mesmo caracterizador foi utilizado para encontrar o desempenho de uma plataforma de amplificação híbrida, constituída de EDFA e Raman. Assim, o processo de caracterização pode ser realizado em qualquer tecnologia de amplificação, seja a fibra dopada com érbio, por efeito Raman ou semicondutor, desde que possua algum mecanismo de controle de ganho configurado remotamente.

O processo de caracterização apresenta duas etapas: a etapa experimental por meio do Labview ${ }^{\circledR}$ e a etapa de tratamento de dados por meio do Matlab ${ }^{\circledR}$. Tais etapas são descritas nas próximas seções.

\subsubsection{Etapa experimental}

A etapa experimental consiste na montagem experimental e no processo de caracterização propriamente dito, onde os parâmetros de potência de entrada e ganho são ajustados e os valores de potência de saída e os espectros de entrada e saída são capturados e armazenados. Este processo utiliza um programa desenvolvido em Labview ${ }^{\circledR}$ para se comunicar com os equipamentos de teste e leitura durante todo o processo.

\section{Montagem experimental}

A montagem experimental consiste dos seguintes dispositivos:

- bancada com 40 canais DWDM (dense - WDM) na grade padrão ITU-T estabilizada tanto em comprimento de onda como em potência;

- analisador de espectro óptico (OSA) que medirá os espectros de entrada e saída do amplificador sob caracterização; 
- amplificador óptico auxiliar para garantir níveis de potência necessários ao longo da máscara;

- uma chave seletora de comprimento de onda (wavelength selective switch, WSS) de 40 canais com atenuadores ópticos variáveis (variable optical attenuator, VOA) por canal, para equalizar o espectro na saída do amplificador auxiliar e garantir espectro plano na entrada do amplificador a ser caracterizado;

- atenuador óptico variável para que o nível de potência na entrada do amplificador a ser caracterizado seja ajustado com elevada precisão;

- chave óptica para selecionar o sinal a ser medido no OSA (potência de entrada ou de saída do amplificador);

- opcional: fibra óptica na entrada do amplificador para o caso de amplificadores distribuídos. Este componente não é necessário para realizar a caracterização de amplificadores discretos.

A Figura 3.1 apresenta o esquemático da montagem experimental.

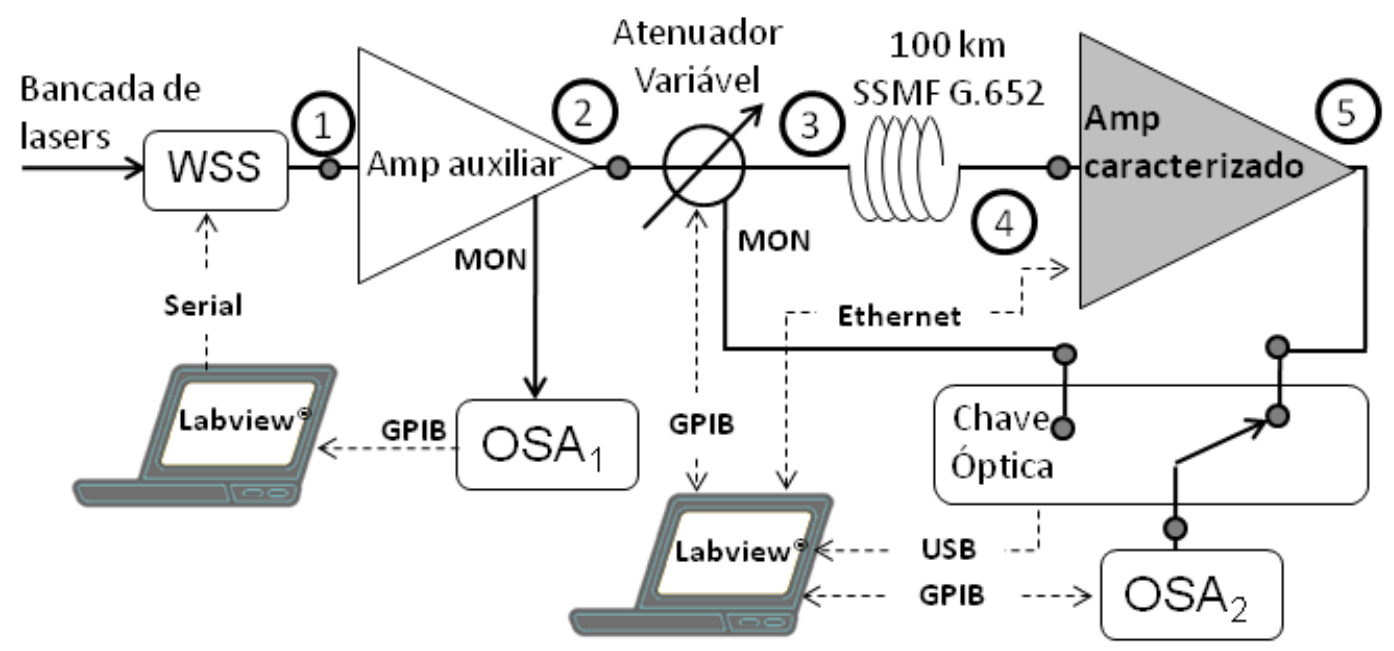

Figura 3.1: Montagem experimental do caracterizador de amplificadores. WSS se refere á chave seletora de comprimento de onda e OSA é o analisador de espectro óptico.

Na Figura 3.1, a bancada de lasers fornece 40 canais DWDM na banda C (192,1 a $196 \mathrm{THz})$. Um amplificador auxiliar é utilizado para fornecer uma potência total máxima de 21,5 dBm. Em seguida, um WSS é utilizado para equalizar o sinal na saída do amplificador auxiliar. Este procedimento é denominado de equalização dos canais e é feito para que o espectro do sinal óptico na entrada do amplificador sob caracterização seja o mais plano possível. Assim, é possível estimar com maior precisão o quanto o amplificador sob caracterização afeta a "planicidade" no espectro de saída. Ele utiliza uma 
amostra do sinal na saída do amplificador auxiliar, saída de monitoramento (MON), medida por meio de um analisador de espectro (OSA 1). Uma rotina no Labview ${ }^{\circledR}$ utiliza esta amostra para calcular as perdas de cada canal que serão fornecidas ao WSS para que o espectro fique plano.

Em seguida, um atenuador variável realiza o ajuste da potência total no sistema de amplificação. Para amplificadores distribuídos, tal sistema pode ser composto por uma fibra óptica e pelo amplificador sob caracterização. No caso de amplificadores discretos, a fibra óptica é desnecessária e a saída do atenuador óptico é ligada diretamente à entrada do amplificador sob caracterização.

Uma amostra do sinal na saída do atenuador variável segue para a chave óptica. Na outra entrada desta chave está o sinal amplificado na saída do amplificador a ser caracterizado e na saída da chave está o analisador de espectro (OSA2). Dessa forma, é possível obter o espectro ora do sinal de entrada ora do sinal de saída, de acordo com a posição da chave.

A comunicação destes equipamentos com o computador é feita por meio de interfaces GPIB, USB, Ethernet e serial, todas suportadas pelo software utilizado.

\section{Processo de caracterização}

O processo de caracterização inicia com a definição dos limites da região da máscara de potência do amplificador sob caracterização: ganhos mínimo e máximo, potência de entrada mínima e potência de saída máxima. O tamanho do passo, em $\mathrm{dB}$, também deve ser fornecido, definindo o passo da potência de entrada e ganho e determinar a quantidade de pontos de varredura da máscara.

Antes de iniciar o processo de caracterização, o atenuador variável (Figura 3.1) é ajustado para o seu valor mínimo, com a finalidade de descobrir a máxima potência possível na entrada do amplificador a ser caracterizado. Se esse valor for inferior à potência de entrada máxima da máscara, uma mensagem indicando este erro é apresentada e o programa termina sua execução, indicando a necessidade de alterar o setup de modo a fornecer uma maior potência na entrada do amplificador ou considerar uma máscara de potência diferente.

Após esta verificação, o programa ajusta o ganho para o seu valor mínimo. O atenuador é ajustado para fornecer a potência máxima da máscara de potência na entrada do amplificador a ser caracterizado. Em seguida, os valores de potência total na entrada e saída, bem como o ganho configurado e medido são armazenados em um arquivo texto. No próximo passo, a chave óptica é ajustada de forma que o OSA capture uma amostra do espectro de entrada 
e, logo em seguida, é ajustada novamente para que o espectro de saída do amplificador seja obtido. Estes dados também são armazenados em arquivos texto para serem posteriormente utilizados no processamento de dados.

Quando todas as potências de entrada foram ajustadas para um dado ganho, este é incrementado e o programa segue até o valor de ganho máximo da máscara de potência, finalizando assim o processo de caracterização.

Ao fim do processo de caracterização, para cada ponto de operação, tem-se três arquivos textos, que serão utilizados na etapa a seguir.

\section{1.2 Etapa de tratamento dos dados experimentais}

Nesta etapa, os dados experimentais são tratados para obter os parâmetros de desempenho do amplificador. Este tratamento é feito por meio de uma rotina implementada no Matlab $^{\circledR}$, que lê os arquivos de dados experimentais armazenados durante a caracterização e faz os cálculos referentes à "planicidade" espectral de ganho, figura de ruído por canal e precisão de controle de ganho para cada ponto da máscara de potência.

Como o espectro do sinal de entrada é plano, optou-se por calcular a "planicidade" espectral de ganho por meio da diferença entre o canal com máxima potência de pico e o canal com mínima potência de pico na saída do amplificador. Para os casos em que esta "planicidade" não é garantida, primeiramente deve-se calcular o ganho por canal e, em seguida, a "planicidade" espectral de ganho deve ser calculada por meio da diferença entre os ganhos máximo e mínimo dos canais.

A figura de ruído, por sua vez, é calculada por canal, de acordo com

$$
N F_{15}^{(c h)}=N F_{12}^{(c h)}+\frac{N F_{45}^{(c h)} A t t_{24}^{(c h)}}{G_{12}^{(c h)}}
$$

que se refere à figura de ruído para amplificadores em cascata com perdas entre eles [23], $A t t_{24}^{(c h)}$ corresponde à atenuação entre os pontos 2 e 4 e $G_{12}^{(c h)}$ se refere ao ganho do amplificador auxiliar, ambos por canal. A figura de ruído entre os pontos 1 e $5, N F_{15}^{(c h)}$, e a figura de ruído do amplificador auxiliar (entre os pontos 1 e 2), $N F_{12}^{(c h)}$ também por canal, na Figura 3.1, são calculadas por meio de

$$
N F^{(c h)}=10 \log _{10}\left(\frac{P a s e^{(c h)}}{h v^{(c h)} G \Delta v^{(c h)}}+\frac{1}{G^{(c h)}}\right)
$$

onde $P a s e^{(c h)}$ refere-se à potência de ruído de ASE no canal correspondente, $h$ é a constante de Planck, $v^{(c h)}$ é a frequência do canal, $\Delta v$ é a largura de banda de medida do canal, e $G^{(c h)}$ é o ganho do canal entre os pontos de medida de NF [23].

Por fim, a precisão de controle de ganho é a diferença entre os valores do 
ganho total configurado e ganho total medido.

\subsubsection{Resultado da caracterização}

Um resultado da caracterização ${ }^{1}$ em laboratório com a finalidade de encontrar o desempenho do amplificador dentro da máscara de potência está na Figura 3.2. O amplificador caracterizado foi um EDFA com potência máxima de saída de $21 \mathrm{dBm}$, ganho entre 14 e $24 \mathrm{~dB}$ e potência mínima de entrada de $-25 \mathrm{dBm}$. Os valores dos parâmetros medidos estão mapeados nas cores dos pontos dentro da máscara, cujos valores são indicados na barra lateral direita.

Figura de Ruído (dB)

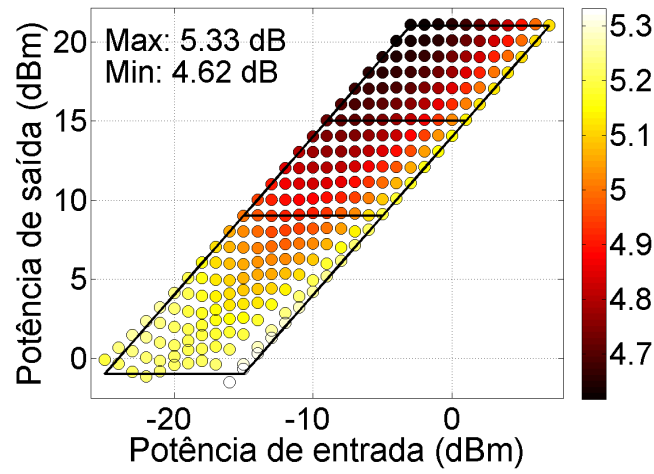

(a)

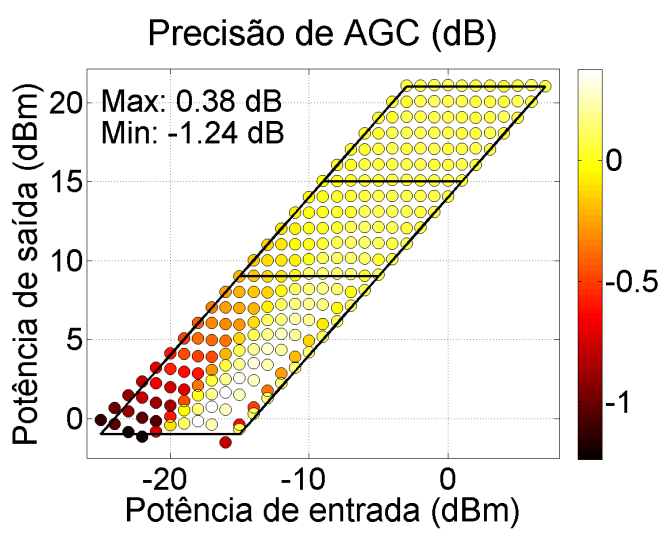

(c)
Planicidade Espectral $(\mathrm{dB})$

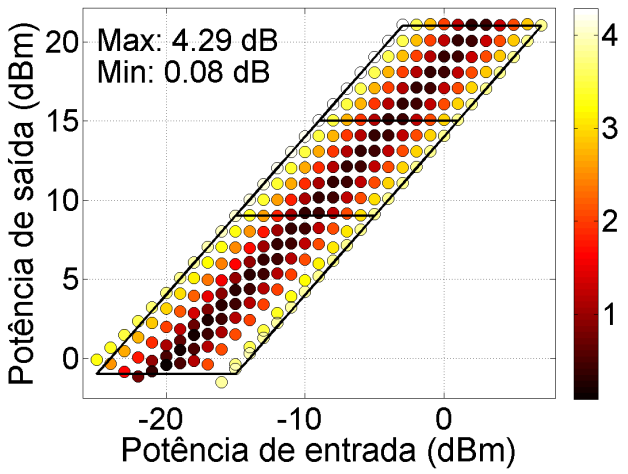

(b)

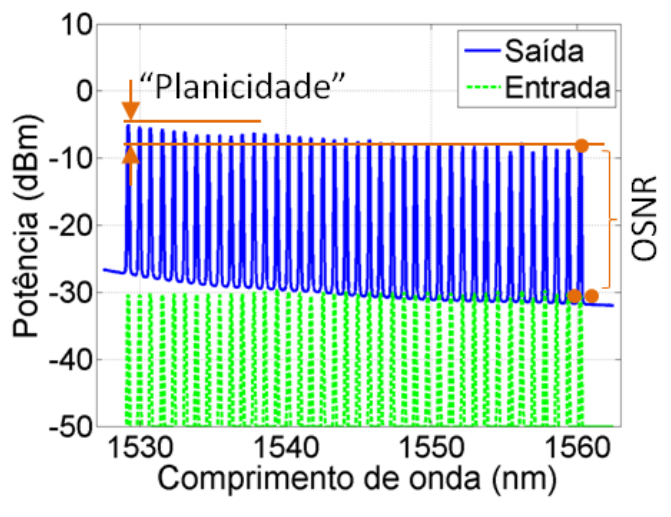

(d)

Figura 3.2: Máscaras de potência com informações de (a) Figura de ruído, (b) "Planicidade" espectral de ganho, (c) Precisão de controle de ganho e (d) medidas dos espectros de entrada e saída exemplificando as medidas de "planicidade" espectral de ganho e OSNR.

A Figura 3.2(a) apresenta o resultado referente ao parâmetro figura de ruído. Nesta figura, verifica-se que os valores mínimos de figura de ruído estão na região superior esquerda da máscara, indicando que é uma boa re-

\footnotetext{
${ }^{1}$ Medidas realizadas na Fundação CPqD.
} 
gião para o amplificador operar, com valores de figura de ruído abaixo de 5 $\mathrm{dB}$.

A Figura 3.2(b) mostra o resultado em termos de "planicidade" espectral de ganho, apresentando valores próximos de zero para a região em torno do ganho de $19 \mathrm{~dB}$ (região em vermelho).

Por fim, com relação à precisão de controle automático de ganho, apresentada na Figura 3.2(c), observa-se que este amplificador apresenta um erro em torno de zero na maior parte da máscara de potência. Porém, observa-se que para os pontos com baixas potências de entrada, a partir de $-20 \mathrm{dBm}$, o erro no controle de ganho apresenta valores menores que $1 \mathrm{~dB}$, o que significa que o ganho medido está abaixo do ganho ajustado.

A Figura 3.2(d) apresenta os espectros de entrada e saída para um ponto da máscara de potência, mostrando como são calculados a "planicidade" espectral de ganho e a OSNR, base para o cálculo de figura de ruído dos canais.

\subsection{Metodologia}

De posse dos resultados obtidos na caracterização em termos de figura de ruído e "planicidade" espectral de ganho, a metodologia adaptativa busca e altera o ponto de operação do amplificador óptico em termos de ganho ajustado. Tal busca visa uma melhor relação custo-benefício entre os parâmetros de figura de ruído e "planicidade" espectral de ganho. Assim, é possivel adaptar o ponto de operação buscando a mínima degradação do sinal óptico em termos de tais parâmetros de acordo com a atual potência de entrada.

As seções a seguir descrevem os passos utilizados na metodologia adaptativa proposta neste trabalho.

\subsection{Função qualidade}

Os dados de figura de ruído (Figura 3.2(a)) e "planicidade" espectral de ganho (Figura 3.2(b)), resultantes da caracterização do amplificador, são utilizados na construção de um gráfico, denominado espaço de objetivos, onde os eixos coincidem com os parâmetros a serem otimizados. A Figura 3.3 ilustra este procedimento para uma potência de entrada de $-15 \mathrm{dBm}$. Cada cor é associada a um valor de ganho indicado na barra de cores à direita.

Em seguida, os valores da função de qualidade são calculados, para cada ponto de operação do amplificador, baseado em target vector optimization [24], o qual minimiza simultaneamente os parâmetros de figura de ruído e "planicidade" espectral de ganho, que corresponde a um problema multiobjetivo [25]. A partir da Figura 3.3, um vetor é associado a cada ponto $i$ do espaço de 


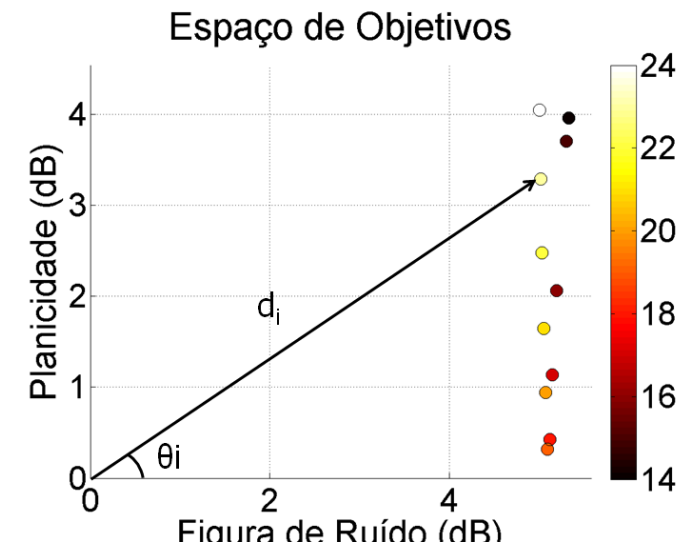

Figura 3.3: Espaço de objetivos (figura de ruído versus "planicidade") para Pin $=-15 \mathrm{dBm}$ com a representação dos parâmetros usados para calcular a função de qualidade: distância $d_{i}$ e ângulo $\theta_{i}$. A barra de cores mapeia os valores de ganho.

objetivos

$$
\text { fitness }_{i}=d_{i}^{-1} \angle \theta_{i}
$$

onde $d_{i}$ é o módulo, $d_{i}=\sqrt{N F_{i}^{2}+G F_{i}^{2}}$ é a distância Euclidiana de cada ponto à origem e $\theta_{i}=\arctan \left(\frac{G F_{i}}{N F_{i}}\right)$ é o argumento.

A menor distância Euclidiana do ponto à origem refere-se ao ponto de operação com o melhor compromisso entre figura de ruído, $N F$, e "planicidade" espectral de ganho, $G F$, e corresponde ao melhor valor da função qualidade. Os valores da função qualidade são normalizados de zero a dez, onde o menor valor é alterado para zero e o máximo para dez. Tais valores são apresentados dentro da máscara de potência da Figura 3.4, onde a região com o melhor (maior) valor de função qualidade são os pontos em amarelo.

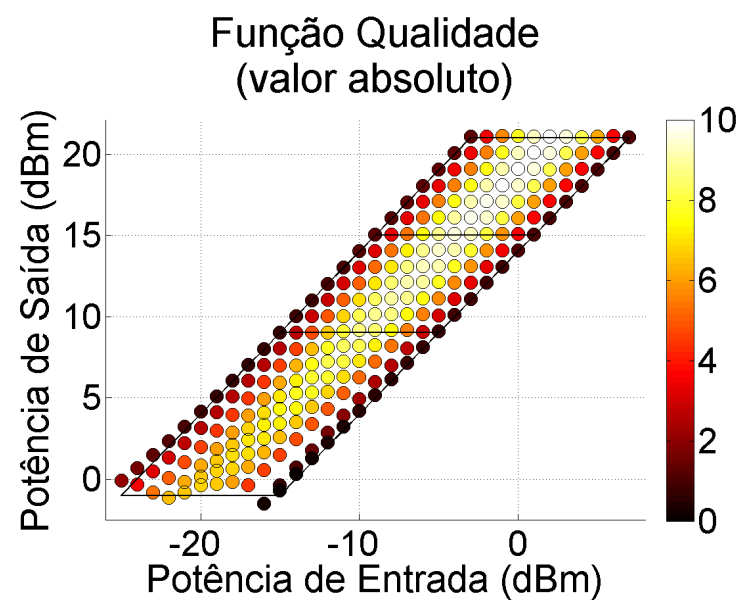

Figura 3.4: Máscara de potência com os valores absolutos da função qualidade. 


\subsubsection{Seleção e ajuste de ganho}

Finalmente, o ponto de operação do amplificador pode ser alterado, visando o ponto de operação com o maior valor de função qualidade, para um valor de potência de entrada específico de acordo com

\section{$\operatorname{Gain}\left[\max \left(\mid\right.\right.$ fitness $\left.\left._{P i n} \mid\right)\right]$}

Nos casos em que dois pontos de operação apresentam o mesmo valor absoluto de função qualidade, o argumento é utilizado para decidir qual dos dois será escolhido. Esta escolha é feita de acordo com o parâmetro priorizado: se o parâmetro for a figura de ruído, a função qualidade com maior ângulo será escolhido, de acordo com

\section{$\operatorname{Gain}\left\{\max \left[\arg \left(\right.\right.\right.$ fitness $_{\text {Pin,max }}\left(\mid\right.$ fitness $\left.\left.\left.\left._{\text {Pin }} \mid\right)\right)\right]\right\}$}

caso contrário, se o parâmetro priorizado for a "planicidade" espectral de ganho, o menor ângulo deve ser escolhido de acordo com

$$
\operatorname{Gain}\left\{\min \left[\arg \left(\text { fitness }_{\text {Pin, }, \max \left(\mid \text { fitness }_{\text {Pin }} \mid\right)}\right)\right]\right\}
$$

A Figura 3.5 apresenta o mesmo espaço de objetivos da Figura 3.3, ilustrando o ponto escolhido com a metodologia para uma potência de entrada de - $15 \mathrm{dBm}$. Neste caso, o ponto de operação escolhido foi o de ganho $19 \mathrm{~dB}$, que apresenta a menor distância à origem, pois uma circunferência de centro na origem e passando por este ponto não contém nenhum outro ponto de operação em seu interior.

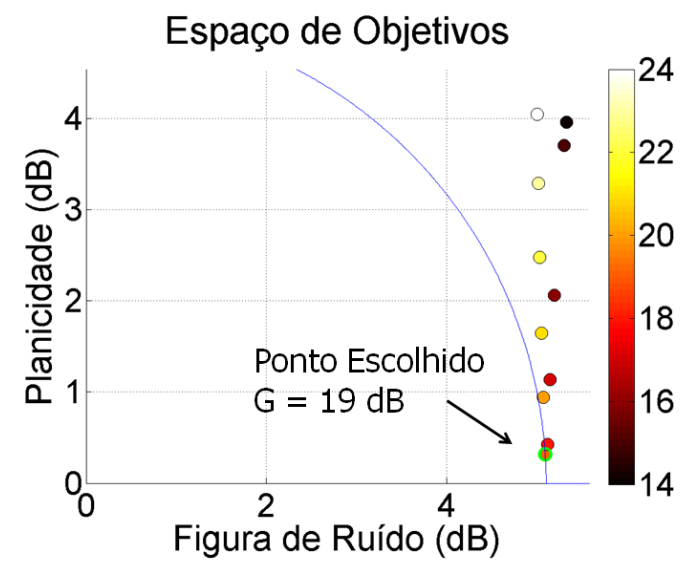

Figura 3.5: Espaço de objetivos para Pin $=-15 \mathrm{dBm}$ com o ponto de operação escolhido: Ganho $(\mathrm{G})=19 \mathrm{~dB}$ por apresentar a menor distância à origem.

Para o modelo de amplificador da Figura 3.4, os melhores valores de função qualidade estão concentrados na região em torno do ganho de $19 \mathrm{~dB}$ (cores 
amarela e branca). Da mesma forma, os melhores valores de "planicidade" espectral de ganho estão concentrados nesta região de ganho (19 dB), como mostra a Figura 3.2(b), que apresenta o resultado da caracterização do mesmo amplificador em termos de "planicidade" espectral de ganho, indicando que este parâmetro tem mais efeito sobre a função qualidade que o parâmetro de figura de ruído. Isso ocorre porque a "planicidade" espectral de ganho varia desde valores próximos de zero até $4,3 \mathrm{~dB}$, enquanto a figura de ruído apresenta uma variação bem menor, de 4,6 a 5,3 dB, dentro de toda a máscara de potência. Dessa forma, a "planicidade" espectral tem uma influência marcante quando comparada à figura de ruído devido à sua maior variação.

\subsubsection{Peso dos parâmetros}

Os valores da função de qualidade dentro da máscara de potência apresentam um comportamento mais parecido com a "planicidade" espectral de ganho devido à maior variação deste parâmetro dentro desta região, como pode ser visto comparando as Figuras 3.2(b) e 3.4, que apresentam a máscara de potência com informação da "planicidade" espectral de ganho e a função qualidade, respectivamente. Assim, quando a metodologia adaptativa seleciona o ponto de operação, ela está otimizando mais a "planicidade" espectral de ganho que a figura de ruído. Sendo possível existir outros pontos de operação com valores de figura de ruído bem melhores, com alguma degradação de "planicidade" espectral de ganho, quando comparados aos pontos com melhor função qualidade. Esta situação é claramente observada na Figura 3.5, que apresenta o ponto de operação selecionado, $19 \mathrm{~dB}$, o qual apresenta a melhor (mínima) "planicidade" espectral de ganho, enquanto todos os pontos com ganho maior que $19 \mathrm{~dB}$ (pontos mais claros) apresentam uma melhor (menor) figura de ruído.

Em alguns casos, uma "planicidade" espectral de ganho levemente degradada é aceitável, com a finalidade de melhorar a figura de ruído quando o sinal está bastante degradado. Dessa forma, para cobrir estes casos, a função qualidade apresentada na seção anterior deve ser modificada.

Para que a metodologia adaptativa passe a tratar tais casos, foram adicionados pesos diferentes para cada parâmetro, enfatizando um deles, antes do processo de otimização. Cada parâmetro tem seu valor multiplicado pelo seu respectivo peso, de zero a um, fazendo diminuir sua variação dentro da máscara de potência (valores máximo e mínimo) e, assim, reduzindo sua influência nos valores da função qualidade.

Estas alterações afetam apenas as que calculam a distância $d_{i}$ e ângulo $\theta_{i}$, reescritas como

$$
d_{i}=\sqrt{\left(N F_{W} \cdot N F_{i}\right)^{2}+\left(G F_{W} \cdot G F_{i}\right)^{2}}
$$




$$
\theta_{i}=\arctan \left(\frac{G F_{W} \cdot G F_{i}}{N F_{W} \cdot N F_{i}}\right)
$$

onde $N F_{W}$ e $G F_{W}$ são os pesos da figura de ruído e da "planicidade" espectral de ganho, respectivamente. A função qualidade é calculada normalmente por meio de (3.3).

Como resultado, a Figura 3.6 apresenta alguns espaços de objetivos e funções qualidade dentro da máscara de potência para alguns valores de peso de "planicidade" espectral de ganho para o amplificador de potência. O peso da figura de ruido permanece inalterado, igual a um.

As Figuras 3.6(a), 3.6(c) e 3.6(e) apresentam os valores de função qualidade dentro da máscara de potência para os pesos de "planicidade" espectral de ganho de 1, 0,5 e 0,25, respectivamente. Estas figuras mostram que na medida em que o peso da "planicidade" espectral de ganho decresce de 1 para 0,25, o comportamento da função qualidade dentro da máscara de potência torna-se mais e mais parecido com o comportamento da figura de ruído apresentado na Figura 3.2(a), uma vez que a influência da "planicidade" espectral é reduzida pelo seu peso. Dessa forma, na Figura 3.6(a), com o peso da "planicidade" igual a um, os melhores valores de função qualidade estão concentrados próximos a $19 \mathrm{~dB}$, assim como os melhores pontos de "planicidade" espectral de ganho na Figura 3.2(b). Esta região de melhor função qualidade se move para a região superior esquerda, assim como na Figura 3.2(a) para a figura de ruído, com o peso da "planicidade" em 0,25 (Figura 3.6(e)).

As Figuras 3.6(b), 3.6(d) e 3.6(f) apresentam o espaço de objetivos para uma potência de entrada de $-15 \mathrm{dBm}$ e o ponto de operação selecionado variando entre 19, 20 e $21 \mathrm{~dB}$ também para os pesos de "planicidade" espectral de ganho de 1, 0,5 e 0,25, respectivamente. Os pontos selecionados estão indicados, e os círculos cujos raios são a distância de cada ponto escolhido à origem indicam que este é o ponto de menor distância uma vez que todos os demais pontos estão fora destes círculos. 


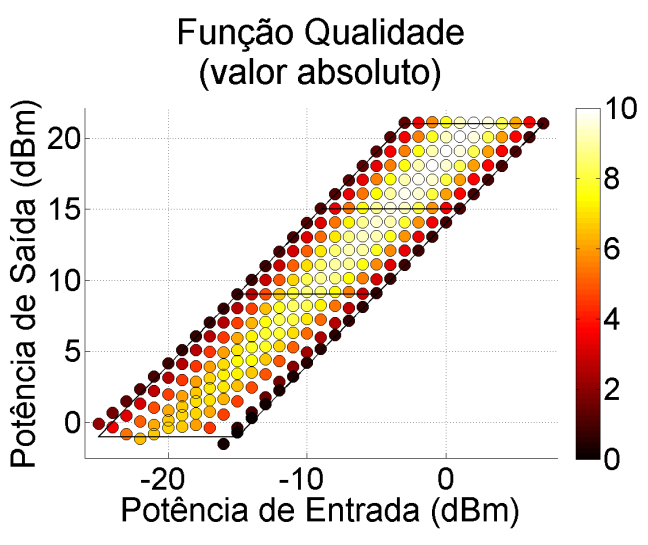

(a)

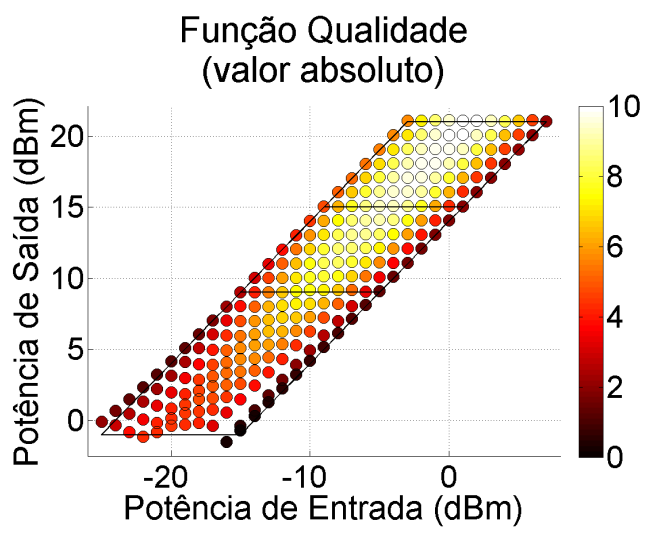

(c)

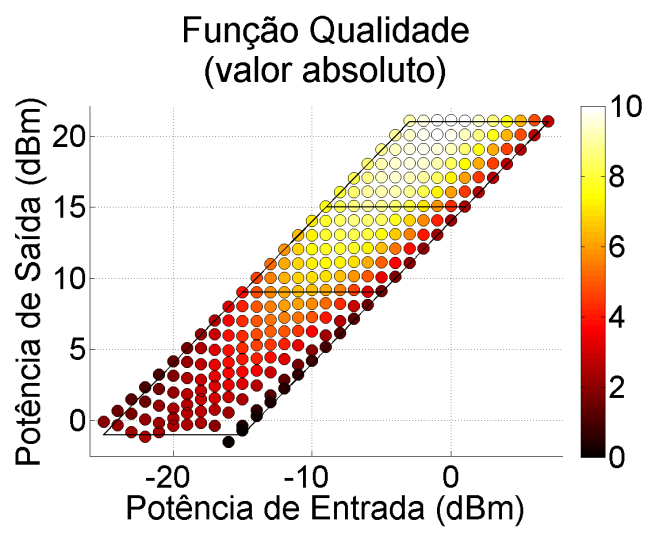

(e)

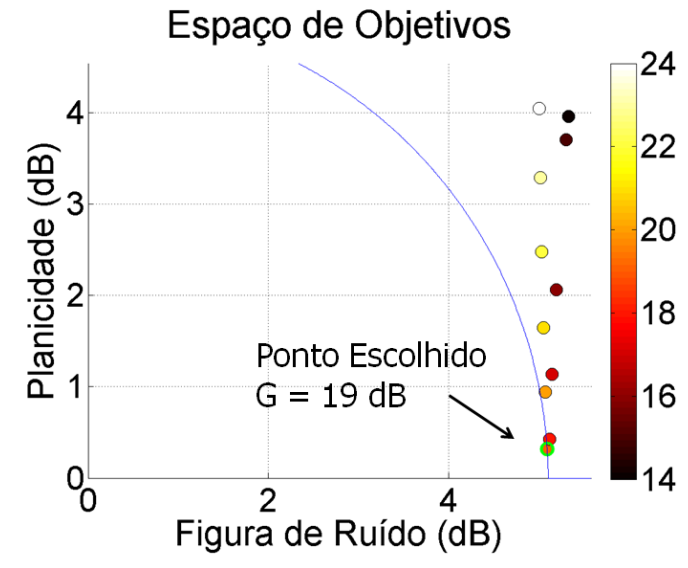

(b)

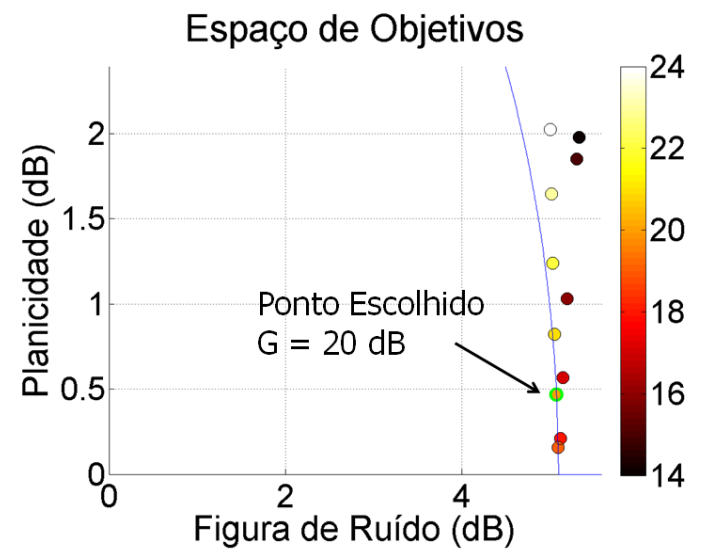

(d)

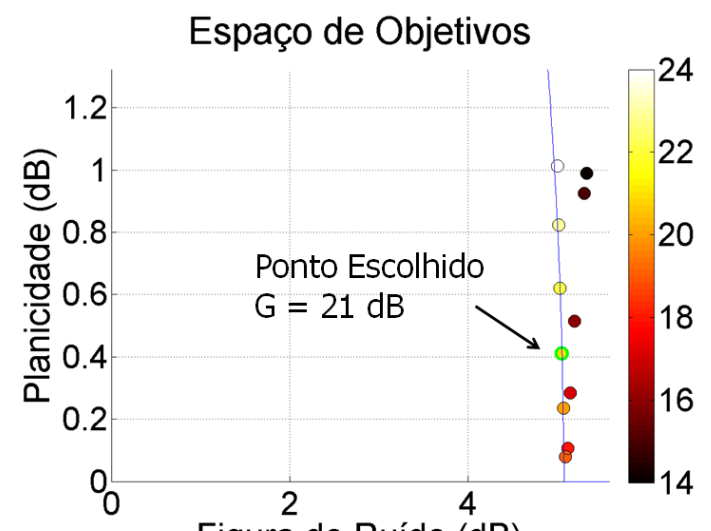

Figura de Ruído (dB)

(f)

Figura 3.6: Espaço de objetivos para Pin $=-15 \mathrm{dBm}$ e máscara da função qualidade para diferentes valores de pesos para a "planicidade" espectral de ganho: (a) e (b) $G F_{W}=1$, (c) e (d) $G F_{W}=0,5$ e (e) e (f) $G F_{W}=0,25$. 
CAPÍTULO

4

\section{Roteamento e Atribuição de Comprimento de Onda (RWA)}

Em redes ópticas WDM em malha, os nós são conectados entre si por meio de fibras ópticas, os quais podem ou não apresentar conversão para o domínio elétrico, onde ocorrem chaveamentos de canais, os quais transportam informações por meio de portadoras ópticas.

Nestas redes, uma conexão entre um par de nós origem-destino é denominada caminho óptico. A matriz de tráfego da rede é formada por todas as conexões que precisam ser estabelecidas, as quais formam o conjunto de demanda. O termo demanda representa um pedido individual de estabelecimento de conexão que pode ser estática, apresentando duração permanente, ou dinâmica, com duração finita [4].

Existem duas categorias de demandas dinâmicas: demandas agendadas, que apresentam tempos de ativação e duração conhecidos a priori e demandas ad hoc, cujos tempos são desconhecidos, podendo ser modelados por processos aleatórios [4].

Neste contexto, um caminho óptico é estabelecido com a atribuição de um comprimento de onda em cada trecho entre nós fonte e destino. Se há recurso de conversão de comprimento de onda nos nós, o fator limitante no estabelecimento do caminho óptico é o número de comprimentos de onda disponíveis em cada trecho. Se não há tal recurso, o comprimento de onda alocado deve permanecer o mesmo ao longo de todo caminho óptico, obedecendo à restrição de continuidade de comprimento de onda [4], como na Figura 4.1 (adaptada de [16]).

O problema de RWA é NP-completo (NP, non-deterministic polynomial time), 


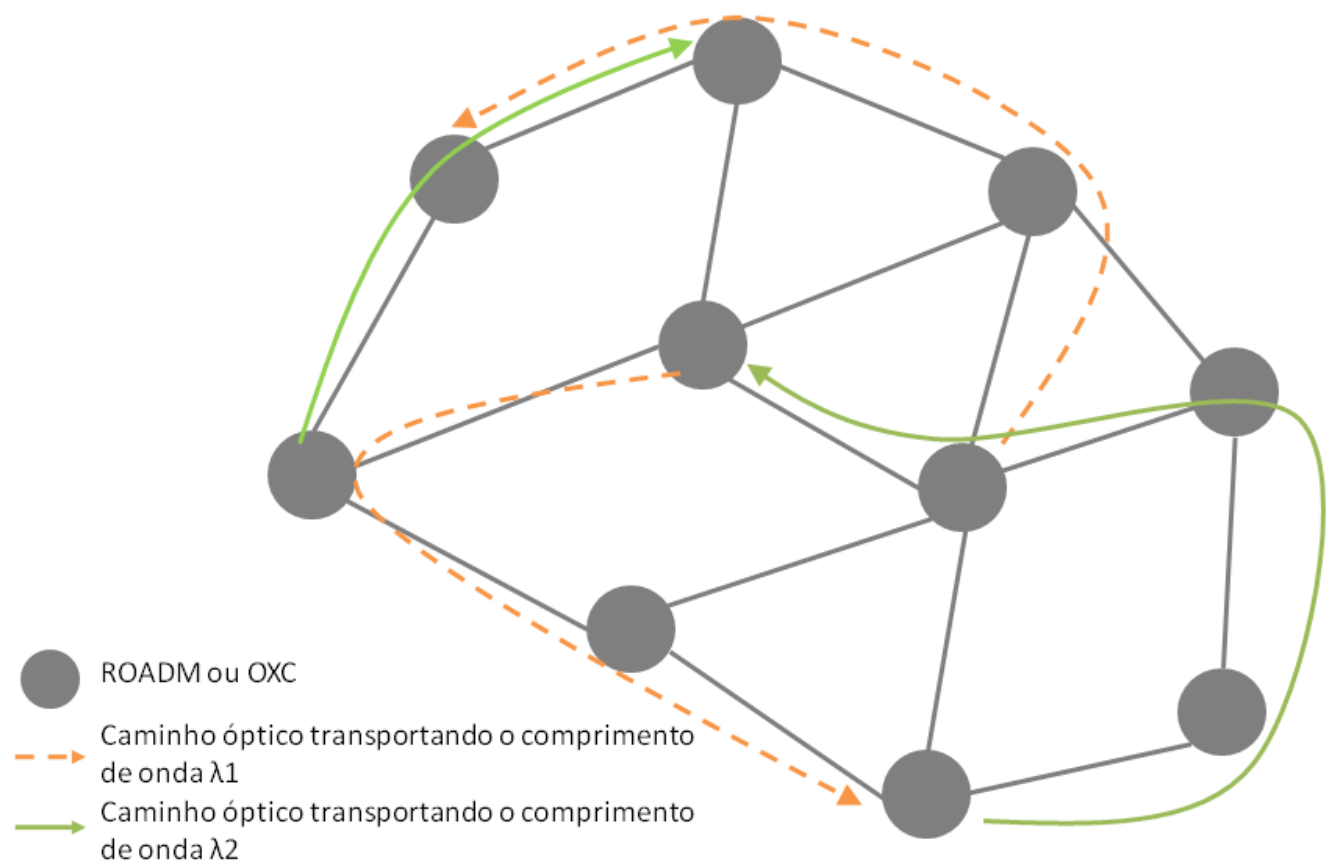

Figura 4.1: Rede óptica WDM com conexões em comprimento de onda.

no qual a solução ótima não pode ser encontrada em tempo polinomial por meio de nenhum algoritmo conhecido [4]. Por simplicidade, o RWA também pode ser tratado separadamente: o subproblema de roteamento e o subproblema de atribuição de comprimento de onda [16]. Apesar desta separação não garantir uma solução ótima, é possível reduzir o tempo computacional consideravelmente [4].

Para o subproblema do roteamento, rotas fixas podem ser encontradas por meio de algoritmos que buscam o menor caminho (short-path, SP), como o Dijkstra ou Bellman-Ford [16]. Sempre que há demanda de tráfego entre dois nós, a mesma rota (menor caminho entre eles) será utilizada. Porém, este tipo de roteamento fixo pode aumentar a probabilidade de bloqueio caso todos os recursos estejam em uso em algum trecho do caminho escolhido [16].

Outras formas de roteamento incluem o roteamento fixo-alternado e o roteamento adaptativo. No roteamento fixo-alternado, cada nó da rede armazena uma tabela de roteamento que contém uma lista ordenada de rotas fixas para cada nó destino e, caso ocorra alguma falha, ou todos os comprimentos de onda estejam ocupados em um determinado trecho, a próxima rota da lista é escolhida (a ordem pode ser do menor caminho para o maior, por exemplo) [16]. Já no roteamento adaptativo, o caminho óptico é escolhido dinamicamente, dependendo do estado atual da rede. Uma forma de roteamento adaptativo é o caminho de menor custo (shortest-cost-path, SCP) e outra é o caminho menos congestionado (least-congested-path, LCP) [16].

No roteamento adaptativo SCP, cada trecho da rede com disponibilidade recebe um custo que pode estar relacionado com sua distância (atenuação), 
quantidade de amplificadores, ou outro parâmetro relacionado com a degradação do sinal. Os trechos sem disponibilidade para realizar a conexão recebem custo infinito. Assim, um algoritmo de menor caminho pode ser aplicado, retornando o caminho de menor custo.

O outro tipo de roteamento adaptativo, o LCP, é parecido com o roteamento fixo-alternado, onde cada par origem-destino armazena a sequência de rotas pré-selecionadas. A diferença é que quando há um pedido de conexão, o caminho menos congestionado (que apresenta mais comprimentos de onda disponiveis) dentre os pré-selecionados será escolhido [16].

O subproblema de atribuição de comprimento de onda pode ser resolvido por meio de algumas heurísticas como: atribuição aleatória de comprimento de onda, em que um comprimento de onda é escolhido aleatoriamente dentro do conjunto de comprimentos de onda disponíveis; first-fit (FF), em que os comprimentos de onda são numerados e o de menor numeração é escolhido (o primeiro comprimento de onda disponível é selecionado); menos usado (leastused, LU), que seleciona o comprimento de onda menos utilizado na rede; mais usado (most-used, MU), que é o oposto da última, selecionando o comprimento mais utilizado; dentre outros métodos descritos em [16].

Tanto em tráfegos dinâmicos quanto estáticos, a medida de desempenho do algoritmo utilizado em redes chaveadas por circuito é a porcentagem de bloqueio de conexões. Também pode ser considerada a quantidade de recursos utilizados, como fibras, regeneradores, comprimentos de onda. Outra métrica utilizada para medida de desempenho do algoritmo é o seu tempo computacional ou de execução [4].

Do ponto de vista das penalidades da camada física, as técnicas de RWA podem ser divididas em duas categorias, o RWA puro, onde os caminhos ópticos são estabelecidos considerando uma camada física ideal, sem penalidades. Esta consideração pode ser adequada nas redes opacas, onde o sinal é regenerado em cada nó ao longo do caminho óptico. Porém, em redes ópticas transparentes, a qualidade do sinal é degradada devido à não regeneração do sinal. Assim, considerando as penalidades da camada física, a segunda categoria de RWA avalia a qualidade do caminho óptico durante o seu estabelecimento [5].

As penalidades da camada física podem ser consideradas como restrições para as decisões do RWA ou as decisões do RWA podem ser feitas já considerando as penalidades. No primeiro caso, tem-se o RWA restrito às penalidades da camada física (physical layer impairment constrained, PLIC-RWA), e no segundo, o RWA ciente das penalidades da camada física (physical layer impairment aware, PLIA-RWA), mas por simplicidade, ambos são referenciados como PLI-RWA em [4].

As penalidades são classificadas em lineares e não-lineares. Dentro das 
penalidades lineares estão [26]:

- Dispersão cromática (chromatic dispersion, CD): É a degradação causada pelas diferentes velocidades de propagação das componentes espectrais que compõem o sinal, causando o alargamento do pulso no domínio do tempo;

- Dispersão por modo de polarização (polarization mode dispersion, PMD): Consiste na diferença entre as velocidades de grupo de cada polarização do sinal, também alargando o pulso no domínio do tempo;

- Perda dependente de polarização (polarization dependent loss, PDL): Referese às diferentes perdas para cada polarização do sinal;

- O ruído ASE, adicionado ao sinal pelos amplificadores ópticos;

- Crosstalk: Interferência entre canais;

- Degradações causadas pela concatenação de filtros e pela "planicidade" do sinal na saída dos amplificadores ópticos.

Os exemplos de penalidades não-lineares são [27]:

- Auto-modulação de fase (self-phase modulation, SPM);

- Modulação de fase cruzada (cross-phase nodulation, XPM);

- Mistura de quatro ondas (four wave mixing, FWM);

- Espalhamento estimulado de Brillouin (stimulated Brillouin scattering, SBS);

- Espalhamento estimulado Raman (stimulated Raman scattering, SRS).

As penalidades não-lineares ocorrem tanto pela variação do índice de refração do meio com a intensidade de potência óptica, como é o caso dos três primeiros, quanto por meio dos fenômenos de espalhamento inelásticos, que também surgem com altos níveis de potência e que é o caso dos dois últimos fenômenos [26], cuja diferença é que fônons acústicos participam do SBS, enquanto fônons ópticos estão envolvidos no SRS [27].

Existem duas formas de incorporar as penalidades da camada física aos algoritmos RWA. A primeira utiliza modelos analíticos para estimar as penalidades e a segunda utiliza resultados simulados, experimentais ou técnicas de monitoramento em tempo real. O monitoramento em tempo real abrange medidas das penalidades (optical impairment monitoring, OIM) como potências de entrada e saída de um amplificador, dispersão residual ou total e medidas 
de desempenho completo da rede (optical performance monitoring, OPM) como parâmetros de BER, OSNR e fator de qualidade [4, 26].

Duas abordagens para solucionar um problema PLI-RWA podem ser utilizadas: centralizada, onde um único elemento armazena todas as informações da topologia da rede e recursos disponíveis, e distribuída, onde cada nó é responsável por calcular, configurar e manter os caminhos ópticos usando um plano de controle comum e distribuído [4].

Dessa forma, os algoritmos PLI-RWA disponiveis na literatura são classificados segundo [26]:

1. Parâmetros de medida utilizados para verificar a viabilidade do caminho óptico como potência, OSNR, BER, fator de qualidade etc.;

2. Penalidades consideradas, tais como CD, PMD, PDL, ASE, crosstalk;

3. Tipo de algoritmo RWA utilizado: RWA calculado em um único passo ou em dois passos;

4. Procedimento de RWA: centralizado ou distribuído;

5. Forma de incorporar as penalidades aos algoritmos RWA: modelos analíticos, medidas, simulações, experimentos ou uma combinação destes.

Para solução de problemas PLI-RWA existem abordagens combinatórias, que buscam uma solução ótima, bem como abordagens sequenciais, baseadas em heurísticas e meta heurísticas, que geralmente não garantem, mas fornecem uma solução próxima da ótima [4].

Neste trabalho, para avaliar a metodologia proposta de controle adaptativo de ganho para amplificadores ópticos, serão utilizadas redes ópticas chaveadas por circuito e com demandas dinâmicas ad hoc. Tais demandas serão apresentadas em uma matriz de tráfego Poissoniano, baseada na modelagem das redes de telefonia tradicionais, onde se assume que as chamadas são independentes e com duração seguindo um modelo exponencialmente distribuído [28].

Para solucionar o subproblema de roteamento, o SCP será utilizado, em conjunto com o Dijkstra, um algoritmo padrão utilizado para encontrar o caminho de menor curso (perda) entre origem e destino [29]. Em seguida, a alocação do comprimento de onda será realizada escolhendo o primeiro comprimento de onda disponivel (first-fit), por ser uma estratégia eficiente e simples de implementar [29].

A penalidade de camada física considerada será a introdução de ruído, ASE pelos amplificadores da rede, representada pela figura de ruído de tais dispositivos, obtida por meio da caracterização prévia destes dispositivos e de suas 
atuais potências de entrada. Tal penalidade será considerada após a escolha do caminho, por meio das medidas de figura de ruído total do caminho ou OSNR no nó destino. Dessa forma, trata-se de um problema de RWA restrito às penalidades da camada física (PLIC-RWA).

Assim, o algoritmo PLI-RWA utilizado neste trabalho, descrito no capítulo a seguir, apresenta as seguintes características:

1. Parâmetros de medida utilizados para verificar a viabilidade do caminho óptico: figura de ruído total e OSNR(estimados);

2. Penalidades consideradas: ASE;

3. RWA calculado em dois passos separados: SCP (Dijkstra) e first-fit;

4. Procedimento de RWA centralizado;

5. Forma de incorporar as penalidades aos algoritmos RWA: por meio de simulações e/ou experimentos; 


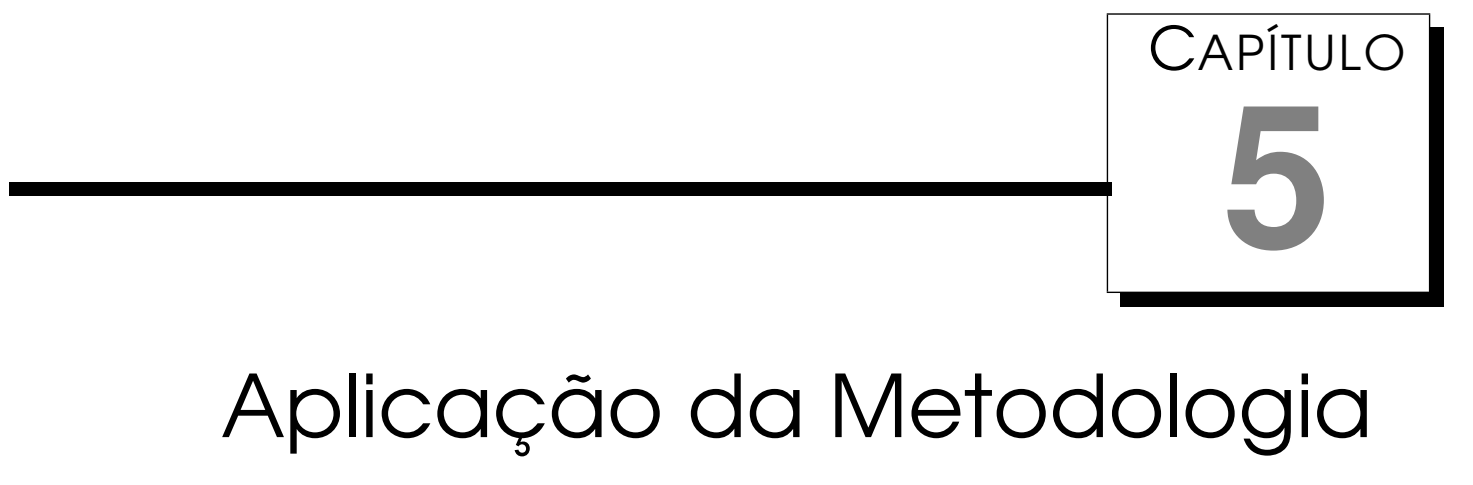

Para avaliar a metodologia proposta, algumas simulações, utilizando o software Matlab ${ }^{\circledR}$, foram realizadas. Estas simulações tratam do problema de PLIRWA em redes ópticas dinâmicas utilizando as informações provenientes da caracterização dos amplificadores ópticos em termos de figura de ruído. Estas informações são utilizadas para calcular as figuras de ruído de cada enlace que formam o caminho-solução e, em seguida, calcular a figura de ruído total deste caminho.

Além da figura de ruído, a OSNR do canal adicionado ao chegar ao destino também pode ser estimada por meio do valor da figura de ruído total do caminho.

Ora a figura de ruído total do caminho, ora a OSNR serão utilizados como restrição para o estabelecimento da chamada. Ou seja, caso a restrição considerada seja a figura de ruído, se seu valor para o caminho escolhido for maior que o valor de limiar preestabelecido, relacionado à qualidade de serviço requerida, este caminho não será utilizado e a conexão não será estabelecida. O mesmo ocorre quando se considera a OSNR como parâmetro de restrição. Se o caminho escolhido apresentar OSNR menor que a requerida, a conexão não será estabelecida.

Dois casos foram avaliados nesta simulação: com e sem a metodologia adaptativa proposta neste trabalho. Assim, primeiramente o tráfego é gerado e tratado com os amplificadores operando com ganho fixo, para compensar as perdas dos enlaces e dispositivos. Em seguida, a metodologia adaptativa é aplicada, de modo a alterar os ganhos dos amplificadores para otimizar o parâmetro figura de ruído.

O objetivo desta simulação é mostrar que com a utilização da metodologia 
adaptativa, que ajusta os ganhos dos amplificadores presentes no caminho escolhido, há redução na probabilidade de bloqueio com relação a um cenário no qual os amplificadores operam com ganhos fixos. Ou seja, uma alteração otimizada do ponto de operação dos amplificadores pode resultar em uma figura de ruído menor que o limiar, ou uma OSNR maior, fazendo com que mais conexões possam ser realizadas.

\section{1 Descrição}

Uma das soluções para o problema RWA consiste em, para uma dada solicitação de chamada entre dois nós, utilizar um algoritmo de busca do menor caminho como o Dijkstra e, em seguida, se houver disponibilidade de comprimento de onda e/ou banda neste caminho, realizar a conexão.

Foram simulados dois casos de solução para o RWA. Em ambos, para cada solicitação de conexão, são encontrados os $k$ menores caminhos entre os nós origem e destino. Para o primeiro menor caminho, é verificado se existe disponibilidade de comprimento de onda. Caso exista, a conexão é realizada. Caso não exista, segue para o próximo menor caminho. Este processo deve seguir até que haja disponibilidade de comprimento de onda ou até que os $k$ caminhos sejam testados, o que ocorrer primeiro.

Para o primeiro caso, restrições relacionadas ora à figura de ruído, ora à OSNR, serão adicionadas ao RWA, bloqueando qualquer conexão que esteja acima ou abaixo de um limiar predefinido para figura de ruído ou OSNR, respectivamente, buscando garantir a qualidade de serviço tanto da nova conexão, quanto das conexões preexistentes.

Para tanto, antes de realizar a conexão, estimam-se quais as novas potências totais nas entradas dos enlaces para, a partir dos novos pontos de operação dos amplificadores ao longo do caminho, estimar seus valores de figura de ruído e OSNR. A partir destes valores, é decidido se a conexão será realizada ou não.

O segundo caso diferencia do primeiro apenas pela utilização da metodologia adaptativa nos amplificadores do caminho antes da estimação da figura de ruído e OSNR. Assim, assumindo que a conexão foi realizada e com os novos valores de potência de entrada nos amplificadores, são obtidos seus novos ganhos por meio da metodologia adaptativa proposta neste trabalho. Em seguida, com estes novos ganhos, figura de ruído e OSNR são estimadas. Porém, de fato, a conexão ainda não foi realizada. Toda esta etapa é realizada antes. Apenas se os valores de figura de ruído ou OSNR respeitarem os limiares especificados, a conexão será realizada e os novos ganhos dos amplificadores, obtidos por meio da metodologia adaptativa, serão aplicados de fato. 
Assim, com a metodologia adaptativa, tem-se a possibilidade do caminho apresentar uma figura de ruído menor ou uma OSNR maior que o limiar e não ser mais bloqueado, como no primeiro caso.

A máscara de potência com as informações de figura de ruído é utilizada para estimar o valor da figura de ruído de todo o caminho. Por este motivo, inicialmente, para a implementação da simulação, optou-se por utilizar uma rede simples, com quatro nós, onde se pode garantir que os pontos de operação dos amplificadores não saiam da região caracterizada, possibilitando sempre a estimação da figura de ruído e, consequentemente, da OSNR.

Em seguida, esta rede foi aumentada para 6, 10 e 15 nós. Mas, sempre ajustando as perdas entre os nós de modo que os pontos de operação dos amplificadores não saíssem da máscara de potência.

No segundo caso, a máscara de potência é utilizada tanto para estimar os valores de figura de ruído, como no primeiro caso, quanto na aplicação da metodologia adaptativa.

A seguir, algumas considerações importantes sobre a rede óptica utilizada:

1. Rede óptica chaveada por circuito e com demanda dinâmica ad hoc;

2. Geração de tráfego poissoniano, com tempo de chegada e duração das conexões modelados por uma distribuição exponencial, conforme apresentado no Apêndice A [28];

3. Rede óptica transparente, sem conversão de comprimento de onda. Assim, a conexão só é realizada quando há disponibilidade de um mesmo comprimento de onda em todos os enlaces que formam a conexão. Caso isso não ocorra, a conexão é bloqueada por restrição de comprimento de onda. Na simulação, foram utilizados 80 canais para que este tipo de bloqueio não mascarasse o bloqueio causado pela restrição de NF ou OSNR;

4. Nós sem agregação de tráfego (grooming), de modo que não é possível aproveitar um comprimento de onda para levar informação proveniente de um nó intermediário, isto é, não é possível "abrir um canal" em nós intermediários mesmo que ele não esteja com sua banda totalmente utilizada;

5. Serão utilizados dois amplificadores por enlace (um amplificador de potência na entrada da fibra óptica e um pré-amplificador na saída da fibra). Por este motivo, são utilizadas redes com baixas perdas entre nós, de modo que dois amplificadores sejam suficientes para compensá-las. Esta condição foi necessária para deixar a rede mais simples, mas suficiente para observar a ação da metodologia adaptativa. 
6. Os ganhos dos amplificadores são ajustados, inicialmente, para compensar as perdas dos enlaces e dos nós, compostos por roteadores ópticos formados por WSSs.

7. A potência por canal na entrada do enlace é sempre fixa (entrada do amplificador de potência). Esta restrição garante que a alteração do ganho dos amplificadores de um caminho não altere as potências de entrada de enlaces que não estão neste caminho;

8. Para garantir o item 5, o WSS que, além de realizar o chaveamento entre canais no nó, também pode atenuá-los individualmente, é utilizado para equalizar os canais na entrada do enlace. Assim, ele garante que as potências dos canais permaneçam fixas na entrada dos enlaces aplicando a atenuação necessária. No início, a atenuação no WSS é $6 \mathrm{~dB}$, e continua 6 em toda a simulação se a metodologia adaptativa não for utilizada. Com a sua utilização, o ganho tende sempre a aumentar. Assim, o WSS precisa apenas aplicar uma atenuação maior que 6 e suficiente para manter a potência dos canais fixas na entrada de cada enlace;

9. Há possibilidade de encontrar $k$ menores caminhos ao invés de um. O algoritmo Yen [30] será utilizado para encontrar os $k$ menores caminhos e é uma adaptação do Djikstra;

10. Alocação de comprimento de onda por first-fit;

11. Serão considerados enlaces bidirecionais (full-duplex). Assim, haverá os caminhos de ida e volta e os parâmetros de figura de ruído e OSNR são calculadas nos dois sentidos. Ambos devem atender às restrições.

Optou-se por apenas dois amplificadores por enlace por questão de simplicidade. Porém, a metodologia adaptativa pode ser aplicada em uma rede com qualquer número de amplificadores por enlace. Basta realizar a caracterização dos possiveis pontos de operação em que cada amplificador irá operar para que seja possível a estimação dos parâmetros de figura de ruído e OSNR. Neste trabalho, para suportar quantidades diferentes de amplificadores por enlace, o programa implementado precisaria de algumas alterações nas funções que calculam os novos ganhos, estimam as novas potências na entrada dos amplificadores e as figuras de ruído de cada enlace que compõe o caminho. Atualmente, estas funções suportam apenas a análise de dois amplificadores por enlace. Para suportar números diferentes de amplificadores, elas precisariam ser realizadas utilizando laços for, de acordo com o número de amplificadores em cada enlace. Porém, como o foco desta simulação é apresentar a melhora na probabilidade de bloqueio com a utilização da metodologia, foram utilizados dois amplificadores. 
A Figura 5.1 apresenta a rede utilizada durante a fase de desenvolvimento da simulação. Nela, cada enlace é composto por um par de amplificadores, um amplificador de potência e um pré-amplificador, e uma fibra óptica. A perda do enlace de ida $L_{x y}$ é igual à perda do enlace de volta $L_{y x}$, onde $x y$ indica o sentido: do nó $x$ ao $y$. Apesar de não representar uma aplicação prática, esta rede foi utilizada durante a construção da simulação e também será utilizada neste texto para apresentar, de forma simples, resultados intermediários da simulação, para melhor entender seu funcionamento.

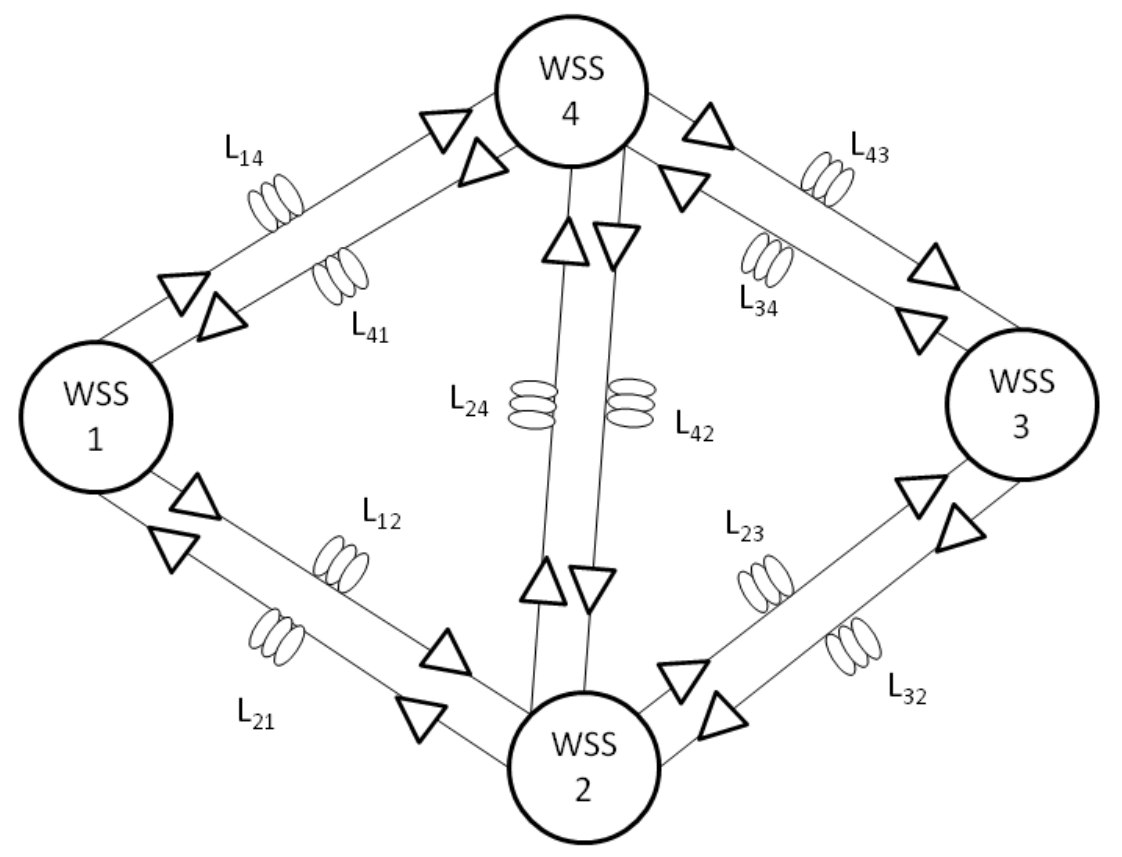

Figura 5.1: Rede de quatro nós utilizada para desenvolver a simulação. WSS são as chaves seletoras de comprimentos de onda.

A Tabela 5.1 apresenta os valores das perdas dos enlaces para a rede de quatro nós da Figura 5.1.

Tabela 5.1: Valores das perdas, em dB, entre nós para a rede com quatro nós da Figura 5.1 (Inf = Infinito, indicando que não há conexão entre os nós).

\begin{tabular}{|c|c|c|c|c|}
\hline Nós & 1 & 2 & 3 & 4 \\
\hline 1 & Inf & 30 & Inf & 27 \\
\hline 2 & 30 & Inf & 31 & 28 \\
\hline 3 & Inf & 31 & Inf & 32 \\
\hline 4 & 27 & 28 & 32 & Inf \\
\hline
\end{tabular}

Neste trabalho, para utilizar os resultados das caracterizações dos dois amplificadores já disponíveis, os valores das perdas dos enlaces apresentados na Tabela 5.1 foram escolhidos de modo que os pontos de operação destes amplificadores permanecessem dentro da máscara de potência predefinida. Em uma rede já instalada, onde os valores das perdas dos enlaces são fixos e conhecidos, é necessário definir a região da máscara de potência do amplificador 
de modo a cobrir todos os pontos de operação possíveis dadas as perdas dos enlaces. Assim, sempre será possivel estimar sua figura de ruído. Em seguida, a metodologia proposta pode ser aplicada da mesma forma.

A Tabela 5.2 apresenta possiveis valores de potência de entrada nos amplificadores com a variação máxima de carregamento de canais (de 1 a 80). Assim, na coluna que refere-se ao amplificador de potência (Amp1), tem-se a mínima potência de entrada (Pin min), quando há apenas um canal no enlace (considerando a potência por canal na entrada do enlace de $-12 \mathrm{dBm}$ ) e a potência de entrada máxima, quando há 80 canais. Neste caso, as possíveis potências de saída, mínimas e máximas, de modo que o amplificador se mantenha dentro da região de operação caracterizada (máscara de potência), também estão apresentados de acordo com os possiveis valores de ganho. A partir destes valores, e dos valores das perdas entre os nós (segunda coluna), são obtidos os valores mínimos e máximos das potências nas entradas dos amplificadores pré (Amp2) de cada enlace. Neste ponto, as perdas dos enlaces foram escolhidas neste trabalho de modo que a potência de entrada não ficasse abaixo ou acima dos valores mínimos e máximos da máscara de potência do Amp 2, fazendo com que seu ponto de operação saísse da máscara. As duas últimas colunas apresentam os possiveis ganhos dentro da máscara, dados os valores das potências de entrada.

Tabela 5.2: Valores de potência de entrada e saída dos amplificadores para o carregamento de canais máximo e mínimo considerando $-12 \mathrm{dBm} /$ canal na entrada do enlace. $P_{i n} \min$ se refere ao carregamento mínimo, 1 canal, e $P_{i n}$ $\max$ ao carregamento máximo, 80 canais.

\begin{tabular}{|c|c|c|c|c|c|c|c|c|c|}
\hline \multirow{4}{*}{ Enlace } & \multirow{4}{*}{$\begin{array}{c}\text { Perda } \\
(d B)\end{array}$} & \multicolumn{4}{|c|}{$\operatorname{Amp} 1(\mathrm{G}=14 \mathrm{~dB})$} & \multicolumn{4}{|c|}{ Amp2 } \\
\hline & & $P_{i n}$ & $P_{i n}$ & $P_{\text {out }}$ & $P_{\text {out }}$ & $P_{i n}$ & $P_{i n}$ & $G$ & $G$ \\
\hline & & $\min$ & $\max$ & $\min$ & $\max$ & $\min$ & $\max$ & $\min$ & $\max$ \\
\hline & & $(d B m)$ & $(d B m)$ & $(d B m)$ & $(d B m)$ & $(d B m)$ & $(d B m)$ & $(d B)$ & $(d B)$ \\
\hline $1-2$ & 30 & -12 & 7 & 2 & 21 & -28 & -9 & 22 & 23 \\
\hline $1-4$ & 27 & -12 & 7 & 2 & 21 & -25 & -6 & 19 & 20 \\
\hline $2-3$ & 31 & -12 & 7 & 2 & 21 & -29 & -10 & 23 & 24 \\
\hline $2-4$ & 28 & -12 & 7 & 2 & 21 & -26 & -7 & 20 & 21 \\
\hline 3-4 & 32 & -12 & 7 & 2 & 21 & -30 & -11 & 24 & 24 \\
\hline
\end{tabular}

As Figuras 5.2 e 5.3 apresentam as máscaras de potências dos amplificadores utilizados em todas as redes desta simulação. A Figura 5.2 apresenta o desempenho, em termos de figura de ruído, resultado da caracterização do primeiro amplificador utilizado em cada enlace. A potência mínima na entrada do amplificador de potência (Amp1), posicionado na entrada do enlace, corresponde à potência de um canal, isto é, -12 dBm. Já a potência máxima corresponde à soma das potências dos 80 canais, $+7 \mathrm{dBm}$, como visto na Tabela 5.2. Na Figura 5.2(a), foram destacados em azul os possíveis pontos de 
operação do amplificador dadas as potências de entrada para todos os carregamentos de canais, de 1 a 80 , sem a metodologia adaptativa. Neste caso, o ganho do amplificador é mantido fixo em $14 \mathrm{~dB}$, uma vez que este valor de ganho pode ser aplicado para qualquer potência de entrada sem que o amplificador saia da região da máscara. Na Figura 5.2(b) estão em destaque em azul os possíveis pontos de operação utilizando a metodologia adaptativa. Neste caso, para cada potência de entrada, o algoritmo retorna o melhor ganho, sempre dentro da região caracterizada.

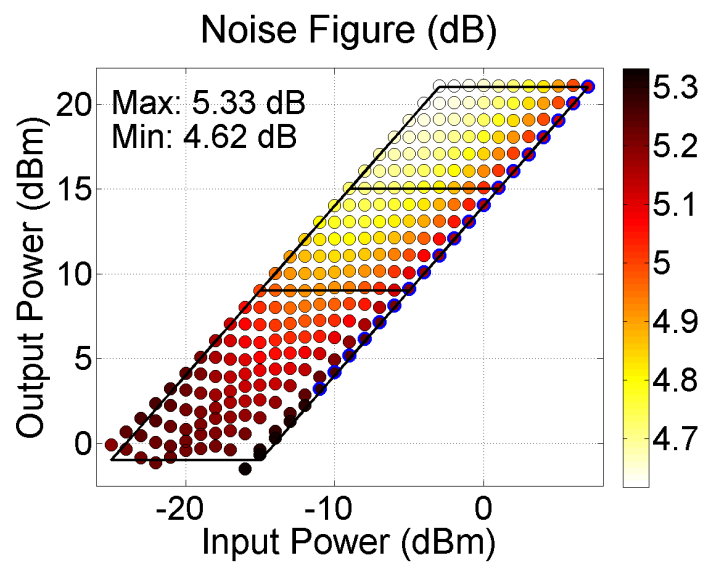

(a)

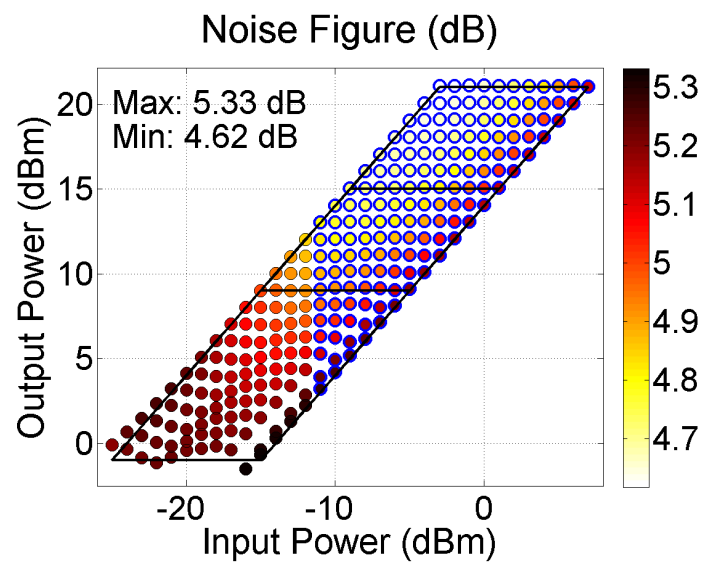

(b)

Figura 5.2: Máscara de potência do amplificador de potência - Amp 1 do enlace. (a) sem e (b) com a metodologia adaptativa. Destaque em azul para os possiveis pontos de operação dada as suas potências de entrada com carregamento variando do mínimo ao máximo.

A Figura 5.3 apresenta a máscara de potência (com resultado da caracterização em termos de figura de ruído) para o segundo amplificador (Amp2) utilizado no enlace entre os nós 1 e 2. Apenas este enlace foi apresentado pois, como a perda é diferente para cada enlace, os possiveis pontos de operação de cada pré-amplificador diferem para cada enlace. Na Figura 5.3(a), novamente, a região em destaque corresponde aos possiveis pontos de operação sem a metodologia adaptativa, onde o ganho (fixo) pode ser 22 ou $23 \mathrm{~dB}$, conforme os valores máximo e mínimo apresentados na Tabela 5.2 para este enlace. Este ganho, porém, deve ser mantido em $22 \mathrm{~dB}$ para compensar a perda do enlace (30 dB) e o WSS fixo em $6 \mathrm{~dB}$, considerando o primeiro amplificador em $14 \mathrm{~dB}$. Na Figura 5.3(b), o destaque em azul se refere ao uso da metodologia adaptativa, onde os possíveis ganhos vão de 14 a $24 \mathrm{~dB}$, de acordo com o valor retornado pela metodologia adaptativa, sem sair da máscara.

Dessa forma, é possível garantir que durante a simulação, independente do carregamento, as potências de entrada dos dois amplificadores estão dentro dos limites de suas máscaras de potência com e sem a metodologia adaptativa.

A Figura 5.4 apresenta a segunda rede utilizada, com seis nós. A mesma quantidade de amplificadores foi utilizada por enlace. Em seguida, a Tabela 


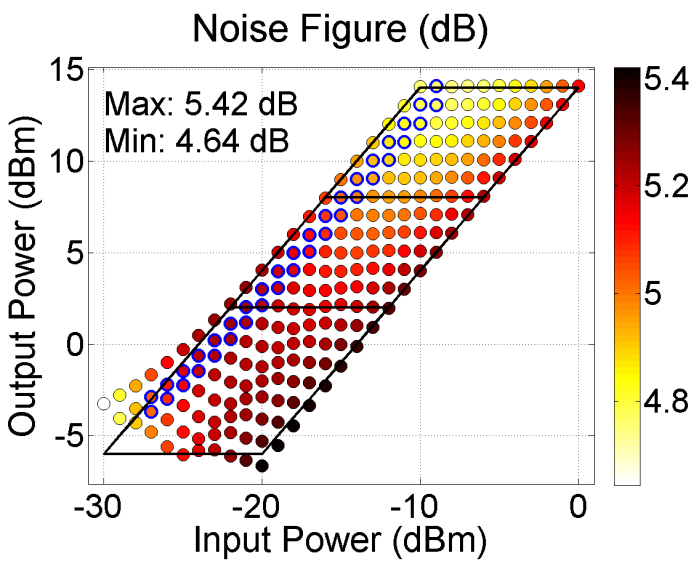

(a)

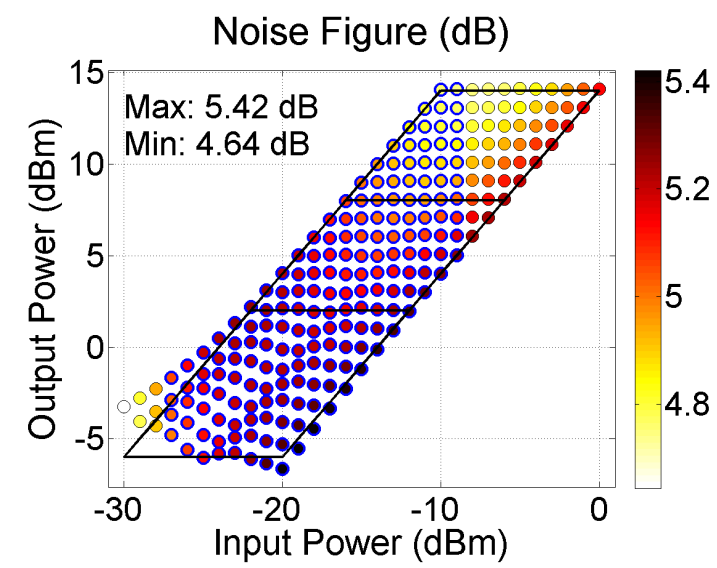

(b)

Figura 5.3: Máscara de potência do pré-amplificador - Amp 2 do enlace. (a) sem e (b) com a metodologia adaptativa. Destaque em azul para os possiveis pontos de operação dada as suas potências de entrada com carregamento variando do mínimo ao máximo.

5.3 apresenta os valores das perdas por enlace desta rede.

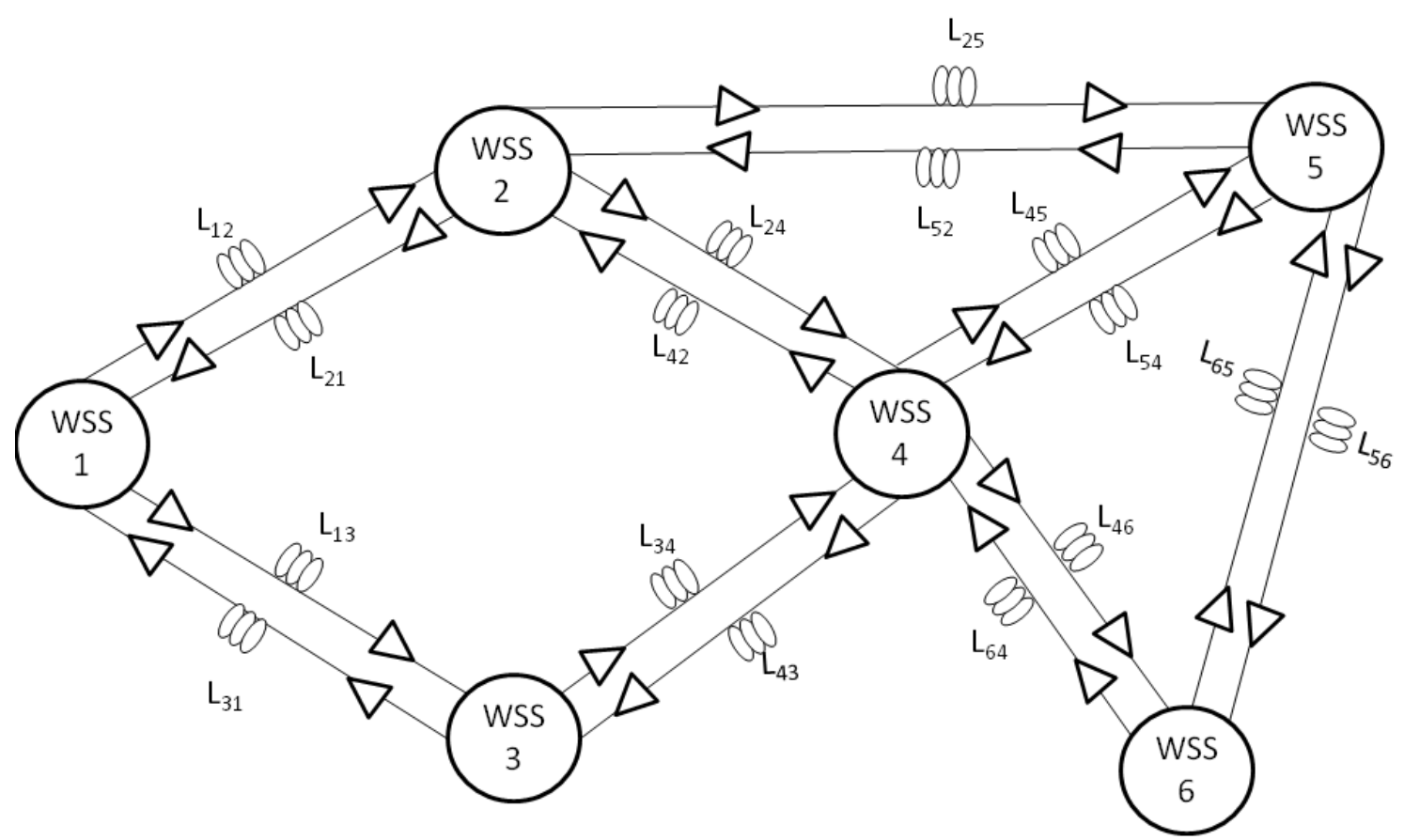

Figura 5.4: Rede de seis nós utilizada na simulação.

As Tabelas 5.4 e 5.5 apresentam as perdas de mais duas redes utilizadas, com dez e quinze nós, respectivamente.

Todos os valores das perdas das topologias de 6, 10 e 15 nós foram obtidos da mesma forma descrita anteriormente para a topologia de 4 nós. 
Tabela 5.3: Valores das perdas, em dB, entre nós para a rede com seis nós (Inf = Infinito, indicando que não há conexão entre os nós).

\begin{tabular}{|c|c|c|c|c|c|c|}
\hline Nós & 1 & 2 & 3 & 4 & 5 & 6 \\
\hline 1 & Inf & 29 & 28 & Inf & Inf & Inf \\
\hline 2 & 29 & Inf & Inf & 27 & 30 & Inf \\
\hline 3 & 28 & Inf & Inf & 31 & Inf & Inf \\
\hline 4 & Inf & 27 & 31 & Inf & 26 & 25 \\
\hline 5 & Inf & 30 & Inf & 26 & Inf & 32 \\
\hline 6 & Inf & Inf & Inf & 25 & 32 & Inf \\
\hline
\end{tabular}

Tabela 5.4: Valores das perdas, em dB, entre nós para a rede com dez nós (Inf = Infinito, indicando que não há conexão entre os nós).

\begin{tabular}{|c|c|c|c|c|c|c|c|c|c|c|}
\hline Nós & 1 & 2 & 3 & 4 & 5 & 6 & 7 & 8 & 9 & 10 \\
\hline 1 & Inf & 29 & 28 & Inf & Inf & Inf & Inf & 27 & 30 & Inf \\
\hline 2 & 29 & Inf & Inf & Inf & 31 & Inf & Inf & 26 & Inf & Inf \\
\hline 3 & 28 & Inf & Inf & 32 & 25 & Inf & Inf & Inf & Inf & Inf \\
\hline 4 & Inf & Inf & 32 & Inf & Inf & 31 & Inf & Inf & Inf & Inf \\
\hline 5 & Inf & 31 & 25 & Inf & Inf & 27 & Inf & 32 & Inf & Inf \\
\hline 6 & Inf & Inf & Inf & 31 & 27 & Inf & 26 & Inf & Inf & Inf \\
\hline 7 & Inf & Inf & Inf & Inf & Inf & 26 & Inf & 30 & Inf & 28 \\
\hline 8 & 27 & 26 & Inf & Inf & 32 & Inf & 30 & Inf & 29 & Inf \\
\hline 9 & 30 & Inf & Inf & Inf & Inf & Inf & Inf & 29 & Inf & 31 \\
\hline 10 & Inf & Inf & Inf & Inf & Inf & Inf & 28 & Inf & 31 & Inf \\
\hline
\end{tabular}

Tabela 5.5: Valores das perdas, em dB, entre nós para a rede com quinze nós (Inf = Infinito, indicando que não há conexão entre os nós).

\begin{tabular}{|c|c|c|c|c|c|c|c|c|c|c|c|c|c|c|c|}
\hline Nós & 1 & 2 & 3 & 4 & 5 & 6 & 7 & 8 & 9 & 10 & 11 & 12 & 13 & 14 & 15 \\
\hline 1 & Inf & 29 & Inf & Inf & Inf & 28 & Inf & Inf & Inf & Inf & Inf & Inf & Inf & Inf & Inf \\
\hline 2 & 29 & Inf & 30 & Inf & 27 & Inf & Inf & Inf & Inf & Inf & Inf & Inf & Inf & Inf & Inf \\
\hline 3 & Inf & 30 & Inf & 31 & Inf & Inf & Inf & Inf & Inf & Inf & Inf & Inf & Inf & Inf & Inf \\
\hline 4 & Inf & Inf & 31 & Inf & 25 & Inf & Inf & Inf & 26 & Inf & Inf & Inf & Inf & Inf & Inf \\
\hline 5 & Inf & 27 & Inf & 25 & Inf & Inf & 32 & 31 & Inf & Inf & Inf & Inf & Inf & Inf & Inf \\
\hline 6 & 28 & Inf & Inf & Inf & Inf & Inf & 27 & Inf & Inf & Inf & Inf & Inf & Inf & Inf & Inf \\
\hline 7 & Inf & Inf & Inf & Inf & 32 & 27 & Inf & 32 & Inf & Inf & 30 & 26 & Inf & Inf & Inf \\
\hline 8 & Inf & Inf & Inf & Inf & 31 & Inf & 32 & Inf & 28 & 29 & Inf & Inf & Inf & Inf & Inf \\
\hline 9 & Inf & Inf & Inf & 26 & Inf & Inf & Inf & 28 & Inf & 31 & Inf & Inf & Inf & Inf & Inf \\
\hline 10 & Inf & Inf & Inf & Inf & Inf & Inf & Inf & 29 & 31 & Inf & Inf & Inf & 32 & Inf & Inf \\
\hline 11 & Inf & Inf & Inf & Inf & Inf & Inf & 30 & Inf & Inf & Inf & Inf & 28 & 27 & 30 & Inf \\
\hline 12 & Inf & Inf & Inf & Inf & Inf & Inf & 26 & Inf & Inf & Inf & 28 & Inf & Inf & Inf & 31 \\
\hline 13 & Inf & Inf & Inf & Inf & Inf & Inf & Inf & Inf & Inf & 32 & 27 & Inf & Inf & 29 & Inf \\
\hline 14 & Inf & Inf & Inf & Inf & Inf & Inf & Inf & Inf & Inf & Inf & 30 & Inf & 29 & Inf & 30 \\
\hline 15 & Inf & Inf & Inf & Inf & Inf & Inf & Inf & Inf & Inf & Inf & Inf & 31 & Inf & 30 & Inf \\
\hline
\end{tabular}

\subsection{Primeiro caso: sem a metodologia adaptativa}

A primeira solução para o RWA apresentada consiste em bloquear a chamada quando os $k$ caminhos apresentarem figura de ruído maior que o limiar 
preestabelecido (ou OSNR menor que o limiar).

Para estimar a figura de ruído total do caminho, utilizou-se a caracterização prévia disponível para todos os amplificadores da rede. Tal caracterização é a mesma apresentada na Seção 3.1 e consiste em obter o desempenho do amplificador em termos de figura de ruído (dentre outros parâmetros, como "planicidade" espectral de ganho, precisão do controle de ganho, corrente e potência do laser) para vários pontos dentro da máscara de potência definida para o amplificador. A partir do ponto de operação em termos de potência de entrada e ganho do amplificador, a tabela com os dados de figura de ruído é consultada para obter o valor da figura de ruído correspondente ao ponto de operação. A partir do valor da figura de ruído de cada amplificador do enlace, a figura de ruído do enlace é calculada e, em seguida, a figura de ruído total do possivel caminho.

Para calcular a figura de ruído de enlaces como o da Figura 5.1, utiliza-se a equação do fator de ruído equivalente $\left(F_{s y s}\right)$ de uma cascata de amplificadores com componentes de perda, de acordo com a Figura 5.5, por meio de (5.1) [23]:

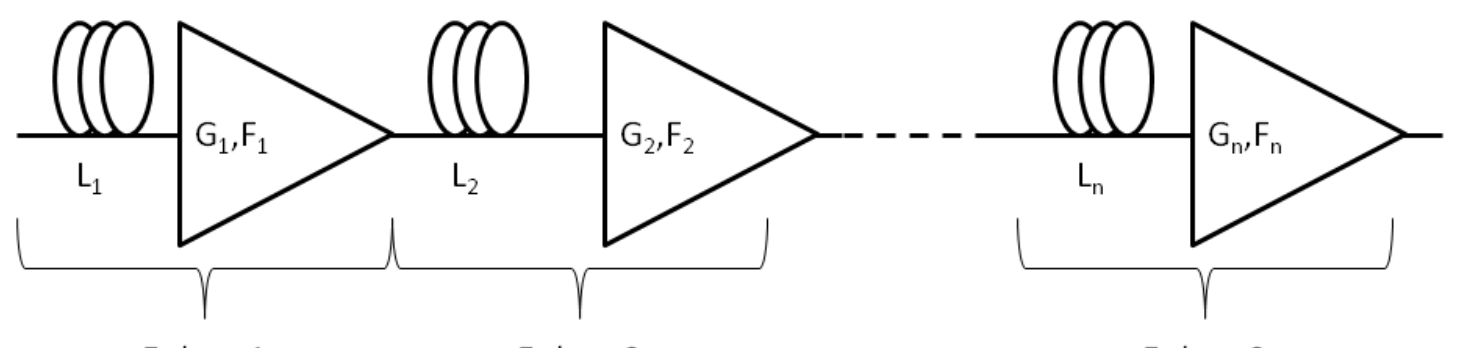

Enlace 1

Enlace 2

Enlace 3

Figura 5.5: Cascata de amplificadores com componentes de perdas.

$$
F_{\text {sys }}=\frac{F_{1}}{L_{1}}+\frac{F_{2}}{L_{1} G_{1} L_{2}}+\ldots+\frac{F_{n}}{L_{1} G_{1} L_{2} G_{2} \ldots L_{n}}
$$

na qual $F_{i}$ é o fator de ruído do amplificador $i$ e $L_{i}$ é a perda do enlace $i$. A figura de ruído do sistema é obtida a partir do fator de ruído $N F_{s y s}=10 \log _{10}\left(F_{\text {sys }}\right)$.

Por outro lado, os enlaces das redes utilizados na simulação são como os da Figura 5.6.

A figura de ruído total do enlace da Figura 5.6 é calculado adaptando (5.1) da Figura 5.5 para a Figura 5.6, resultando em

$$
F^{(i)}=F_{1}^{(i)}+\frac{F_{2}^{(i)}}{G_{1}^{(i)} L_{F O}^{(i)}}
$$

O que equivale à (5.1) com $L_{1}=1$.

Em cada enlace, a perda do WSS não interfere na figura de ruído do sistema uma vez que ela não degrada a relação sinal-ruído. Já a perda entre os 


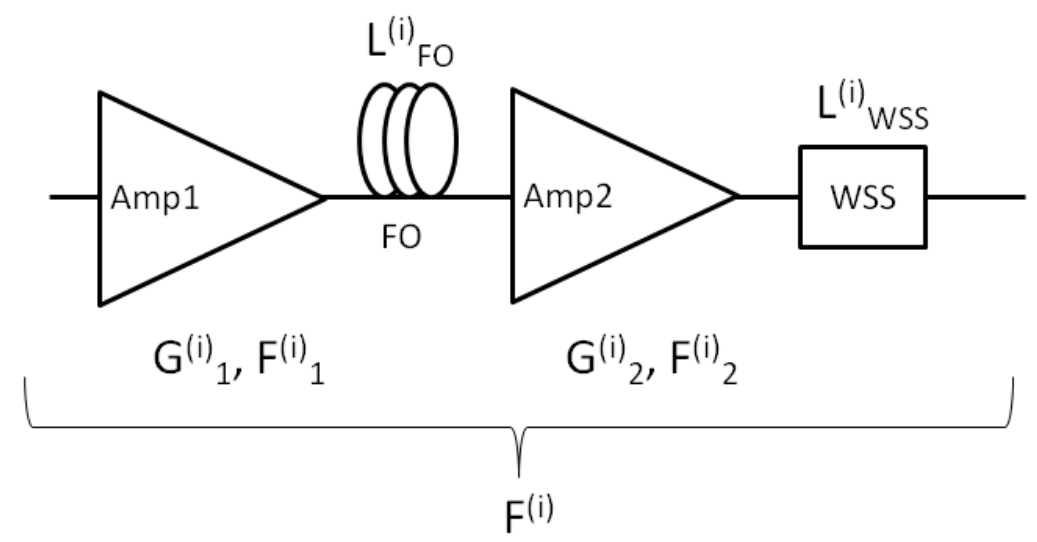

Figura 5.6: Topologia de enlace utilizado nas redes simuladas.

amplificadores, representado pela fibra óptica, reduz a potência na entrada do segundo amplificador, fazendo com que o sinal fique mais fraco e não estimule tanta emissão de fótons na fibra dopada com érbio do segundo amplificador, dando mais chance para a emissão espontânea estimular emissão de novos fótons, gerando mais ruído e reduzindo a OSNR do sinal na saída.

Por fim, para calcular o fator de ruído do caminho é necessário considerar cada enlace da Figura 5.6 como uma caixa preta, como mostra a Figura 5.7, representado pelo seu fator de ruído, $F^{(i)}$, e pelo seu ganho $G^{(i)}$. Assim, o fator de ruído do caminho pode ser calculado de forma análoga ao cálculo do fator de ruído do enlace por (5.3).

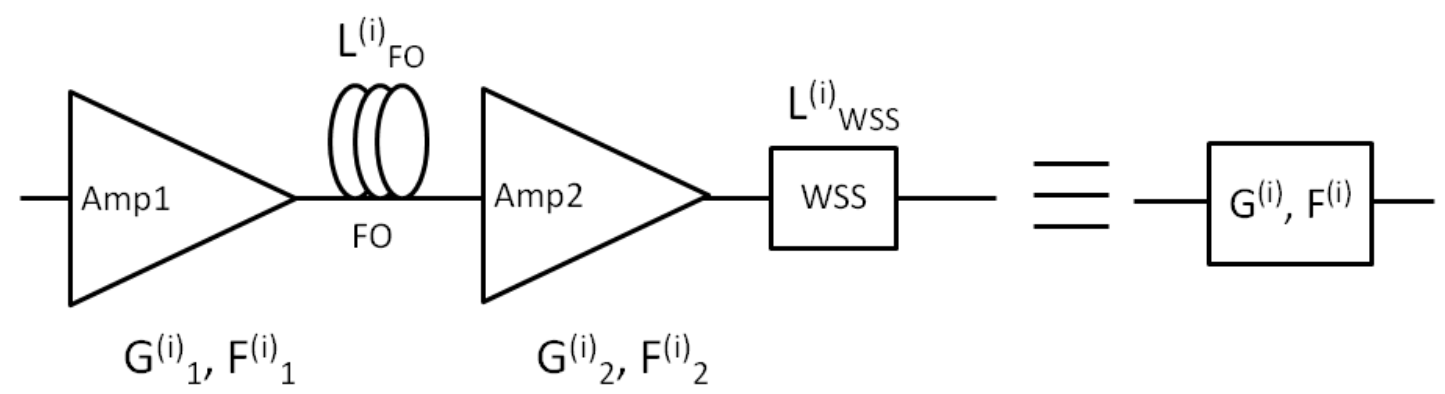

Figura 5.7: Enlace visto como uma caixa preta para cálculo do fator de ruído do caminho.

$$
F_{\text {caminho }}=F^{(1)}+\frac{F^{(2)}}{G^{(1)}}+\ldots+\frac{F^{(n)}}{G^{(1)} G^{(2)} \ldots G^{(n-1)}}
$$

sendo $G^{(i)}=G_{1}^{(i)} L_{F O}^{(i)} G_{2}^{(i)} L_{W S S}^{(i)}$ e $F^{(i)}$ como em (5.2).

É possível observar que para o cálculo da figura de ruído do caminho a perda do WSS entre os enlaces é considerada. Isso ocorre porque ela reduz a potência na entrada de cada enlace e causa o mesmo efeito da perda do enlace (fibra óptica) no segundo amplificador. Já o último WSS, no nó destino, novamente não é considerada para o cálculo da figura de ruído total do caminho 
por não degradar a relação sinal-ruído.

No primeiro caso, sem a metodologia adaptativa, os ganhos dos amplificadores são ajustados de modo a compensar as perdas do enlace (perda na fibra óptica e perda no WSS) e são mantidos fixos durante toda a simulação.

Além da figura de ruído, também é medida a OSNR do sinal ao chegar no nó destino. Dessa forma, podemos também utilizar um limiar de OSNR de modo que caminhos que apresentarem uma OSNR abaixo do limiar sejam bloqueados.

A OSNR estimada é obtida a partir da equação do fator de ruído [23]

$$
F^{(c h)}=\frac{P a s e^{(c h)}}{h v^{(c h)} G^{(c h)} \Delta v^{(c h)}}+\frac{1}{G^{(c h)}}
$$

onde $P a s e^{(c h)}$ se refere à potência de ruído de ASE no canal correspondente, $h$ é a constante de Planck, $v^{(c h)}$ é a frequência do canal, $\Delta v$ é a largura de banda de medida do canal, e $G^{(c h)}$ é o ganho do canal entre os pontos de medida de F.

Considerando

$$
\text { OSNR } R^{(c h)}=\frac{P_{\text {out }}^{(c h)}}{\text { Pase }^{(c h)}}
$$

e

$$
G^{(c h)}=\frac{P_{o u t}^{(c h)}}{P_{\text {in }}^{(c h)}}
$$

Substituindo (5.5) e (5.6) em (5.4)

$$
F^{(c h)}-\frac{1}{G^{(c h)}}=\frac{G^{(c h)} P_{i n}^{(c h)}}{O S N R^{(c h)} h v^{(c h)} G^{(c h)} \Delta v^{(c h)}}
$$

Simplificando

$$
\frac{G^{(c h)} F^{(c h)}-1}{G^{(c h)}}=\frac{P_{i n}^{(c h)}}{O S N R^{(c h)} h v^{(c h)} \Delta v^{(c h)}}
$$

Reorganizando, obtemos a OSNR do canal na saída do caminho com fator de ruído $F^{(c h)}$ e ganho $G^{(c h)}$

$$
O S N R^{(c h)}=\frac{G^{(c h)} P_{i n}^{(c h)}}{\left(G^{(c h)} F^{(c h)}-1\right) h v^{(c h)} \Delta v^{(c h)}}
$$

O pseudocódigo que trata do evento de alocação para o primeiro caso é apresentado em Algoritmo 1. 


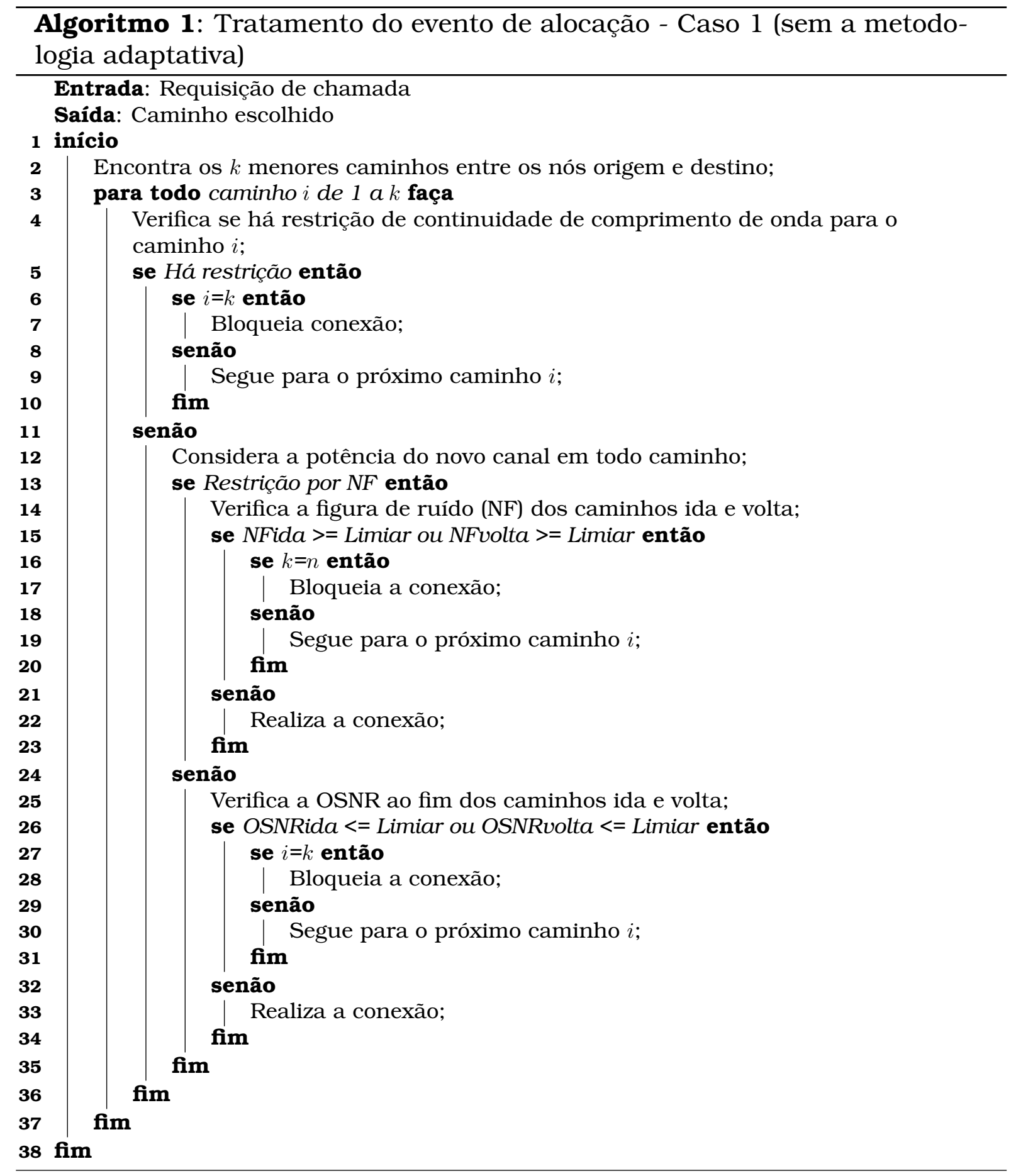

\subsection{Segundo caso: com a metodologia adaptativa}

O segundo caso utiliza as mesmas condições do caso anterior, com a única diferença de utilizar a metodologia de controle adaptativo de ganho com o objetivo de obter menor probabilidade de bloqueio.

O pseudocódigo de tratamento do evento de alocação é apresentado em Algoritmo 2. Ele é muito parecido com o pseudocódigo do caso anterior, exceto pelo novo passo que aplica a metodologia adaptativa.

As figuras de ruído dos enlaces e caminhos, bem como a OSNR no sinal ao 


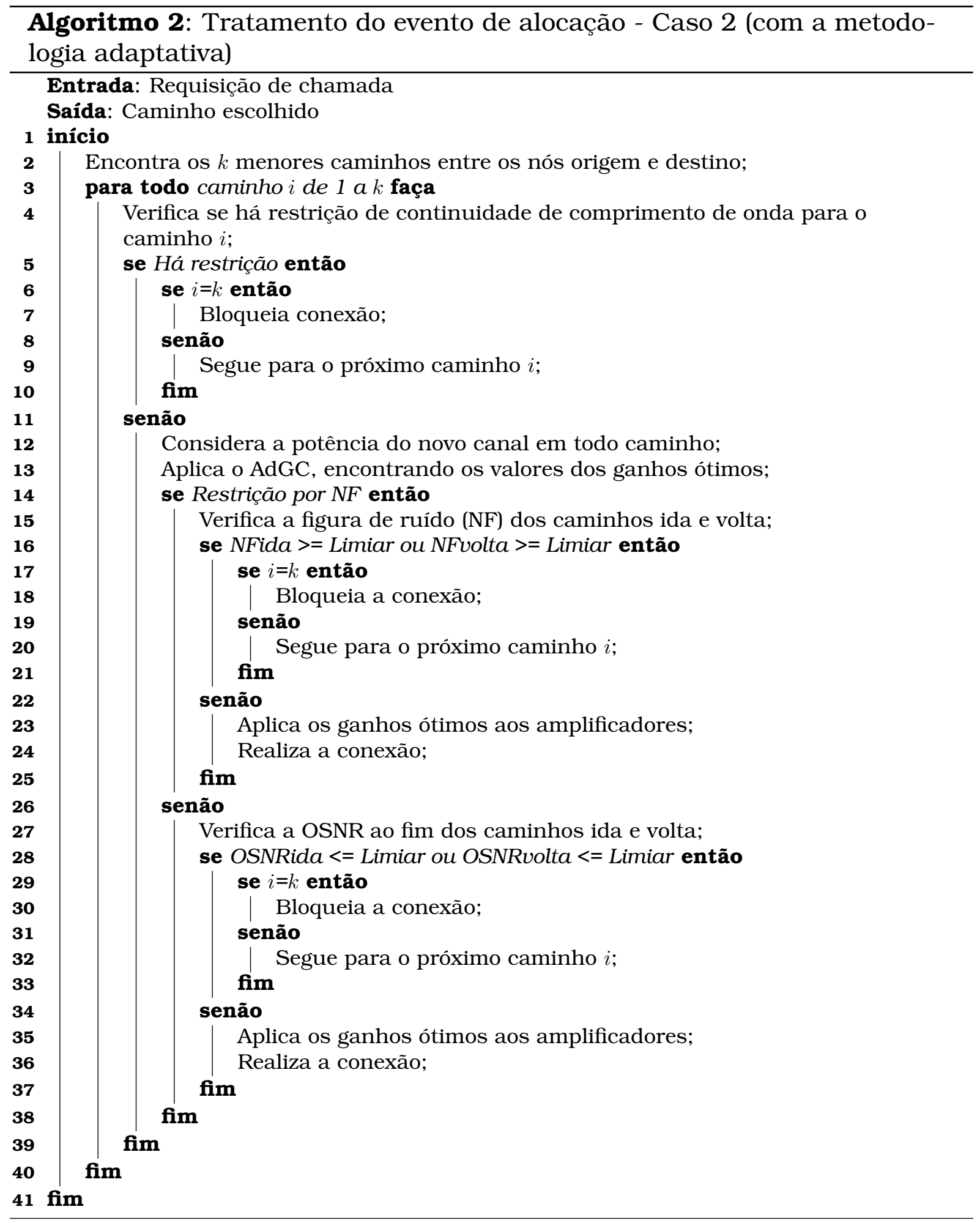

fim do caminho, são obtidas utilizando as mesmas equações apresentadas no primeiro caso.

No Apêndice B é apresentado um comparativo de tratamento da geração de dez solicitações de chamadas com e sem a metodologia adaptativa. São realizados 20 tratamentos, considerando alocação e desalocação. Para cada tratamento, são apresentados o número da conexão, o caminho escolhido, o ganho total do caminho (ida e volta), as OSNRs e figuras de ruídos dos cami- 
nhos de ida e volta, bem como as potências de entrada totais de cada enlace, com os ganhos de cada amplificador. É possivel observar que os valores de figura de ruído e OSNR são sempre os mesmos para os caminhos de ida e volta.

Ainda no Apêndice B, outra observação é sobre o ganho total dos caminhos de ida e volta. Sem a aplicação da metodologia, estes ganhos são sempre nulos, uma vez que os ganhos dos amplificadores são fixos, de modo a compensar as perdas dos enlaces e WSS. Já com a aplicação da metodologia, os ganhos dos amplificadores são diferentes de zero e, as vezes, diferentes entre si. Isso ocorre porque os WSSs atuam para manter a mesma potência por canal na entrada do enlace em todos os nós intermediários, exceto no nó destino. Assim, os nós destinos dos caminhos de ida e volta podem apresentar valores diferentes de potência no receptor. Como esta última perda não interfere nos cálculos de figura de ruído, os valores de figura de ruído total e OSNR final dos caminhos de ida e volta são os mesmos.

\subsection{Validação da simulação}

Para validar os cálculos de figura de ruído e OSNR (Equações 5.3 e 5.9) realizados neste trabalho, uma das soluções de caminho obtida para a rede de seis nós e com a metodologia adaptativa foi reproduzido no software de simulação óptica Optisystem ${ }^{\circledR}$. Esta simulação consiste em apenas uma solicitação de chamada, entre os nós 1 e 6 passando pelos nós 2 e 4 da Figura 5.4, de modo que apenas um canal, com frequência de 192,1 THz, está presente no caminho. A Figura 5.8 apresenta o caminho com os valores dos ganhos dos amplificadores em azul após a aplicação da metodologia adaptativa. A mesma figura também apresenta as perdas das fibras ópticas e dos roteadores ópticos (WSS) em vermelho, bem como a potência do canal na entrada de cada enlace em preto.

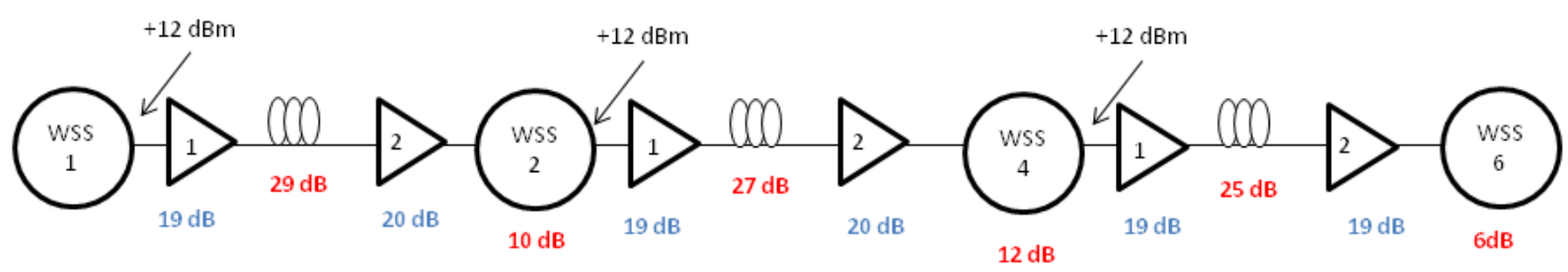

Figura 5.8: Caminho utilizado para validação dos cálculos de figura de ruído e OSNR.

As perdas dos WSSs, inicialmente em $6 \mathrm{~dB}$, são ajustadas para que a potência do canal seja - $12 \mathrm{dBm}$ na entrada do enlace.

Os valores obtidos de figura de ruído e OSNR nas duas simulações (Optisystem ${ }^{\circledR}$ e Matlab ${ }^{\circledR}$ ) estão apresentados na Tabela 5.6. Nesta tabela é possível 
observar que os valores obtidos nas duas simulações são muito próximos, indicando que os cálculos realizados para obter a figura de ruído e a OSNR na simulação do Matlab ${ }^{\circledR}$ para tratamento dos eventos de alocação estão corretos.

Tabela 5.6: Valores de figura e ruído e OSNR obtidos na validação pelo software de simulação óptica Optisystem ${ }^{\circledR}$.

\begin{tabular}{|c|c|c|c|c|c|c|}
\hline & \multicolumn{3}{|c|}{ Matlab $^{(\mathbb{R}}$} & \multicolumn{3}{|c|}{ Optisystem $^{\circledR}$ (validação) } \\
\hline Enlace & $1-2$ & $2-4$ & $4-6$ & $1-2$ & $2-4$ & $4-6$ \\
\hline Ganho $_{A m p 1}(\mathrm{~dB})$ & 19 & 19 & 19 & 18,64 & 19,2 & 19,09 \\
\hline Ganho $_{A m p 2}(\mathrm{~dB})$ & 20 & 20 & 19 & 20,18 & 19,98 & 19,4 \\
\hline$N F_{A m p 1}(\mathrm{~dB})$ & 4,98 & 4,98 & 4,98 & 4,79 & 4,77 & 4,77 \\
\hline$N F_{A m p 2}(\mathrm{~dB})$ & 5,22 & 5,22 & 5,2 & 4,98 & 4,91 & 4,86 \\
\hline Pin $_{\text {enlace }}(\mathrm{dBm})$ & -12 & -12 & -12 & -12 & -12 & -12 \\
\hline$W S S_{l o s s}(\mathrm{~dB})$ & 10 & 12 & 6 & 10 & 12 & 6 \\
\hline$F_{\text {enlace }}$ & 36,41 & 24,14 & 16,33 & 37,21 & 21,66 & 14,94 \\
\hline$G_{\text {enlace }}(\mathrm{dB})$ & 0 & 0 & 7 & $-0,18$ & 0,18 & 7,49 \\
\hline$G_{\text {enlace }}$ & 1 & 1 & 5,01 & 0,96 & 1,04 & 5,61 \\
\hline$F_{\text {total }}$ & \multicolumn{3}{|c|}{76,88} & \multicolumn{3}{|c|}{74,73} \\
\hline$N F_{\text {total }}(\mathrm{dB})$ & \multicolumn{3}{|c|}{18,86} & \multicolumn{3}{|c|}{18,73} \\
\hline
\end{tabular}

Por outro lado, para validar o procedimento criado para geração e tratamento das conexões neste trabalho, cada topologia de rede foi simulada sem restrição e sem a metodologia adaptativa com o objetivo de obter a probabilidade de bloqueio em função da carga para alguns valores de canais (comprimentos de onda) disponíveis. Assim, é possível observar o comportamento da probabilidade de bloqueio quando se aumenta os recursos da rede. O número de canais foi variado de 20 a 80 , com passo de 20 , e a carga de 10 a 500 erlangs, com passo de 10. Para cada valor de carga, foram geradas 100 repetições de 300 conexões e calculada a média e a variância da probabilidade de bloqueio destas 100 repetições.

A Figura 5.9 apresenta o resultado desta simulação em termos de média e desvio padrão. Os valores do desvio padrão são muito baixos, na ordem de $10^{-3}$, e por isso não podem ser vistos na figura. Nela, é possível observar uma curva de probabilidade de bloqueio versus carga já bem conhecida. Com o aumento de recurso, representado pelo aumento no número de canais, a probabilidade tente a zero mesmo para valores elevados de carga. Por esse motivo, para que se possa observar apenas a probabilidade de bloqueio referente às restrições impostas pelos limiares, optou-se pela utilização de 80 canais na rede para esta simulação. 


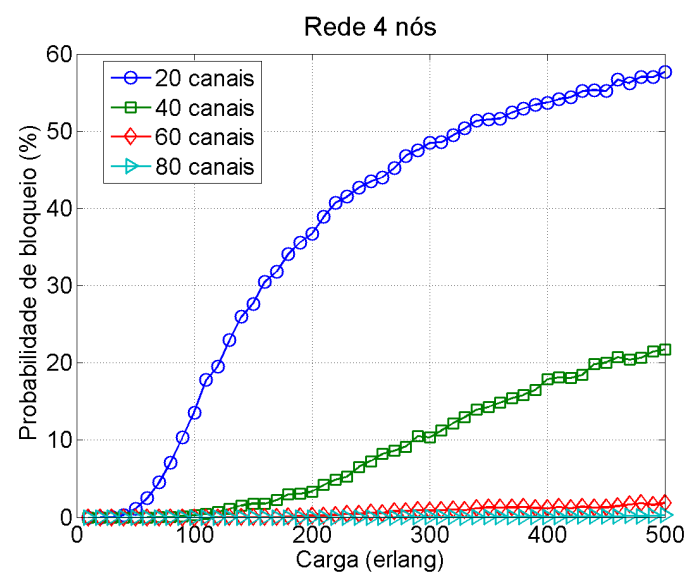

(a)

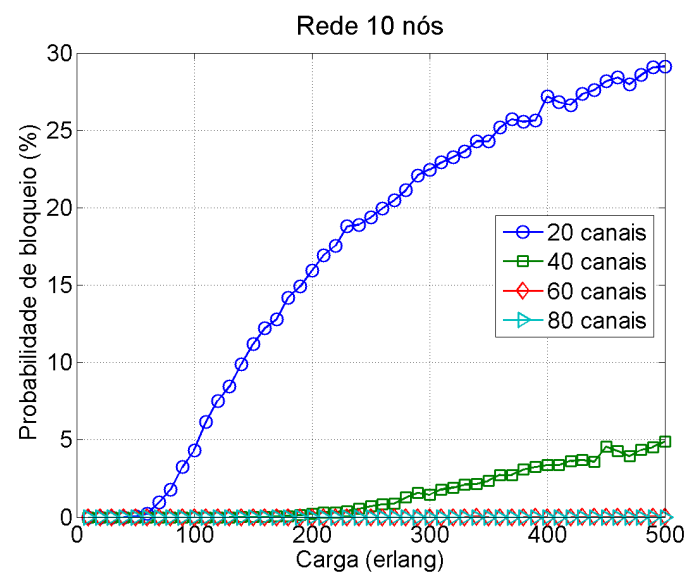

(c)

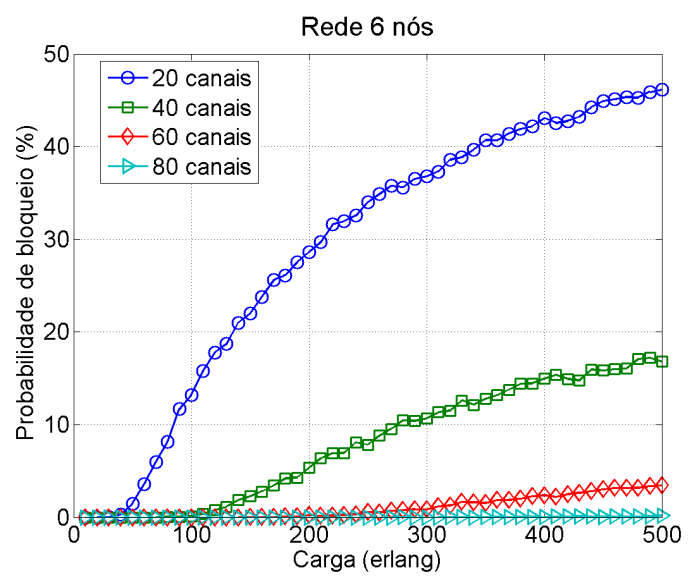

(b)

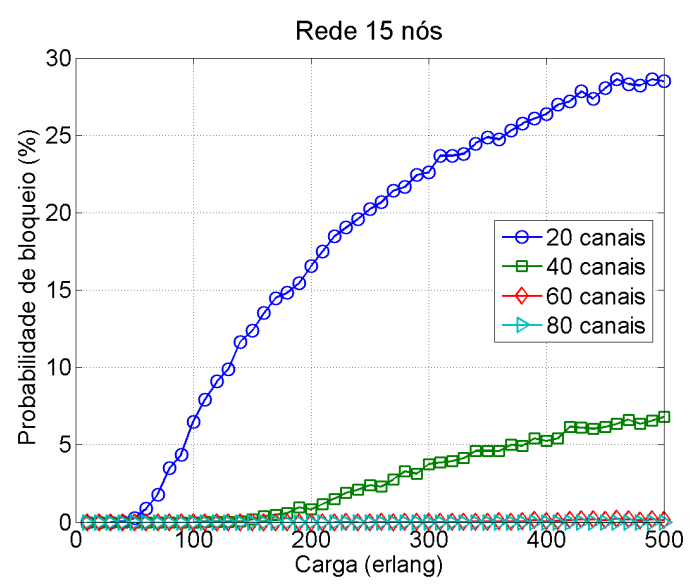

(d)

Figura 5.9: Probabilidade de bloqueio versus carga para as topologias de rede de (a) quatro, (b) seis, (c) dez e (d) quinze nós para algumas condições de canais disponíveis sem restrições e sem a utilização da metodologia adaptativa.

\subsection{Escolha dos limiares}

Para melhor visualizar os resultados, foram definidos limiares diferentes para cada topologia, de acordo com os valores de figura de ruído e OSNR obtidos nas conexões. Para obter tais valores, cada topologia foi simulada sem restrição, de modo que, independente dos valores de figura de ruído e OSNR obtidos para o caminho, a conexão sempre era realizada. Um tráfego com 300 conexões foi gerado para dois valores de carga, 50 e 200 erlangs, e os valores de figura de ruído e OSNR de cada conexão foram plotados com e sem a utilização da metodologia adaptativa (AdGC).

Os resultados desta simulação, com relação à OSNR, para as topologias de seis e quinze nós, estão nas Figuras 5.10 e 5.11, respectivamente. Para não sobrecarregar o texto, os mesmos resultados para as redes de quatro e dez nós foram apresentados no Apêndice C. Pelo mesmo motivo, os resultados com relação à figura de ruído, para todas as redes, também foram apresentado 
no Apêndice D.

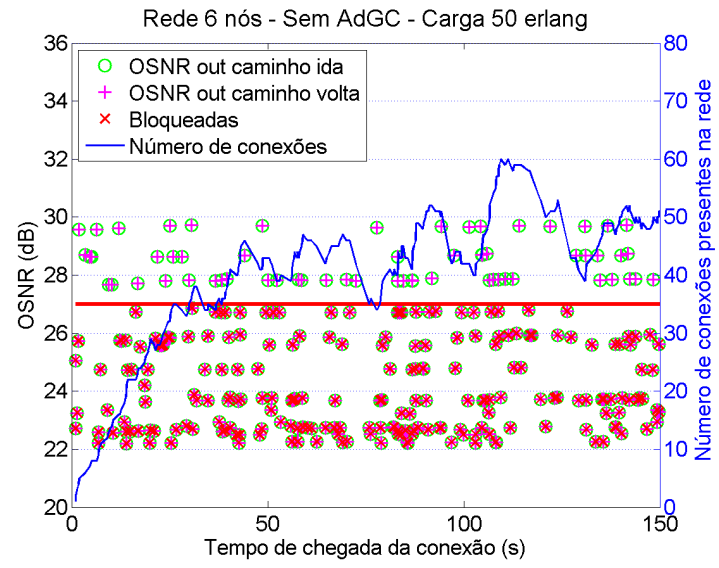

(a)

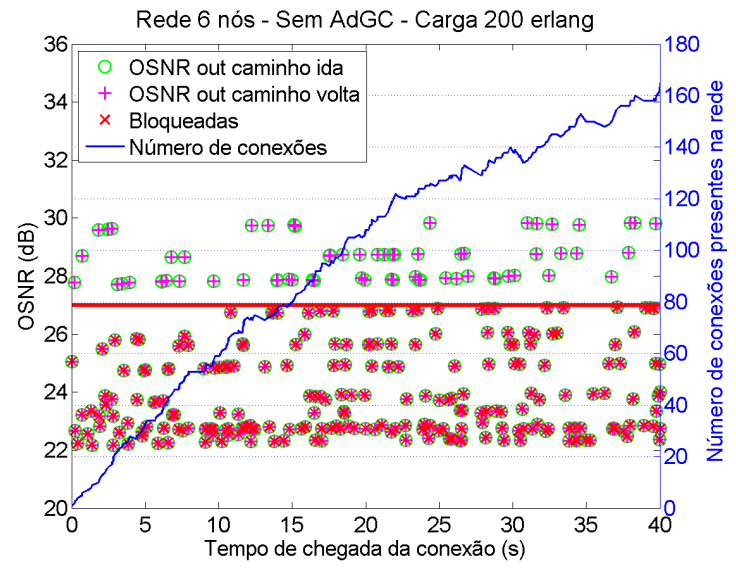

(c)

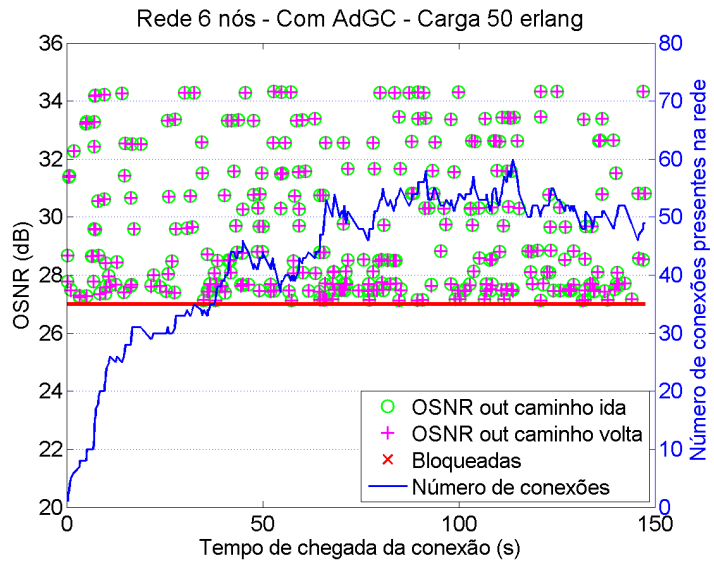

(b)

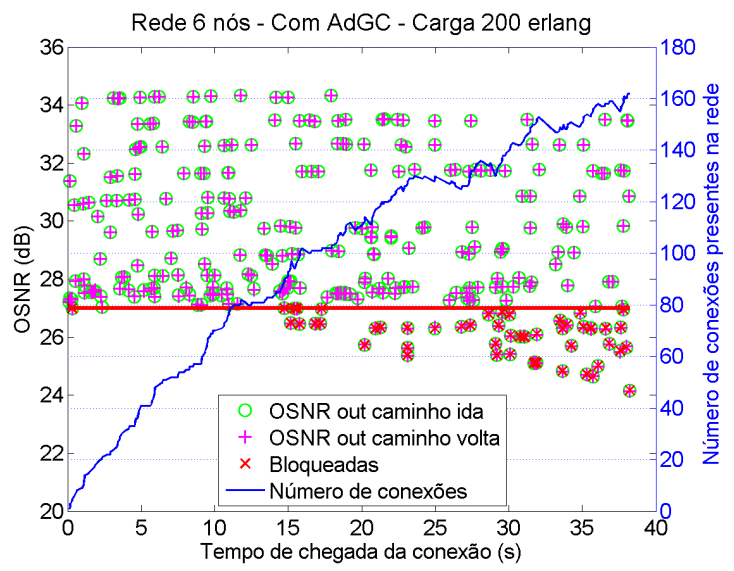

(d)

Figura 5.10: OSNR na recepção de cada conexão para os caminhos de ida e volta para uma rede de seis nós: (a) sem AdGC e carga de 50 erlangs, (b) com AdGC e carga de 50 erlangs, (c) sem AdGc e carga de 200 erlangs e (d) com AdGC e carga de 200 erlangs. Curva em azul corresponde à evolução do número de canais presentes na rede em função do tempo de chegada e a linha em vermelho é o limiar escolhido.

As Figuras 5.10 e 5.11 apresentam os valores de OSNR (eixo y à esquerda) de cada conexão no momento da sua realização para os caminhos de ida e volta. No eixo x está o tempo de chegada de cada conexão, para melhor visualizar a variação destes valores em função do tempo. Por esse motivo, há um aumento no número de conexões na rede (eixo y à direita) com o passar do tempo e, apesar de não ser exibido no gráfico, a partir do última conexão realizada, ocorrem apenas desalocações e a curva de conexões presentes na rede começa a decrescer, chegando a zero, como pode ser visto na Figura 5.12. A Figura 5.12(a) apresenta a variação do número de conexões presentes na rede com o passar do tempo para um tráfego de 50 erlangs, enquanto a 5.12(b) se refere a uma carga de 200 erlangs, ambas para uma topologia de rede de quinze nós. Além disso, apesar de terem sido geradas 300 conexões, 


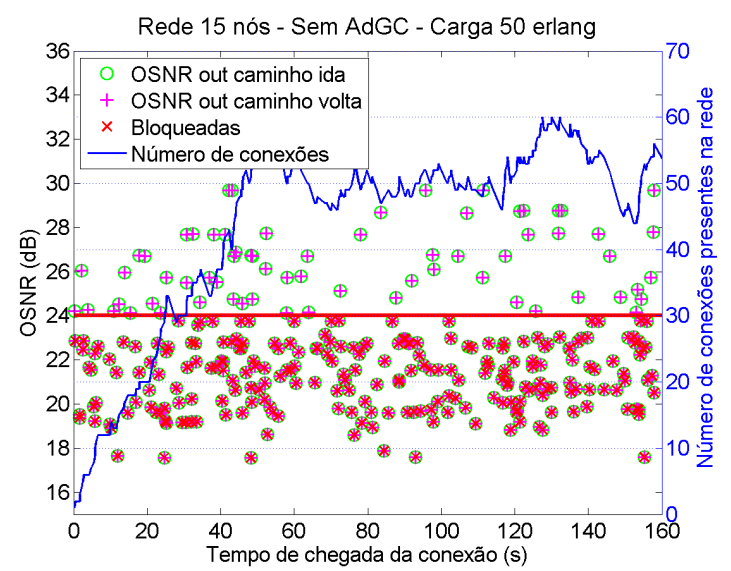

(a)

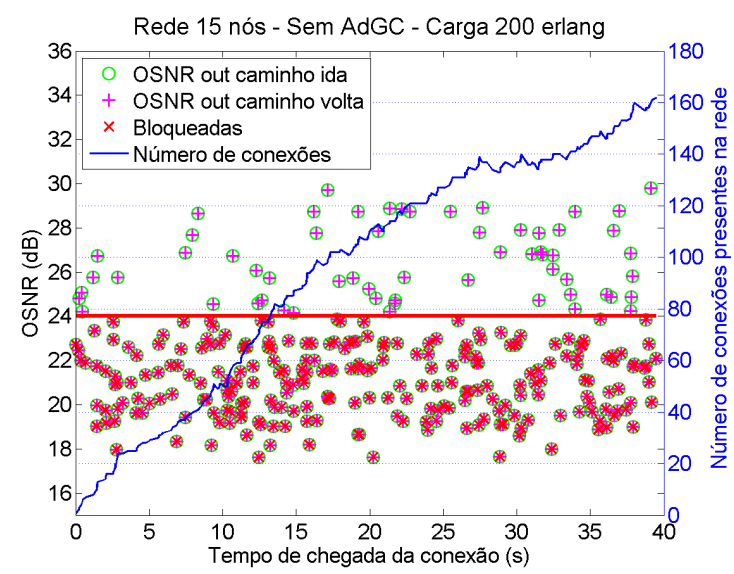

(c)

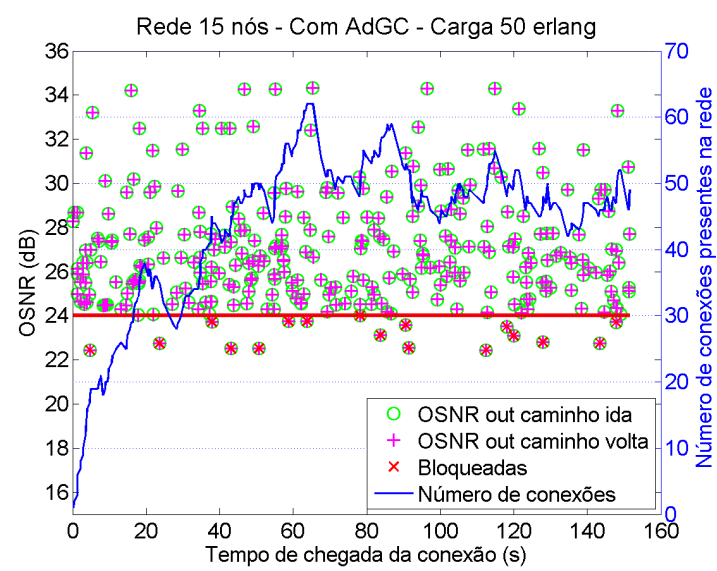

(b)

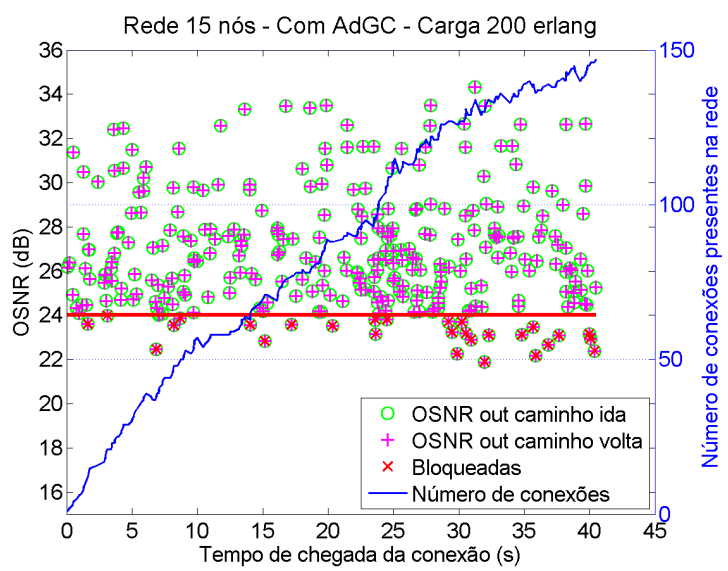

(d)

Figura 5.11: OSNR na recepção de cada conexão para os caminhos de ida e volta para uma rede de quinze nós: (a) sem AdGC e carga de 50 erlangs, (b) com AdGC e carga de 50 erlangs, (c) sem AdGc e carga de 200 erlangs e (d) com AdGC e carga de 200 erlangs. Curva em azul corresponde à evolução do número de canais presentes na rede em função do tempo de chegada e a linha em vermelho é o limiar escolhido.

em nenhum momento a rede está com todas as 300 conexões alocadas.

Voltando aos resultados apresentados nas Figuras 5.10 e 5.11, é possível observar que, independente do valor da carga (50 ou 200 erlangs), sem a aplicação da metodologia adaptativa, os valores das OSNRs das conexões permanecem no mesmo intervalo: entre 22 e $30 \mathrm{~dB}$ para a topologia de seis nós (Figuras 5.10(a) e 5.10(c)) e entre 16 e $30 \mathrm{~dB}$ para topologia de quinze nós (Figuras 5.11(a) e 5.11(c)).

Por outro lado, quando a metodologia adaptativa é utilizada para alterar os ganhos dos amplificadores, os valores de OSNR das conexões apresentam valores maiores, com faixa variando em função da carga para as duas topologias apresentadas. Para a topologia de seis nós, estes valores vão de 27 a $36 \mathrm{~dB}$ para uma carga de 50 erlangs e de 24 a 36 para uma carga de 200 erlangs (Figuras 5.10(b) e 5.10(d), respectivamente). Já para a topologia de quinze 


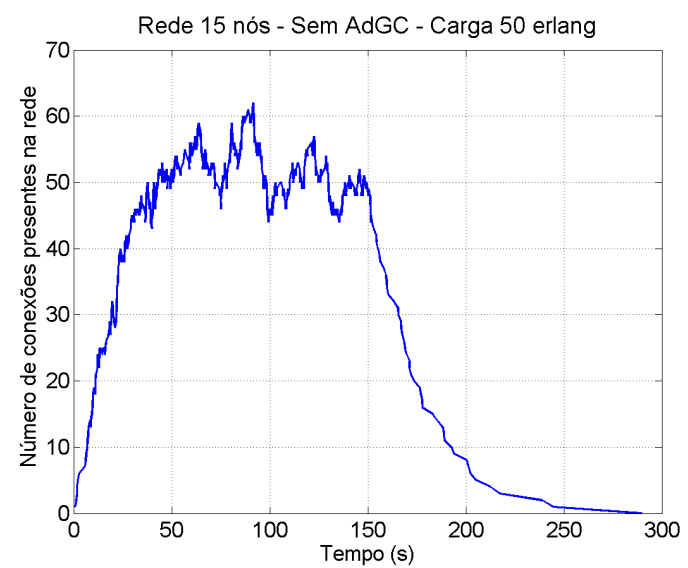

(a)

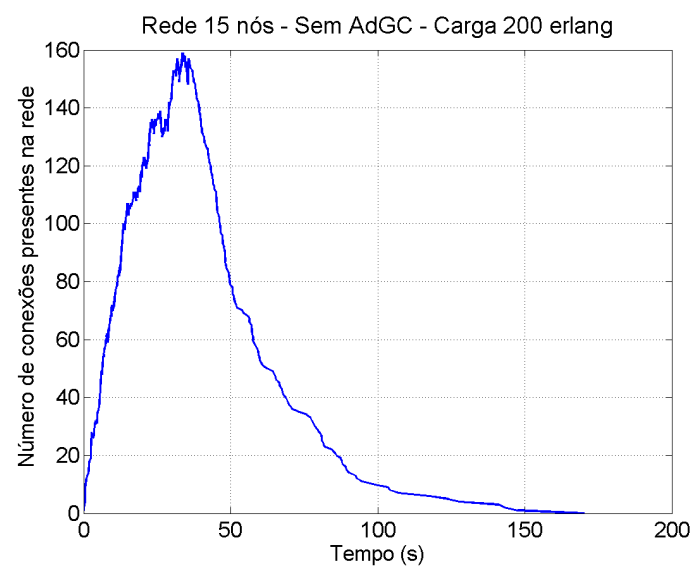

(b)

Figura 5.12: Número de conexões presentes na rede de quinze nós ao longo de todo tempo de alocações e desalocações com uma carga de (a) 50 erlangs e (b) 200 erlangs e sem a metodologia adaptativa.

nós, os valores de figura de ruído vão de 22 a $35 \mathrm{~dB}$ para 50 erlangs e de 22 a $34 \mathrm{~dB}$ para 200 erlangs (Figuras 5.11(b) e 5.11(d), respectivamente).

Como as simulações serão realizadas com 80 canais, não haverá bloqueio por falta de recurso na rede. Sendo assim, os bloqueios serão causados apenas pelas restrições adotadas (figura de ruído ou OSNR). Por esse motivo, os limiares de figura de ruído e OSNR foram escolhidos de modo a melhor visualizar a variação da probabilidade de bloqueio com e sem a metodologia, com a variação da carga entre 50 e 200 erlangs.

Para a rede de seis nós, escolhendo um limiar de OSNR menor que $24 \mathrm{~dB}$, a probabilidade de bloqueio seria nula independente da carga para o caso com a metodologia adaptativa, como observado na Figura 5.10(b) e 5.10(d), apesar de apresentar valores altos para o caso sem a metodologia, como pode ser visto nas Figuras 5.10(a) e 5.10(c). Por esse motivo, para esta rede, adotou-se um limiar de $27 \mathrm{~dB}$, apresentado na 5.10 com uma linha vermelha. Assim, tem-se um valor diferente de zero para probabilidade de bloqueio com a metodologia adaptativa para valores de carga de 50 e 200 erlangs.

O mesmo procedimento foi utilizado para escolha dos limiares de OSNR e figura de ruído das demais topologias, de modo a obter sempre uma probabilidade de bloqueio diferente de zero com a aplicação da metodologia.

A Tabela 5.7 resume os valores dos limiares escolhidos para cada topologia, tanto para figura de ruído, quanto para OSNR.

Os limiares práticos de OSNR encontrados na literatura se referem à BER suficiente para a utilização de códigos corretores de erros. Tais valores são sempre inferiores ao pior caso de OSNR obtido nas simulações neste trabalho (em torno de $18 \mathrm{~dB}$ ). Assim, considerando os limiares práticos com a utilização dos códigos corretores de erro, o resultado será probabilidade de bloqueio 
Tabela 5.7: Valores dos limiares de figura de ruído e OSNR para cada topologia de rede utilizada neste trabalho.

\begin{tabular}{|c|c|c|}
\hline Topologia & Limiar de NF (dB) & Limiar de OSNR (dB) \\
\hline 4 nós & 20 & 26 \\
\hline 6 nós & 19 & 27 \\
\hline 10 nós & 20 & 26 \\
\hline 15 nós & 22 & 24 \\
\hline
\end{tabular}

nula para os dois casos, com e sem a metodologia, e para qualquer topologia. Dessa forma, o limiar prático de OSNR que será utilizado neste trabalho não considera a utilização de códigos corretores de erro e foi obtido para um fator de qualidade 8, uma taxa de transmissão de sinal de $10 \mathrm{~Gb} / \mathrm{s}$ e codificação RZ (return-to-zero): 26,32 dB [31]. Este limiar será aplicado em todas as topologias e o resultado também será apresentado a seguir, juntamente com os resultados com os limiares individuais para cada topologia.

\subsection{Resultados}

Todas as redes foram simuladas nas seguintes condições:

1. Foi gerado um tráfego de 300 conexões;

2. As porcentagens de bloqueio apresentadas nos gráficos são as médias e os desvios padrão das porcentagens de bloqueio de 100 repetições de geração de tráfego;

3. Foram utilizados 80 canais (evitando o bloqueio por falta de recurso);

4. A carga foi variada de 50 a 200 erlangs, um bom intervalo para verificar as probabilidade de bloqueio de acordo os resultados obtidos e apresentados na Figura 5.9;

5. Apenas um caminho foi avaliado. Ou seja, $k=1$ nos Algoritmos 1 e 2 .

Nos resultados, é mostrada a probabilidade de bloqueio média entre as 100 repetições considerando a geração de 300 conexões, com carga variando de 50 a 200 erlangs para os casos com e sem a metodologia adaptativa e para todas as topologias de rede apresentadas neste trabalho.

Quatro tipos de bloqueio foram definidos e avaliados:

1. Bloqueio por falta de caminho: ocorre quando não há caminho disponível entre origem e destino porque todos os comprimentos de onda estão utilizados em ao menos um dos enlaces; 
2. Bloqueio por restrição de continuidade comprimento de onda: como consideramos uma rede sem conversão de comprimento de onda nos nós, pode ocorrer de um mesmo comprimento de onda não estar disponível em todos os enlaces do caminho escolhido. Neste caso, há bloqueio por restrição de comprimento de onda;

3. Bloqueio por restrição de NF ou OSNR: ocorre sempre que a figura de ruído ou a OSNR do caminho escolhido apresenta valor acima ou abaixo do limiar, respectivamente. Quando se trata de figura de ruído, caminhos com figura de ruído acima do limiar são bloqueados. Quando se trata de OSNR, caminhos com OSNR na saída menor que o limiar são bloqueados;

4. Bloqueio por sair da máscara: como é preciso medir a figura de ruído ou OSNR do caminho, é necessário saber as figuras de ruído dos amplificadores do enlace. Pontos de operação fora da região caracterizada não dispõem de figuras de ruído medidas. Assim, sempre que isso ocorre, temos bloqueio por sair da máscara de potência, pois não podemos avaliar o caminho nestas condições. Este tipo de bloqueio pode ser evitado a partir da escolha e caracterização adequada do amplificador para a rede. Assim, pode-se garantir que, independente do carregamento, dados os ganhos máximos e mínimos, os amplificadores irão operar dentro da máscara de potência.

A probabilidade de bloqueio total corresponde à soma das porcentagens bloqueio individuais definidas acima. Os bloqueios 1 e 2 podem ser eliminados elevando o número de canais, como visto na Figura 5.9. Assim, há recurso suficiente para realização de conexões. Por este motivo, o número de canais utilizado foi 80. Por outro lado, o bloqueio bloqueio 4, que considera os casos em que o ponto de operação saiu da máscara e não pode ser avaliado quanto ao valor de figura de ruído ou OSNR, também é nulo devido à escolha correta das perdas das redes para os amplificadores utilizados. Lembrar que, em um caso real, os amplificadores devem ser caracterizados de modo a cobrir todos os possiveis pontos de operação dadas as características da rede.

Os resultados obtidos são exibidos em gráficos de porcentagem de bloqueio versus carga, em erlang. A Figura 5.13 apresenta tais resultados para um rede de seis nós com restrição de $27 \mathrm{~dB}$ para a OSNR. O resultado com restrição de figura de ruído está no Apêndice $\mathrm{E}$ pois os resultados para as duas restrições (OSNR e NF) são bem parecidos. Porém, o valor de OSNR é mais utilizado, pois está mais relacionado com o valor da BER na recepção.

Na Figura 5.13, também é apresentado o desvio padrão. Porém, seu valor é muito pequeno, ordem de $10^{-3} \mathrm{e}$, por este motivo, não pode ser visto nos gráficos da Figura 5.13. 

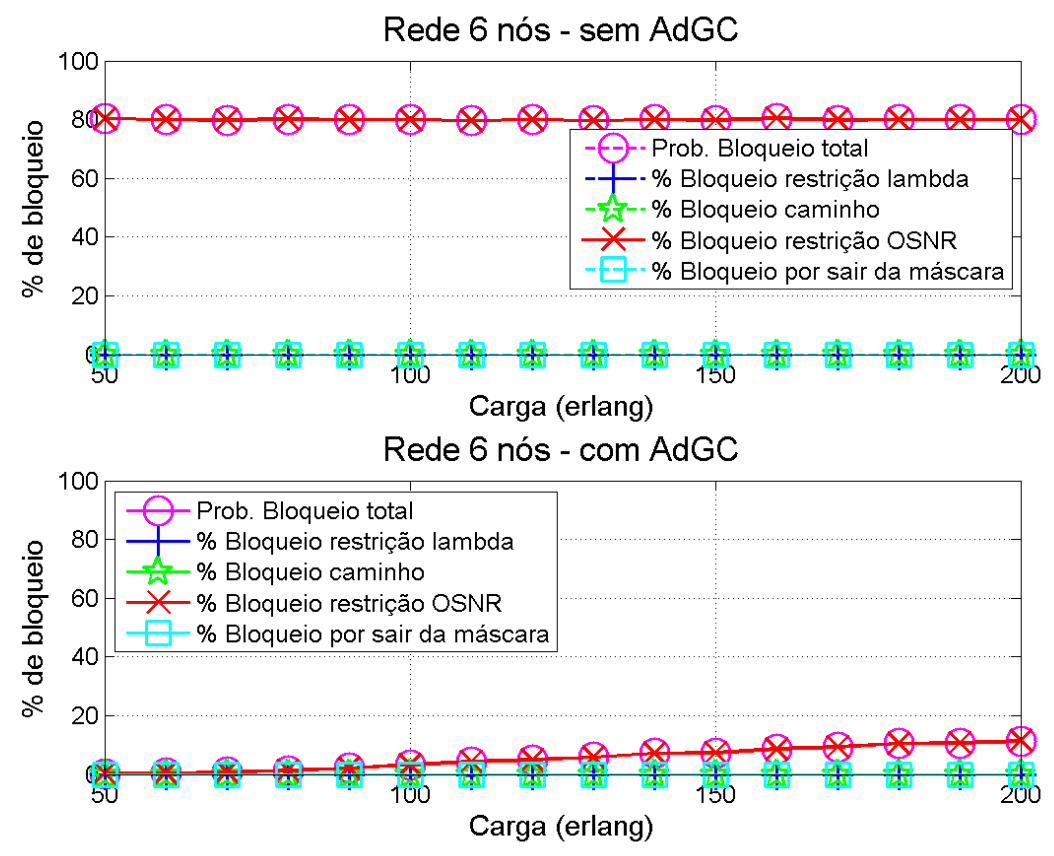

Figura 5.13: Probabilidade de bloqueio versus carga para a topologia de seis nós com restrição de OSNR (limiar de $27 \mathrm{~dB}$ ) com e sem a metodologia adaptativa (AdGC).

No gráfico superior da Figura 5.13 são apresentadas as curvas de porcentagem de cada tipo de bloqueio e a probabilidade de bloqueio total, sem a aplicação da metodologia adaptativa, com valores elevados e constantes em relação à carga (80\%) para probabilidade de bloqueio total. Já no gráfico inferior, tem-se as mesmas curvas de porcentagem de bloqueio e probabilidade de bloqueio total com a aplicação da metodologia. Porém, a probabilidade de bloqueio total agora apresenta valores abaixo de $20 \%$, aumentando levemente em função da carga. O comportamento da probabilidade de bloqueio total nos dois casos é reflexo do que foi observado na Figura 5.10(a) para 5.10(c), para o caso sem adaptação e com a carga variando de 50 a 200 erlangs, onde os valores das OSNRs das conexões mantiveram-se entre 22 e $30 \mathrm{~dB}$. Assim, quando a restrição passa a ser aplicada, a mesma quantidade de conexões será bloqueada para os dois casos de carregamento. Por outro lado, para o caso com a metodologia, observando a Figura 5.10(b), com a carga de 50 erlangs há quase nenhuma conexão abaixo do limiar de $27 \mathrm{~dB}$, e na Figura 5.10(d), com a carga de 200 erlangs, a quantidade de conexões abaixo do limiar aumenta. Este mesmo comportamento é observado no gráfico inferior da Figura 5.13, um aumento do bloqueio com a carga devido ao fato de mais conexões apresentarem OSNR abaixo do limiar.

Nos dois casos, a probabilidade de bloqueio total é composta apenas pelo porcentagem de bloqueio por restrição de OSNR. Isso ocorre devido à quantidade de recursos da rede ser elevada (80 canais). Podemos recorrer à Fi- 
gura 5.9, que mostra, para cada rede, como varia a probabilidade de bloqueio em função do número de canais, para cada topologia de rede. Como nem a metodologia adaptativa e nem as restrições foram consideradas nesta simulação, apenas os bloqueios 1, 2 e 4 podem contribuir para a probabilidade de bloqueio total, que apresenta valores nulos, para todas as redes, com 80 canais.

Dessa forma, sabendo que apenas o bloqueio 3 contribui para a probabilidade de bloqueio total, os resultados para as demais redes serão apresentados apenas com a curva de probabilidade de bloqueio total versus carga. Estes resultados podem ser vistos na Figura 5.14.

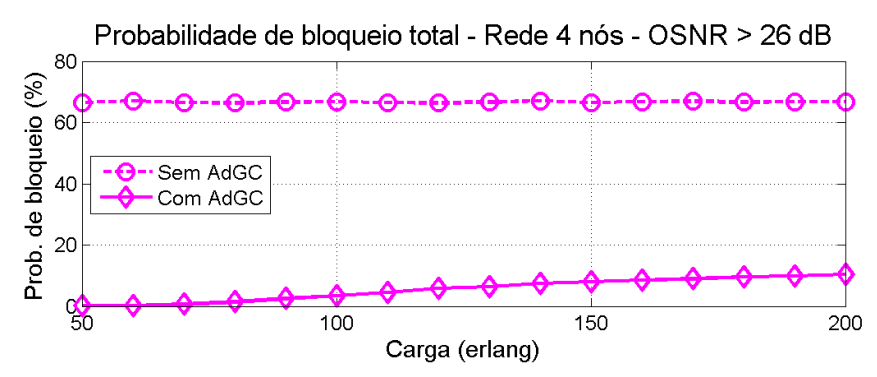

(a)

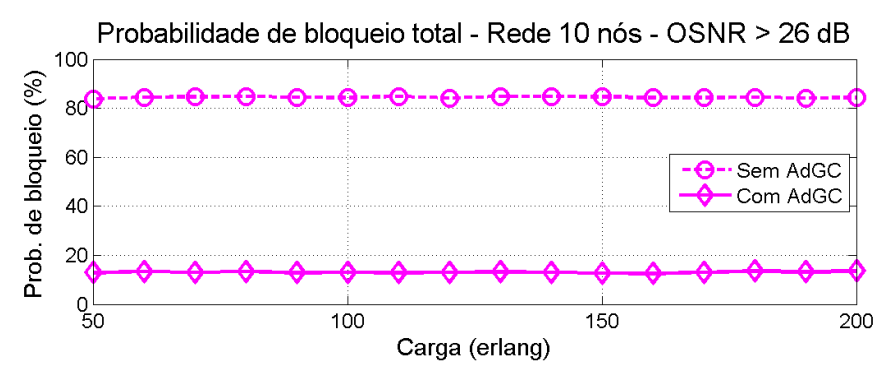

(b)

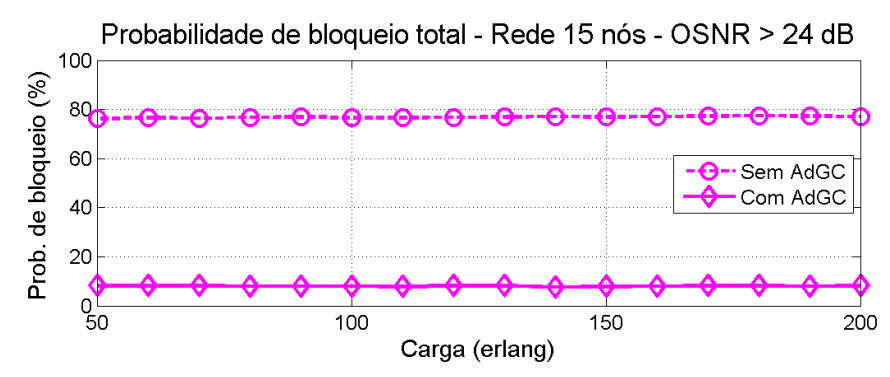

(c)

Figura 5.14: Probabilidade de bloqueio total versus carga para: (a) topologia de quatro nós com restrição de OSNR (limiar de $26 \mathrm{~dB}$ ), (b) topologia de dez nós com restrição de OSNR (limiar de $26 \mathrm{~dB}$ ) e (c) topologia de quinze nós com restrição de OSNR (limiar de $24 \mathrm{~dB}$ ). Todas com e sem a metodologia adaptativa (AdGC)

Novamente, o desvio padrão também foi inserido nos gráficos da Figura 5.14, porém, como seus valores são muito baixos, não é possível visualizá-los. 
Por serem similares aos resultados com restrição por OSNR, os resultados com restrição de figura de ruído de todas as topologias estão no Apêndice E.

Também é possivel observar, nos gráficos da Figuras 5.14, que a probabilidade de bloqueio total é elevada, superior a 60\%, para os casos sem a metodologia adaptativa. Quando a metodologia adaptativa é utilizada, este valor cai para valores em torno de $10 \%$, mantendo-se constante para as redes de dez e quinze nós, ou aumentando muito pouco com o aumento da carga para a rede de quatro nós. Estes resultados mostram a vantagem da utilização da metodologia adaptativa, garantindo que, com o ajuste dos ganhos dos amplificadores, pode-se reduzir a probabilidade de bloqueio total em cenários onde há restrições de ONSR ou NF para as conexões.

Porém, os casos apresentados na Figura 5.14 são para um rede com muito recurso, de modo que a probabilidade de bloqueio total é devido apenas ao bloqueio quando a conexão não é realizada por não atender à restrição. Para verificar o desempenho da metodologia em uma rede com menos recursos, onde o bloqueio pode ocorrer por outros motivos, como restrição de comprimento de onda, também é possível verificar o desempenho da metodologia.

Dessa forma, nas mesmas condições das simulações anteriores, todas as topologias foram simuladas com 20 canais disponíveis. O resultado desta simulação, para a topologia de seis nós, com restrição de OSNR, pode ser visto na Figura 5.15 em termos de média e variância das 100 repetições. A variância, novamente, apresenta valores muito pequenos, novamente na ordem de $10^{-3}$, não sendo possível observá-los na figura.

No gráfico superior da Figura 5.15 tem-se as curvas de porcentagem de bloqueio sem a aplicação da metodologia adaptativa. Neste caso, o comportamento é similar ao da Figura 5.13, pois a grande quantidade de bloqueio devido à restrição (80\%) resulta em comprimentos de onda disponíveis para as demais conexões, reduzindo a zero as porcentagens de bloqueios por falta de recurso. Já no gráfico inferior da Figura 5.15, quando a metodologia AdGC é aplicada, a grande redução do bloqueio devido à restrição faz com que a quantidade de canais disponíveis não seja mais suficiente, aumentando assim a ocorrência dos demais bloqueios.

Assim, apesar da aplicação da metodologia aumentar o bloqueio por restrição de comprimento de onda, ela reduz bastante a probabilidade de bloqueio total: de 80\% para valores em torno de 30\% (para uma carga de 200 erlangs).

Para não sobrecarregar o texto, optou-se por apresentar os resultados das demais topologias no Apêndice $\mathrm{F}$, os quais apresentam o mesmo comportamento observado para a topologia de seis nós, isto é, a aplicação da metodologia reduz significativamente a probabilidade de bloqueio total, ficando em torno de $20 \%$ para as redes com 10 e 15 nós e em torno de $40 \%$ para a rede de 

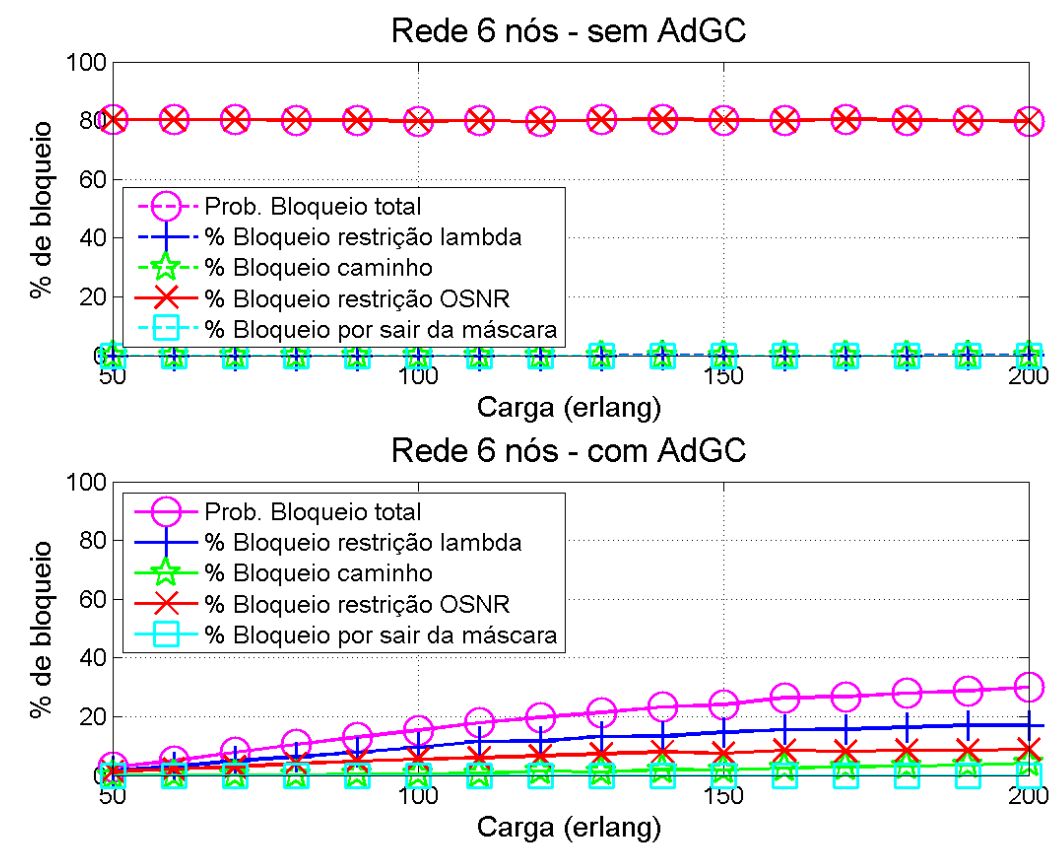

Figura 5.15: Probabilidade de bloqueio total versus carga para a topologia de seis nós com restrição de OSNR (limiar de 27 dB) com 20 canais disponíveis na rede com e sem a metodologia adaptativa (AdGC).

4 nós. Da mesma forma, as porcentagens de bloqueio por restrição de lambda ou por falta de caminho aumentam, pois com a redução da probabilidade de bloqueio com relação a restrição de OSNR, as conexões que agora podem ser realizadas precisam disputar pelo recurso reduzido que a rede oferece (20 canais).

Novamente, por serem similares aos resultados com restrição por OSNR, os resultados com restrição de figura de ruído de todas as topologias para a simulação com 20 canais também estão no Apêndice $\mathrm{F}$.

Por fim, uma última simulação foi realizada com um mesmo valor limiar de OSNR (limiar obtido na literatura é 26,32 dB [31]) para todas as topologias, com disponibilidade de recursos reduzida (20 canais), com e sem a metodologia adaptativa. O resultado está apresentado no gráfico resumo da Figura 5.16, onde apenas a curva de probabilidade de bloqueio total de cada topologia foi exibida, para não sobrecarregar o gráfico.

Da mesma forma, na Figura 5.16, é possível observar uma redução na probabilidade de bloqueio total quando a metodologia é aplicada (gráfico inferior) em relação à simulação sem a metodologia (gráfico superior). A topologia que apresentou a maior probabilidade de bloqueio, com e sem a metodologia, foi a de 15 nós. Isso ocorre porque o limiar de $26,32 \mathrm{~dB}$ é um valor alto para a rede de 15 nós, como pode ser visto na Figura 5.11. Assim, mais conexões são bloqueadas em relação ao limiar anterior de 24 dB. Já para as demais redes, este limiar é próximo do que já estava sendo utilizado e por esse motivo, o 

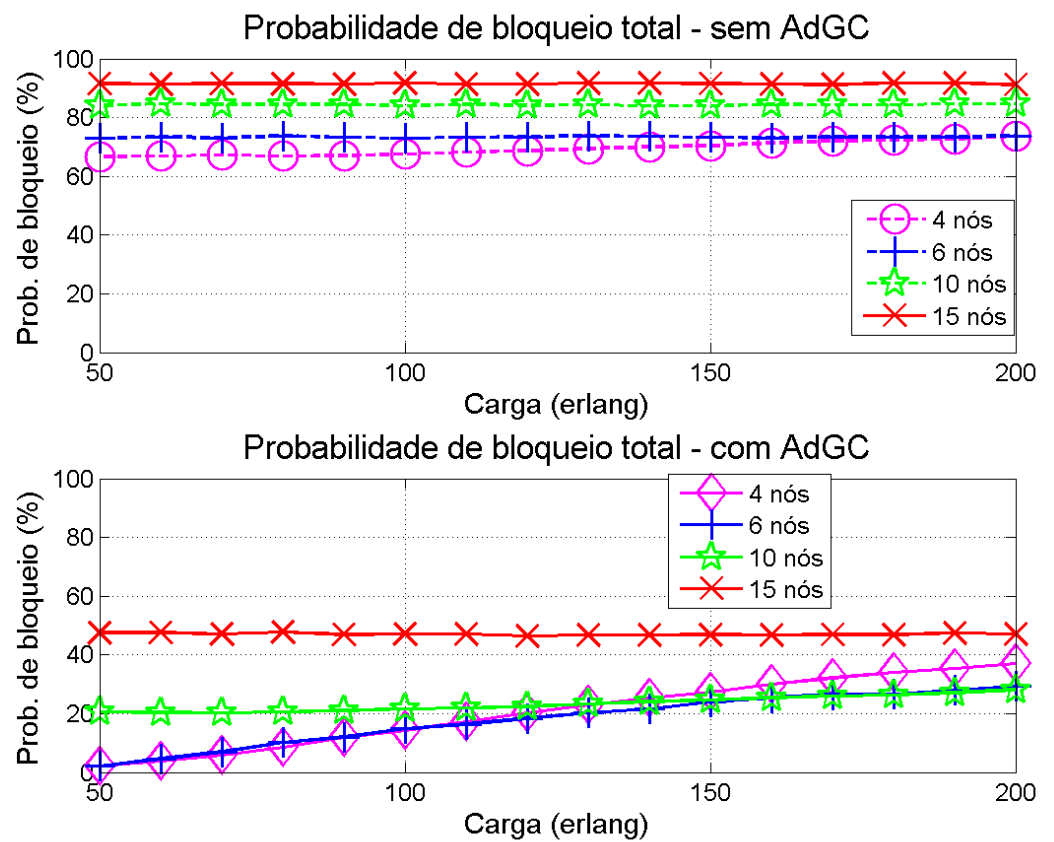

Figura 5.16: Probabilidade de bloqueio total versus carga para todas as topologia com restrição de OSNR (limiar de 26,32 dB) com 20 canais disponíveis na rede com e sem a metodologia adaptativa (AdGC).

resultado é parecido com o já obtido para a simulação anterior, com 20 canais e os limiares da Tabela 5.7. 


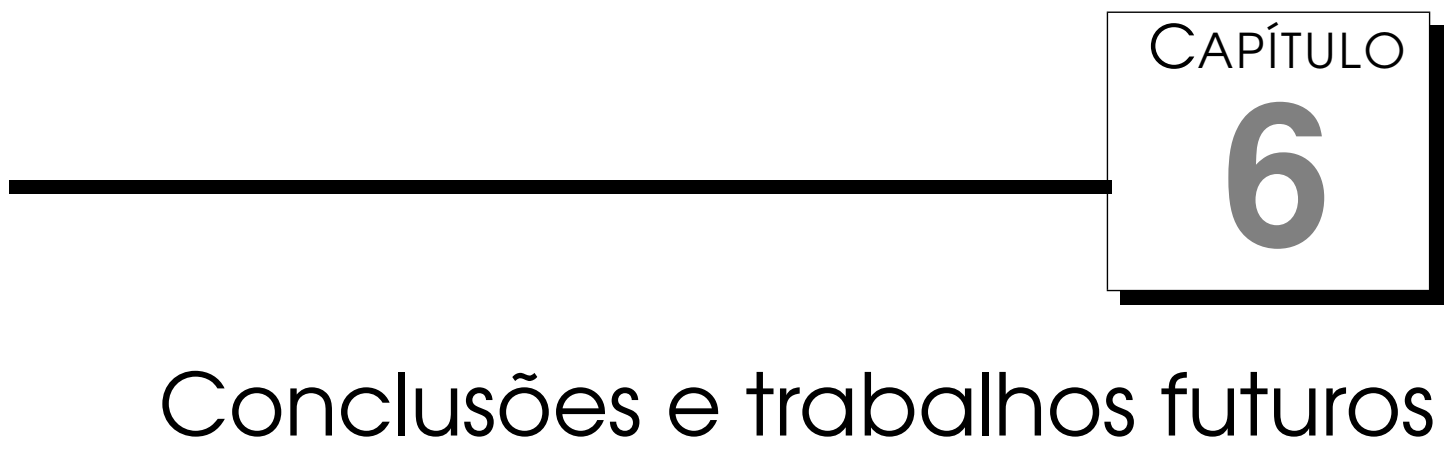

Novos desafios estão surgindo na medida em que as redes ópticas estão se tornando dinâmicas e heterogêneas em termos de serviços e tecnologias de transmissão. Existem estudos que, baseados nas redes sem fio, sugerem a utilização de processos cognitivos nos dispositivos da rede óptica, principalmente na transmissão e recepção. Porém, em uma rede cognitiva, os dispositivos precisam atender a alguns requisitos como ser cientes, adaptativos e apresentar capacidade de aprendizado.

Como primeiro passo em direção às redes cognitivas, este trabalho foca nos dois primeiros requisitos destas redes, propondo uma metodologia de controle adaptativo de ganho em amplificadores. Segundo ela, conhecendo a atual potência de entrada e o desempenho óptico para vários pontos de operação, a partir de uma base de dados estática obtida por meio de uma caracterização prévia, o amplificador é capaz de decidir e atuar, alterando o ponto de operação para otimizar simultaneamente seus parâmetros de figura de ruído e "planicidade" espectral de ganho.

Com a utilização da metodologia, o amplificador é capaz de atuar ao longo do enlace baseado apenas na sua condição atual de potência de entrada e no seu desempenho óptico previamente obtido dentro da máscara de potência, causando melhora no desempenho sistêmico fim-a-fim em termos de figura de ruído total do enlace, OSNR na recepção e, consequentemente, menores valores de BER.

Para avaliar a metodologia proposta foram realizadas algumas simulações, com e sem a metodologia adaptativa, em topologias de redes com 4, 6, 10 e 15 nós. A partir dos resultados obtidos, foi possível observar, em todos os casos, uma redução considerável na probabilidade de bloqueio. 
Todas as simulações consideraram restrições de OSNR para a realização das conexões, isto é, escolhido o caminho, a OSNR do sinal no destino é estimada e se seu valor estiver abaixo do limiar especificado, a conexão não é realizada. Assim, para verificar o efeito da aplicação da metodologia apenas neste tipo de bloqueio, por restrição de OSNR, uma rede com muito recurso de canais foi simulada. Como resultado, sem a metodologia adaptativa, obtiveram-se probabilidades de bloqueio constante em torno de $60 \%$ para a topologia de 4 nós e de $80 \%$ para as de 6, 10 e 15 nós, para a carga variando de 50 a 200 erlangs. Por outro lado, com a aplicação da metodologia adaptativa, estas probabilidades de bloqueio caíram para valores máximos em torno de 10\% para as redes de 6, 4 e 15 nós, e 15\% para a rede de 10 nós. Nestas simulações, foram considerados limiares de OSNR diferentes para cada topologia.

Em seguida, o recurso da rede foi reduzido, de forma a avaliar os efeitos da metodologia com a presença de outros tipos de probabilidades de bloqueio, relacionados à falta de caminho ou restrição de comprimento de onda. Neste caso, também foram observadas reduções nas probabilidade de bloqueio total quando a metodologia foi aplicada, de $80 \%$ para um pouco acima de $30 \%$, para a rede de 6 nós. As demais metodologias também apresentaram redução, ficando em 20\% para as redes de 10 e 15 nós e em torno de $40 \%$ para a rede de 4 nós. Todas com valores em torno de $80 \%$ antes da aplicação da metodologia. Em todos os casos, com a aplicação da metodologia, a probabilidade de bloqueio por restrição de OSNR baixou e as demais probabilidades de bloqueio, relacionadas à disponibilidade de recurso (restrição de lambda e falta de caminho), aumentaram. Isso ocorreu porque, com a redução da OSNR, mais conexões puderam ser realizadas. Assim, um maior número de conexões precisaram disputar entre si os poucos canais disponiveis na rede, gerando probabilidades de bloqueio por falta de caminho e restrição de comprimento de onda.

Por fim, utilizou-se o mesmo limiar para todas as redes e as simulações, com e sem a metodologia, que mostraram, mais uma vez, redução na probabilidade de bloqueio total de valores em torno de $80 \%$ para valores um pouco acima e constante em $40 \%$ para a rede de 15 nós, crescente de zero a 30\% para a rede 6 nós, também crescente de zero a um pouco abaixo de $40 \%$ para a rede de 4 nós e quase constante, em torno de $20 \%$, para a rede de 6 nós.

Assim, a partir de todos os resultados, a utilização da metodologia proposta por este trabalho garante a redução da probabilidade de bloqueio em redes que operam sob algum tipo de restrição relacionado à qualidade de serviço para realização das conexões. Isto ocorre devido ao ajuste dos pontos de operação dos amplificadores visando a otimização dos parâmetros de figura de ruído e 
"planicidade" espectral de ganho. Podendo ser utilizado em várias topologias de redes, com qualquer tipo de amplificador, desde que previamente caracterizado para uma máscara de potência que compreenda todos os possiveis pontos de operação.

A aplicação da metodologia neste trabalho ajustou o ganho dos amplificadores ao longo do caminho, verificando a OSNR/NF do canal adicionado e utilizando esta informação para realizar o bloqueio ou não da conexão. Visando trabalhos futuros, um estudo interessante pode ser realizado verificando o impacto deste ajuste nos canais preexistentes que compartilham os enlaces do caminho escolhido.

Outra ideia interessante é realizar o RWA não pelo menor custo (distância), e sim pela menor OSNR. Assim, alguns caminhos são escolhidos e suas OSNRs são calculadas. A menor OSNR que estiver acima do limiar pode ser escolhida, garantindo que conexões futuras poderão ser realizadas.

Ainda, conhecidos a taxa e o formato de modulação do sinal, é possível relacionar a ONSR à BER, e realizar o mesmo procedimento utilizando um limiar de BER, parâmetro mais facilmente medido.

Além disso, o algoritmo da metodologia desenvolvido neste trabalho considerou um número fixo, 2, de amplificadores por enlace. Assim, outra evolução interessante que pode ser realizada a partir deste trabalho é a alteração do algoritmo para suportar diferentes números de amplificadores por enlace. Assim, é possível deixá-lo mais geral, para resolver qualquer rede, não importando o número de amplificadores por enlace. Isso é possível realizando algumas alterações nas funções que calculam os novos ganhos, estimam as novas potências na entrada dos amplificadores e as figuras de ruído de cada enlace que compõe o caminho.

Finalmente, tendo em vista que a motivação deste trabalho foi tornar o dispositivo amplificador preparado para os processos cognitivos, um trabalho consequente deste é a realização de alterações na metodologia para tornála cognitiva. Isso pode ser realizado a partir do ajuste dos pesos de cada parâmetro a partir de processos cognitivos, buscando informações passadas que devem estar armazenados em uma base de dados que é continuamente atualizada com os resultados obtidos de desempenho após as decisões. 


\section{Referências Bibliográficas}

[1] G. Agrawal, Fiber-optic communication systems, vol. 1 of Wiley series in microwave and optical engineering. Wiley-Interscience, 2002. 1, 7, 8

[2] O. Ozolins, V. Bobrovs, J. Porins, and G. Ivanovs, "Fiber bragg grating technology for new generation optical access systems," in Current Trends in Short- and Long-period Fiber Gratings (D. C. Cuadrado-Laborde, ed.), InTech, 2013. 1

[3] A. Willner, X. Wu, and J.-Y. Yang, "Optical performance monitoring: Perspectives and challenges," in Optical Performance Monitoring, pp. 1 - 19, Oxford: Academic Press, 2010. 1

[4] S. Azodolmolky, M. Klinkowski, E. Marin, D. Careglio, J. S. Pareta, and I. Tomkos, "A survey on physical layer impairments aware routing and wavelength assignment algorithms in optical networks," Computer Networks, vol. 53, no. 7, pp. 926 - 944, 2009. 1, 2, 6, 25, 26, 27, 29

[5] A. Rahbar, "Review of dynamic impairment-aware routing and wavelength assignment techniques in all-optical wavelength-routed networks," Communications Surveys Tutorials, IEEE, vol. PP, no. 99, pp. 1-25, 2011. 2, 27

[6] I. de Miguel, R. J. Durán, T. Jiménez, N. Fernández, J. C. Aguado, R. M. Lorenzo, A. Caballero, I. T. Monroy, Y. Ye, A. Tymecki, I. Tomkos, M. Angelou, D. Klonidis, A. Francescon, D. Siracusa, and E. Salvadori, "Cognitive dynamic optical networks - invited," J. Opt. Commun. Netw., vol. 5, pp. A107-A1 18, Oct 2013. 3, 5, 13

[7] S. Xiao, Q. Zeng, C. Jiang, J. Wang, X. Yang, F. Liu, and X. Zhu, "Adaptive optical amplifier technology,” Proc. SPIE, vol. 4604, pp. 73-79, 2001. 3, 4

[8] R. Thomas, D. Friend, L. DaSilva, and A. MacKenzie, "Cognitive networks: 
adaptation and learning to achieve end-to-end performance objectives," Communications Magazine, IEEE, vol. 44, no. 12, pp. 51-57, 2006. 3

[9] Q. H. Mahmoud, Cognitive networks. Wiley Online Library, 2007. 3

[10] G. S. Zervas and D. Simeonidou, "Cognitive optical networks: Need, requirements and architecture," in Transparent Optical Networks (ICTON), 2010 12th International Conference on, pp. 1-4, IEEE, 2010. 3, 13

[11] W. Wei, C. Wang, and J. Yu, "Cognitive optical networks: key drivers, enabling techniques, and adaptive bandwidth services," Communications Magazine, IEEE, vol. 50, no. 1, pp. 106-113, 2012. 3

[12] T. Jimenez, J. Aguado, I. de Miguel, R. Duran, M. Angelou, N. Merayo, P. Fernandez, R. Lorenzo, I. Tomkos, and E. Abril, "A cognitive quality of transmission estimator for core optical networks," Lightwave Technology, Journal of, vol. 31, no. 6, pp. 942-951, 2013. 3

[13] A. Caballero, J. C. Aguado, R. Borkowski, S. S. na, T. Jiménez, I. de Miguel, V. Arlunno, R. J. Durán, D. Zibar, J. B. Jensen, R. M. Lorenzo, E. J. Abril, and I. T. Monroy, "Experimental demonstration of a cognitive quality of transmission estimator for optical communication systems," Optics Express, vol. 20, pp. B64-B70, Dec 2012. 3

[14] M. Jinno, B. Kozicki, H. Takara, A. Watanabe, Y. Sone, T. Tanaka, and A. Hirano, "Distance-adaptive spectrum resource allocation in spectrumsliced elastic optical path network [topics in optical communications]," Communications Magazine, IEEE, vol. 48, no. 8, pp. 138-145, 2010. 4

[15] H. Y. Choi, L. Liu, T. Tsuritani, and I. Morita, "Demonstration of beradaptive wson employing flexible transmitter/receiver with an extended openflow-based control plane," Photonics Technology Letters, IEEE, vol. 25, no. 2, pp. 119-121, 2013. 4

[16] H. Zang, J. P. Jue, and B. Mukherjee, "A review of routing and wavelength assignment approaches for wavelength-routed optical wdm networks," Optical Networks Magazine, vol. 1, pp. 47 - 60, 2000. 5, 25, 26, 27

[17] R. Ramaswami, K. Sivarajan, and G. Sasaki, Optical Networks: A Practical Perspective. The Morgan Kaufmann series in networking, Elsevier/Morgan Kaufmann, 2009. 7, 8, 9, 10

[18] G. Paiva, J. Oliveira, U. Moura, R. Amgarten, and J. Oliveira, "Metodologia de projeto de edfas de alto desempenho para redes wdm reconfiguráveis," in XV Simpósio Brasileiro de Microondas e Optoeletrônica, João Pessoa. MOMAG, 2012. 11 
[19] G. Cowle, "Challenges and opportunities for optical amplifiers in metro optical networks," in Proceedings of SPIE, vol. 7621, p. 76210B, 2010. 11

[20] JDSU, Multichannel Erbium-Doped Fiber Amplifier (EDFA), 2009. 11

[21] U. C. Moura, J. R. F. Oliveira, R. L. Amgarten, G. E. R. Paiva, and J. C. R. F. Oliveira, "Caracterizador automatizado de máscara de potência de amplificadores ópticos para redes wdm reconfiguráveis," Anais do $\mathrm{SBrT}$, 2012. 13, 14

[22] J. R. F. Oliveira, U. C. Moura, J. C. R. F. Oliveira, and M. A. Romero, "Hybrid distributed raman/edfa amplifier with hybrid automatic gain control for reconfigurable wdm optical networks," Journal of Microwaves, Optoelectronics and Electromagnetic Applications, vol. 13, no. 1, pp. 24-32, 2013. 14

[23] P. M. Becker, A. A. Olsson, and J. R. Simpson, Erbium-doped fiber amplifiers: fundamentals and technology. Access Online via Elsevier, 1999. 17, 40,42

[24] C.-H. Ko and S.-F. Wang, "Precast production scheduling using multiobjective genetic algorithms," Expert Systems with Applications, vol. 38, no. 7, pp. 8293-8302, 2011. 19

[25] K. Deb, Multi-Objective Optimization using Evolutionary Algorithms. Wiley Interscience Series in Systems and Optimization, Wiley, 2001. 19

[26] C. Saradhi and S. Subramaniam, "Physical layer impairment aware routing (pliar) in wdm optical networks: issues and challenges," Communications Surveys Tutorials, IEEE, vol. 11, pp. 109 -130, quarter 2009. 28, 29

[27] G. Agrawal, Nonlinear Fiber Optics. Optics and Photonics, Academic Press, 2006. 28

[28] E. M. G. de Queiroz, Redes ópticas multidomínio: métodos de escolha de nós de borda e algoritmo de roteamento de tráfego. $\mathrm{PhD}$ thesis, Escola de Engenharia de São Carlos, Universidade de São Paulo, São Carlos, 2012. $29,33,67,68$

[29] B. Mukherjee, Optical WDM Networks (Optical Networks). Secaucus, NJ, USA: Springer-Verlag New York, Inc., 2006. 29

[30] J. Y. Yen, "An algorithm for finding shortest routes from all source nodes to a given destination in general networks," Quart. Appl. Math, vol. 27, no. 4, pp. 526-530, 1970. 34 
[31] M. Cvijetic, Optical Transmission Systems Engineering. Artech House optoelectronics library, Artech House, 2004. 51, 56

[32] G. S. Pavani, Otimização por colônia de formigas e sua aplicação em redes ópticas. PhD thesis, Unicamp, 2006. 67 
APÊNDICE

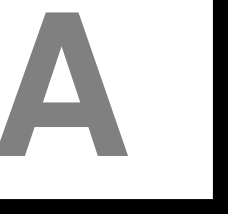

\section{Modelagem do tráfego da rede}

O Tráfego da rede é Poissoniano, em que o intervalo de tempo entre as gerações de solicitações de conexões é exponencialmente distribuído, definido pelo método da função inversa [32]

$$
T_{g}=\frac{-\log _{10}(1-\omega)}{\lambda}
$$

na qual $\omega$ é uma variável aleatória com valores entre 0 e 1 e $\lambda$ é a taxa de chegada das conexões, definida como

$$
\lambda=\frac{E r}{T}
$$

em que $E r$ é a carga em erlang e T é a média de duração das conexões da rede e é dado por

$$
\lambda=\frac{1}{\mu}
$$

em que $\mu$ é a taxa de serviço.

O tempo de duração de cada conexão é [32]

$$
c_{d}=\frac{-\log _{10}(1-f)}{\mu}
$$

na qual $f$ é uma variável aleatória com valores de 0 a 1.

Pode-se entender o funcionamento da geração de tráfego da rede com o auxilio da Figura A.1 [28]. É possível visualizar a geração das solicitações de conexão conforme o tempo $t_{g}$. A duração das conexões é definida por $c_{d}$ e o sistema aloca largura de faixa no início, liberando no fim da conexão. Como há várias conexões presentes na rede, a Figura A.1 apresenta algumas conexões 
em paralelo [28].

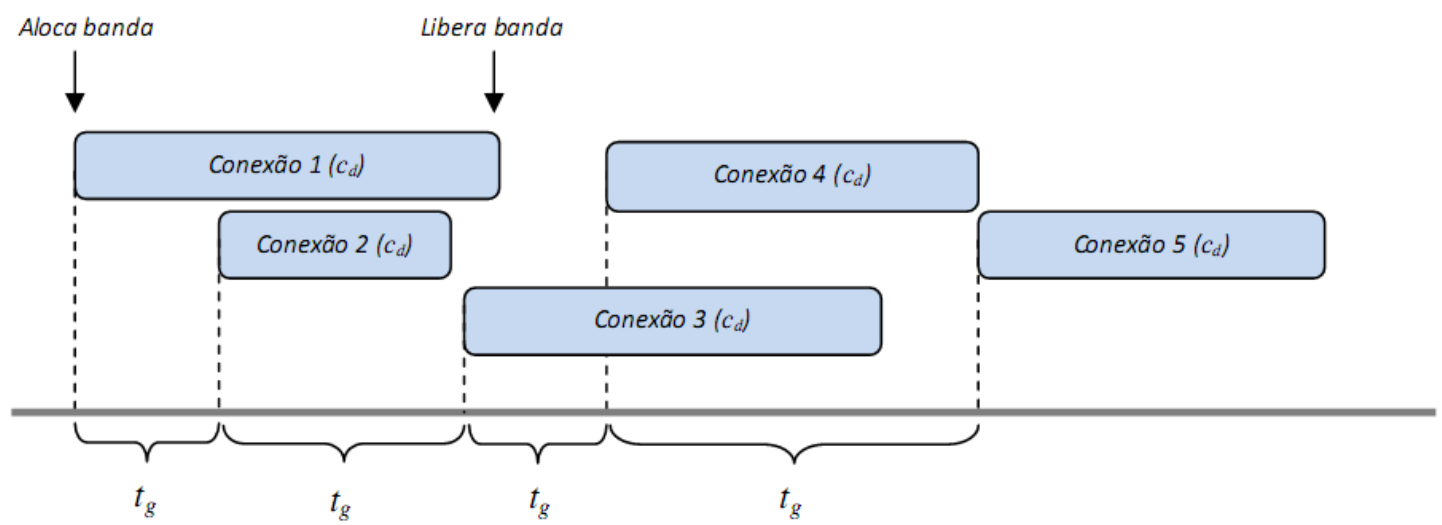

Figura III.1. Geração de tráfego da rede.

Figura A. 1: Geração de tráfego da rede. 


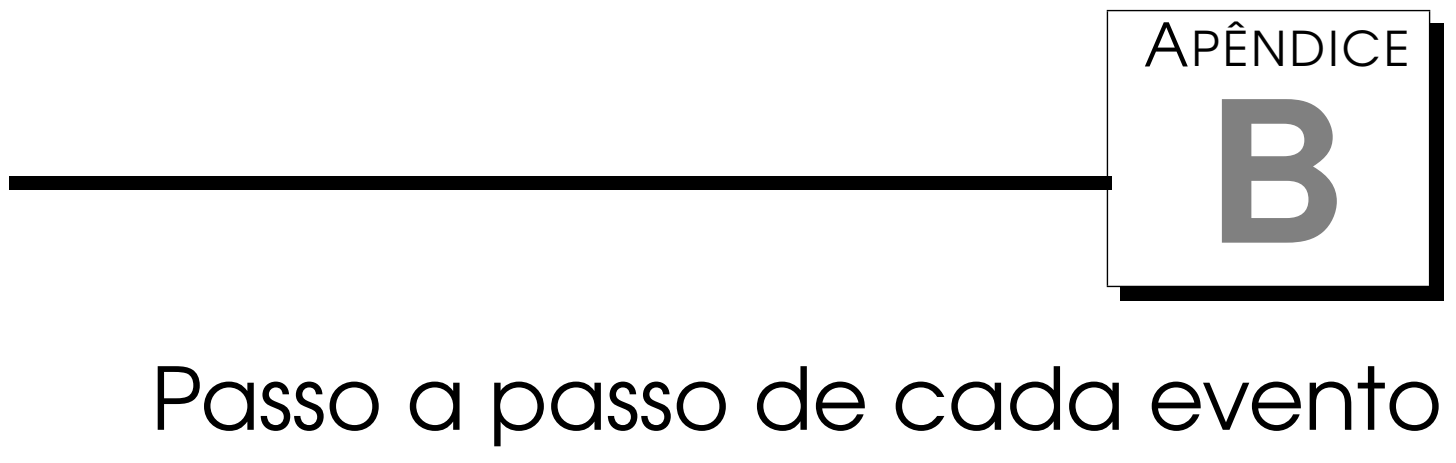

Sequência de tratamento de eventos de alocação e desalocação de chamadas com e sem a metodologia adaptativa para a geração de dez conexões.

Sem AdGC

Alocar

Conexão 10

Caminho: 124600

Ganho total caminho ida: $0 \mathrm{~dB}$

Ganho total caminho volta: $0 \mathrm{~dB}$

OSNR saída ida: $22.7142 \mathrm{~dB}$

OSNR saída volta: $22.7142 \mathrm{~dB}$

NF caminho ida: $23.3557 \mathrm{~dB}$

$\mathrm{NF}$ caminho volta: $23.3557 \mathrm{~dB}$

$\rightarrow$ IDA $->$

Enlace 1 - 2

Pin total: $-12 \mathrm{dBm}$

Ganho Amp1: $14 \mathrm{~dB}$

Ganho Amp2: $21 \mathrm{~dB}$

Enlace 2 - 4

Pin total: $-12 \mathrm{dBm}$

Ganho Amp1: $14 \mathrm{~dB}$

Ganho Amp2: $19 \mathrm{~dB}$

Enlace 4 - 6

Pin total: $-12 \mathrm{dBm}$

Ganho Amp1: $14 \mathrm{~dB}$
Com AdGC

Alocar

Conexão 10

Caminho: 124600

Ganho total caminho ida: $7 \mathrm{~dB}$

Ganho total caminho volta: $4 \mathrm{~dB}$

OSNR saída ida: $27.2054 \mathrm{~dB}$

OSNR saída volta: $27.2166 \mathrm{~dB}$

NF caminho ida: $18.8558 \mathrm{~dB}$

NF caminho volta: $18.8558 \mathrm{~dB}$

-> IDA ->

Enlace 1 - 2

Pin total: $-12 \mathrm{dBm}$

Ganho Amp 1: $19 \mathrm{~dB}$

Ganho Amp2: $20 \mathrm{~dB}$

Enlace 2 - 4

Pin total: $-12 \mathrm{dBm}$

Ganho Amp 1: $19 \mathrm{~dB}$

Ganho Amp2: $20 \mathrm{~dB}$

Enlace 4 - 6

Pin total: $-12 \mathrm{dBm}$

Ganho Amp 1: $19 \mathrm{~dB}$ 
Ganho Amp2: $17 \mathrm{~dB}$

$<-$ VOLTA <-

Enlace 6 - 4

Pin total: $-12 \mathrm{dBm}$

Ganho Amp 1: $14 \mathrm{~dB}$

Ganho Amp2: $17 \mathrm{~dB}$

Enlace 4 - 2

Pin total: $-12 \mathrm{dBm}$

Ganho Amp 1: $14 \mathrm{~dB}$

Ganho Amp2: $19 \mathrm{~dB}$

Enlace 2 - 1

Pin total: $-12 \mathrm{dBm}$

Ganho Amp 1: $14 \mathrm{~dB}$

Ganho Amp2: $21 \mathrm{~dB}$

Conexão 9

Caminho: 4600

Ganho total caminho ida: $0 \mathrm{~dB}$

Ganho total caminho volta: $0 \mathrm{~dB}$

OSNR saída ida: $29.565 \mathrm{~dB}$

OSNR saída volta: $29.565 \mathrm{~dB}$

NF caminho ida: $16.578 \mathrm{~dB}$

NF caminho volta: $16.578 \mathrm{~dB}$

-> IDA ->

Enlace 4 - 6

Pin total: $-8.9897 \mathrm{dBm}$

Ganho Amp1: $14 \mathrm{~dB}$

Ganho Amp2: $17 \mathrm{~dB}$

$<-$ VOLTA <-

Enlace 6 - 4

Pin total: $-8.9897 \mathrm{dBm}$

Ganho Amp 1: $14 \mathrm{~dB}$

Ganho Amp2: $17 \mathrm{~dB}$

$$
\text { Alocar }
$$

Conexão 8

Caminho: 64300

Ganho total caminho ida: $0 \mathrm{~dB}$

Ganho total caminho volta: $0 \mathrm{~dB}$

OSNR saída ida: $23.0663 \mathrm{~dB}$

OSNR saída volta: $23.0663 \mathrm{~dB}$
Ganho Amp2: $19 \mathrm{~dB}$

$<-$ VOLTA <-

Enlace 6 - 4

Pin total: $-12 \mathrm{dBm}$

Ganho Amp 1: $19 \mathrm{~dB}$

Ganho Amp2: $19 \mathrm{~dB}$

Enlace 4 - 2

Pin total: $-12 \mathrm{dBm}$

Ganho Amp1: $19 \mathrm{~dB}$

Ganho Amp2: $20 \mathrm{~dB}$

Enlace 2 - 1

Pin total: $-12 \mathrm{dBm}$

Ganho Amp1: $19 \mathrm{~dB}$

Ganho Amp2: $20 \mathrm{~dB}$

Conexão 9

Caminho: 4600

Ganho total caminho ida: $7 \mathrm{~dB}$

Ganho total caminho volta: $7 \mathrm{~dB}$

OSNR saída ida: $34.0661 \mathrm{~dB}$

OSNR saída volta: $34.0661 \mathrm{~dB}$

NF caminho ida: $12.0349 \mathrm{~dB}$

NF caminho volta: $12.0349 \mathrm{~dB}$

-> IDA ->

Enlace $4-6$

Pin total: $-8.9897 \mathrm{dBm}$

Ganho Amp 1: $19 \mathrm{~dB}$

Ganho Amp2: $19 \mathrm{~dB}$

$<-$ VOLTA <-

Enlace 6 - 4

Pin total: $-8.9897 \mathrm{dBm}$

Ganho Amp 1: $19 \mathrm{~dB}$

Ganho Amp2: $19 \mathrm{~dB}$

Alocar

Conexão 8

Caminho: 64300

Ganho total caminho ida: $2 \mathrm{~dB}$

Ganho total caminho volta: $7 \mathrm{~dB}$

OSNR saída ida: $27.5718 \mathrm{~dB}$

OSNR saída volta: $27.5452 \mathrm{~dB}$ 
NF caminho ida: $22.9985 \mathrm{~dB}$

NF caminho volta: $22.9985 \mathrm{~dB}$

-> IDA ->

Enlace 6 - 4

Pin total: $-7.2288 \mathrm{dBm}$

Ganho Amp1: $14 \mathrm{~dB}$

Ganho Amp2: $17 \mathrm{~dB}$

Enlace 4 - 3

Pin total: $-12 \mathrm{dBm}$

Ganho Amp1: $14 \mathrm{~dB}$

Ganho Amp2: $23 \mathrm{~dB}$

$<-$ VOLTA <-

Enlace 3 - 4

Pin total: $-12 \mathrm{dBm}$

Ganho Amp1: $14 \mathrm{~dB}$

Ganho Amp2: $23 \mathrm{~dB}$

Enlace 4 - 6

Pin total: $-7.2288 \mathrm{dBm}$

Ganho Amp1: $14 \mathrm{~dB}$

Ganho Amp2: $17 \mathrm{~dB}$

Conexão 7

Caminho: 6500

Ganho total caminho ida: $0 \mathrm{~dB}$

Ganho total caminho volta: $0 \mathrm{~dB}$

OSNR saída ida: $23.3502 \mathrm{~dB}$

OSNR saída volta: $23.3502 \mathrm{~dB}$

NF caminho ida: $22.7229 \mathrm{~dB}$

NF caminho volta: $22.7229 \mathrm{~dB}$

-> IDA ->

Enlace 6 - 5

Pin total: $-12 \mathrm{dBm}$

Ganho Amp1: $14 \mathrm{~dB}$

Ganho Amp2: $24 \mathrm{~dB}$

$<-$ VOLTA <-

Enlace 5 - 6

Pin total: $-12 \mathrm{dBm}$

Ganho Amp1: $14 \mathrm{~dB}$

Ganho Amp2: $24 \mathrm{~dB}$
NF caminho ida: $18.51 \mathrm{~dB}$

NF caminho volta: $18.51 \mathrm{~dB}$

-> IDA ->

Enlace 6 - 4

Pin total: $-7.2288 \mathrm{dBm}$

Ganho Amp1: $19 \mathrm{~dB}$

Ganho Amp2: $19 \mathrm{~dB}$

Enlace 4 - 3

Pin total: $-12 \mathrm{dBm}$

Ganho Amp1: $19 \mathrm{~dB}$

Ganho Amp2: $20 \mathrm{~dB}$

$<-$ VOLTA <-

Enlace 3 - 4

Pin total: $-12 \mathrm{dBm}$

Ganho Amp 1: $19 \mathrm{~dB}$

Ganho Amp2: $20 \mathrm{~dB}$

Enlace 4 - 6

Pin total: $-7.2288 \mathrm{dBm}$

Ganho Amp 1: $19 \mathrm{~dB}$

Ganho Amp2: $19 \mathrm{~dB}$ Alocar

\section{Conexão 7}

Caminho: 6500

Ganho total caminho ida: $1 \mathrm{~dB}$ Ganho total caminho volta: $1 \mathrm{~dB}$ OSNR saída ida: $27.773 \mathrm{~dB}$ OSNR saída volta: $27.773 \mathrm{~dB}$ NF caminho ida: $18.3278 \mathrm{~dB}$ NF caminho volta: $18.3278 \mathrm{~dB}$ -> IDA ->

Enlace 6 - 5

Pin total: $-12 \mathrm{dBm}$

Ganho Amp 1: $19 \mathrm{~dB}$

Ganho Amp2: $20 \mathrm{~dB}$

$<-$ VOLTA <-

Enlace 5 - 6

Pin total: $-12 \mathrm{dBm}$

Ganho Amp 1: $19 \mathrm{~dB}$

Ganho Amp2: $20 \mathrm{~dB}$ 
Conexão 6

Caminho: 6500

Ganho total caminho ida: $0 \mathrm{~dB}$

Ganho total caminho volta: $0 \mathrm{~dB}$ OSNR saída ida: $22.943 \mathrm{~dB}$

OSNR saída volta: $22.943 \mathrm{~dB}$

NF caminho ida: $23.1247 \mathrm{~dB}$

NF caminho volta: $23.1247 \mathrm{~dB}$

-> IDA ->

Enlace 6 - 5

Pin total: $-8.9897 \mathrm{dBm}$

Ganho Amp 1: $14 \mathrm{~dB}$

Ganho Amp2: $24 \mathrm{~dB}$

$<-$ VOLTA <-

Enlace 5 - 6

Pin total: $-8.9897 \mathrm{dBm}$

Ganho Amp 1: $14 \mathrm{~dB}$

Ganho Amp2: $24 \mathrm{~dB}$

$$
\text { Alocar }
$$

Conexão 5

Caminho: 4200

Ganho total caminho ida: $0 \mathrm{~dB}$

Ganho total caminho volta: $0 \mathrm{~dB}$

OSNR saída ida: $27.678 \mathrm{~dB}$

OSNR saída volta: $27.678 \mathrm{~dB}$

NF caminho ida: $18.4312 \mathrm{~dB}$

NF caminho volta: $18.4312 \mathrm{~dB}$

$\rightarrow>$ IDA $->$

Enlace 4 - 2

Pin total: $-8.9897 \mathrm{dBm}$

Ganho Amp 1: $14 \mathrm{~dB}$

Ganho Amp2: $19 \mathrm{~dB}$

$<-$ VOLTA <-

Enlace 2 - 4

Pin total: $-8.9897 \mathrm{dBm}$

Ganho Amp 1: $14 \mathrm{~dB}$

Ganho Amp2: $19 \mathrm{~dB}$

$$
\text { Alocar }
$$

Conexão 4

Caminho: 12500
Conexão 6

Caminho: 6500

Ganho total caminho ida: $1 \mathrm{~dB}$

Ganho total caminho volta: $1 \mathrm{~dB}$ OSNR saída ida: $27.683 \mathrm{~dB}$

OSNR saída volta: $27.683 \mathrm{~dB}$

NF caminho ida: $18.4135 \mathrm{~dB}$

NF caminho volta: $18.4135 \mathrm{~dB}$

$->$ IDA $->$

Enlace 6 - 5

Pin total: $-8.9897 \mathrm{dBm}$

Ganho Amp1: $19 \mathrm{~dB}$

Ganho Amp2: $20 \mathrm{~dB}$

$<-$ VOLTA <-

Enlace 5 - 6

Pin total: $-8.9897 \mathrm{dBm}$

Ganho Amp1: $19 \mathrm{~dB}$

Ganho Amp2: $20 \mathrm{~dB}$

Conexão 5

Caminho: 4200

Ganho total caminho ida: $5 \mathrm{~dB}$

Ganho total caminho volta: $5 \mathrm{~dB}$

OSNR saída ida: $32.3323 \mathrm{~dB}$

OSNR saída volta: $32.3323 \mathrm{~dB}$

NF caminho ida: $13.7722 \mathrm{~dB}$

NF caminho volta: $13.7722 \mathrm{~dB}$

$\rightarrow$ IDA $->$

Enlace 4 - 2

Pin total: $-8.9897 \mathrm{dBm}$

Ganho Amp1: $19 \mathrm{~dB}$

Ganho Amp2: $19 \mathrm{~dB}$

$<-$ VOLTA <-

Enlace 2 - 4

Pin total: $-8.9897 \mathrm{dBm}$

Ganho Amp 1: $19 \mathrm{~dB}$

Ganho Amp2: $19 \mathrm{~dB}$ Alocar

Conexão 4

Caminho: 12500 
Ganho total caminho ida: $0 \mathrm{~dB}$ Ganho total caminho volta: $0 \mathrm{~dB}$ OSNR saída ida: $22.3716 \mathrm{~dB}$ OSNR saída volta: $22.3716 \mathrm{~dB}$ NF caminho ida: $23.6935 \mathrm{~dB}$ $\mathrm{NF}$ caminho volta: $23.6935 \mathrm{~dB}$ -> IDA ->

Enlace 1 - 2

Pin total: $-8.9897 \mathrm{dBm}$

Ganho Amp1: $14 \mathrm{~dB}$

Ganho Amp2: $21 \mathrm{~dB}$

Enlace 2 - 5

Pin total: $-12 \mathrm{dBm}$

Ganho Amp1: $14 \mathrm{~dB}$

Ganho Amp2: $22 \mathrm{~dB}$

$<-$ VOLTA <-

Enlace 5 - 2

Pin total: $-12 \mathrm{dBm}$

Ganho Amp1: $14 \mathrm{~dB}$

Ganho Amp2: $22 \mathrm{~dB}$

Enlace 2 - 1

Pin total: $-8.9897 \mathrm{dBm}$

Ganho Amp1: $14 \mathrm{~dB}$

Ganho Amp2: $21 \mathrm{~dB}$

Conexão 3 Alocar

Caminho: 1300

Ganho total caminho ida: $0 \mathrm{~dB}$ Ganho total caminho volta: $0 \mathrm{~dB}$ OSNR saída ida: $26.8644 \mathrm{~dB}$ OSNR saída volta: $26.8644 \mathrm{~dB}$ NF caminho ida: $19.2375 \mathrm{~dB}$ NF caminho volta: $19.2375 \mathrm{~dB}$

$\rightarrow$ IDA ->

Enlace 1 - 3

Pin total: $-12 \mathrm{dBm}$

Ganho Amp1: $14 \mathrm{~dB}$

Ganho Amp2: $20 \mathrm{~dB}$

$<-$ VOLTA <-

Enlace 3 - 1
Ganho total caminho ida: $3 \mathrm{~dB}$ Ganho total caminho volta: $4 \mathrm{~dB}$ OSNR saída ida: $26.9859 \mathrm{~dB}$ OSNR saída volta: $26.9803 \mathrm{~dB}$ NF caminho ida: $19.0875 \mathrm{~dB}$ NF caminho volta: $19.0875 \mathrm{~dB}$ $\rightarrow$ IDA $->$

Enlace 1 - 2

Pin total: $-8.9897 \mathrm{dBm}$

Ganho Amp 1: $19 \mathrm{~dB}$

Ganho Amp2: $20 \mathrm{~dB}$

Enlace 2 - 5

Pin total: $-12 \mathrm{dBm}$

Ganho Amp 1: $19 \mathrm{~dB}$

Ganho Amp2: $20 \mathrm{~dB}$

$<-$ VOLTA <-

Enlace 5 - 2

Pin total: $-12 \mathrm{dBm}$

Ganho Amp 1: $19 \mathrm{~dB}$

Ganho Amp2: $20 \mathrm{~dB}$

Enlace 2 - 1

Pin total: $-8.9897 \mathrm{dBm}$

Ganho Amp 1: $19 \mathrm{~dB}$

Ganho Amp2: $20 \mathrm{~dB}$ Alocar

Conexão 3

Caminho: 1300

Ganho total caminho ida: $5 \mathrm{~dB}$ Ganho total caminho volta: $5 \mathrm{~dB}$ OSNR saída ida: $31.3855 \mathrm{~dB}$ OSNR saída volta: $31.3855 \mathrm{~dB}$ NF caminho ida: $14.711 \mathrm{~dB}$ NF caminho volta: $14.711 \mathrm{~dB}$ -> IDA ->

Enlace 1 - 3

Pin total: $-12 \mathrm{dBm}$ Ganho Amp 1: $19 \mathrm{~dB}$ Ganho Amp2: $20 \mathrm{~dB}$ $<-$ VOLTA <Enlace 3 - 1 
Pin total: $-12 \mathrm{dBm}$

Ganho Amp 1: $14 \mathrm{~dB}$

Ganho Amp2: $20 \mathrm{~dB}$ Desalocar

Conexão 4

Caminho: 12500

-> IDA ->

Enlace 1 - 2

Pin total: $-12 \mathrm{dBm}$

Enlace 2 - 5

Pin total: -Inf $\mathrm{dBm}$

$<-$ VOLTA <-

Enlace 5 - 2

Pin total: -Inf $\mathrm{dBm}$

Enlace 2 - 1

Pin total: $-12 \mathrm{dBm}$ Alocar

Conexão 2

Caminho: 21300

Ganho total caminho ida: $0 \mathrm{~dB}$

Ganho total caminho volta: $0 \mathrm{~dB}$

OSNR saída ida: $23.1889 \mathrm{~dB}$

OSNR saída volta: $23.1889 \mathrm{~dB}$

NF caminho ida: $22.88 \mathrm{~dB}$

NF caminho volta: $22.88 \mathrm{~dB}$

-> IDA ->

Enlace 2 - 1

Pin total: $-8.9897 \mathrm{dBm}$

Ganho Amp 1: $14 \mathrm{~dB}$

Ganho Amp2: $21 \mathrm{~dB}$

Enlace 1 - 3

Pin total: $-8.9897 \mathrm{dBm}$

Ganho Amp 1: $14 \mathrm{~dB}$

Ganho Amp2: $20 \mathrm{~dB}$

<- VOLTA <-

Enlace 3 - 1

Pin total: $-8.9897 \mathrm{dBm}$

Ganho Amp 1: $14 \mathrm{~dB}$

Ganho Amp2: $20 \mathrm{~dB}$

Enlace 1 - 2
Pin total: $-12 \mathrm{dBm}$

Ganho Amp 1: $19 \mathrm{~dB}$

Ganho Amp2: $20 \mathrm{~dB}$

Desalocar

Conexão 4

Caminho: 12500

-> IDA ->

Enlace 1 - 2

Pin total: $-12 \mathrm{dBm}$

Enlace 2 - 5

Pin total: -Inf $\mathrm{dBm}$

$<-$ VOLTA <-

Enlace 5 - 2

Pin total: -Inf $\mathrm{dBm}$

Enlace 2 - 1

Pin total: $-12 \mathrm{dBm}$ Alocar

Conexão 2

Caminho: 21300

Ganho total caminho ida: $4 \mathrm{~dB}$

Ganho total caminho volta: $4 \mathrm{~dB}$

OSNR saída ida: $27.9049 \mathrm{~dB}$ OSNR saída volta: $27.9049 \mathrm{~dB}$

NF caminho ida: $18.1679 \mathrm{~dB}$

NF caminho volta: $18.1679 \mathrm{~dB}$

-> IDA ->

Enlace 2 - 1

Pin total: $-8.9897 \mathrm{dBm}$

Ganho Amp1: $19 \mathrm{~dB}$

Ganho Amp2: $20 \mathrm{~dB}$

Enlace 1 - 3

Pin total: $-8.9897 \mathrm{dBm}$

Ganho Amp 1: $19 \mathrm{~dB}$

Ganho Amp2: $19 \mathrm{~dB}$

$<-$ VOLTA <-

Enlace 3 - 1

Pin total: $-8.9897 \mathrm{dBm}$

Ganho Amp1: $19 \mathrm{~dB}$

Ganho Amp2: $19 \mathrm{~dB}$

Enlace 1 - 2 
Pin total: $-8.9897 \mathrm{dBm}$

Ganho Amp1: $14 \mathrm{~dB}$

Ganho Amp2: $21 \mathrm{~dB}$ Desalocar

Conexão 9

Caminho: 4600

-> IDA ->

Enlace 4 - 6

Pin total: $-8.9897 \mathrm{dBm}$

$<-$ VOLTA <-

Enlace 6 - 4

Pin total: $-8.9897 \mathrm{dBm}$

Conexão 1

Caminho: 5200

Ganho total caminho ida: $0 \mathrm{~dB}$ Ganho total caminho volta: $0 \mathrm{~dB}$ OSNR saída ida: $25.0638 \mathrm{~dB}$ OSNR saída volta: $25.0638 \mathrm{~dB}$ NF caminho ida: $21.0205 \mathrm{~dB}$ $\mathrm{NF}$ caminho volta: $21.0205 \mathrm{~dB}$

$\rightarrow$ IDA ->

Enlace 5 - 2

Pin total: $-12 \mathrm{dBm}$

Ganho Amp1: $14 \mathrm{~dB}$

Ganho Amp2: $22 \mathrm{~dB}$

$<-$ VOLTA <-

Enlace 2 - 5

Pin total: $-12 \mathrm{dBm}$

Ganho Amp1: $14 \mathrm{~dB}$

Ganho Amp2: $22 \mathrm{~dB}$ Desalocar

Conexão 7

Caminho: 6500

-> IDA ->

Enlace 6 - 5

Pin total: $-12 \mathrm{dBm}$

$<-$ VOLTA <-

Enlace 5 - 6

Pin total: $-12 \mathrm{dBm}$
Pin total: $-8.9897 \mathrm{dBm}$

Ganho Amp 1: $19 \mathrm{~dB}$

Ganho Amp2: $20 \mathrm{~dB}$ Desalocar

Conexão 9

Caminho: 4600

-> IDA ->

Enlace $4-6$

Pin total: $-8.9897 \mathrm{dBm}$

$<-$ VOLTA <-

Enlace 6 - 4

Pin total: $-8.9897 \mathrm{dBm}$ Alocar

Conexão 1

Caminho: 5200

Ganho total caminho ida: $3 \mathrm{~dB}$

Ganho total caminho volta: $3 \mathrm{~dB}$

OSNR saída ida: $29.5834 \mathrm{~dB}$

OSNR saída volta: $29.5834 \mathrm{~dB}$

$\mathrm{NF}$ caminho ida: $16.5153 \mathrm{~dB}$

NF caminho volta: $16.5153 \mathrm{~dB}$

$\rightarrow$ IDA $->$

Enlace 5 - 2

Pin total: $-12 \mathrm{dBm}$

Ganho Amp 1: $19 \mathrm{~dB}$

Ganho Amp2: $20 \mathrm{~dB}$

$<-$ VOLTA <-

Enlace 2 - 5

Pin total: $-12 \mathrm{dBm}$

Ganho Amp1: $19 \mathrm{~dB}$

Ganho Amp2: $20 \mathrm{~dB}$ Desalocar

Conexão 7

Caminho: 6500

-> IDA ->

Enlace 6 - 5

Pin total: $-12 \mathrm{dBm}$

$<-$ VOLTA <-

Enlace 5 - 6

Pin total: $-12 \mathrm{dBm}$ 
Conexão 8

Caminho: 64300

-> IDA ->

Enlace 6 - 4

Pin total: $-12 \mathrm{dBm}$

Enlace 4 - 3

Pin total: -Inf dBm

$<-$ VOLTA <-

Enlace 3 - 4

Pin total: -Inf dBm

Enlace 4 - 6

Pin total: $-12 \mathrm{dBm}$

Desalocar

Conexão 3

Caminho: 1300

-> IDA ->

Enlace 1 - 3

Pin total: $-12 \mathrm{dBm}$

$<-$ VOLTA <-

Enlace 3 - 1

Pin total: $-12 \mathrm{dBm}$

\section{Desalocar}

Conexão 6

Caminho: 6500

-> IDA ->

Enlace 6 - 5

Pin total: -Inf $\mathrm{dBm}$

$<-$ VOLTA <-

Enlace 5 - 6

Pin total: -Inf $\mathrm{dBm}$

Desalocar

Conexão 1

Caminho: 5200

-> IDA ->

Enlace 5 - 2

Pin total: -Inf dBm

<- VOLTA <-

Enlace 2 - 5

Pin total: -Inf dBm
Conexão 8

Caminho: 64300

-> IDA ->

Enlace 6 - 4

Pin total: $-12 \mathrm{dBm}$

Enlace 4 - 3

Pin total: -Inf $\mathrm{dBm}$

$<-$ VOLTA <-

Enlace 3 - 4

Pin total: -Inf $\mathrm{dBm}$

Enlace 4 - 6

Pin total: $-12 \mathrm{dBm}$

Desalocar

Conexão 3

Caminho: 1300

-> IDA ->

Enlace 1 - 3

Pin total: $-12 \mathrm{dBm}$

<- VOLTA <-

Enlace 3 - 1

Pin total: $-12 \mathrm{dBm}$ Desalocar

Conexão 6

Caminho: 6500

-> IDA ->

Enlace 6 - 5

Pin total: -Inf $\mathrm{dBm}$

$<-$ VOLTA <-

Enlace 5 - 6

Pin total: -Inf $\mathrm{dBm}$

Desalocar

Conexão 1

Caminho: 5200

-> IDA ->

Enlace 5 - 2

Pin total: -Inf $\mathrm{dBm}$

$<-$ VOLTA <-

Enlace 2 - 5

Pin total: -Inf $\mathrm{dBm}$ 
Conexão 5

Caminho: 4200

-> IDA ->

Enlace 4 - 2

Pin total: $-12 \mathrm{dBm}$

$<-$ VOLTA <-

Enlace 2 - 4

Pin total: $-12 \mathrm{dBm}$

- Desalocar

Conexão 2

Caminho: 21300

-> IDA ->

Enlace 2 - 1

Pin total: $-12 \mathrm{dBm}$

Enlace 1 - 3

Pin total: -Inf $\mathrm{dBm}$

$<-$ VOLTA <-

Enlace 3 - 1

Pin total: -Inf $\mathrm{dBm}$

Enlace 1 - 2

Pin total: $-12 \mathrm{dBm}$

\section{Desalocar}

Conexão 10

Caminho: 124600

-> IDA ->

Enlace 1 - 2

Pin total: -Inf $\mathrm{dBm}$

Enlace 2 - 4

Pin total: -Inf dBm

Enlace 4 - 6

Pin total: -Inf dBm

$<-$ VOLTA <-

Enlace 6 - 4

Pin total: -Inf $\mathrm{dBm}$

Enlace 4 - 2

Pin total: -Inf $\mathrm{dBm}$

Enlace 2 - 1

Pin total: -Inf dBm
Conexão 5

Caminho: 4200

-> IDA ->

Enlace 4 - 2

Pin total: $-12 \mathrm{dBm}$

$<-$ VOLTA <-

Enlace 2 - 4

Pin total: $-12 \mathrm{dBm}$

Desalocar

Conexão 2

Caminho: 21300

$\rightarrow$ IDA ->

Enlace 2 - 1

Pin total: $-12 \mathrm{dBm}$

Enlace 1 - 3

Pin total: -Inf dBm

$<-$ VOLTA <-

Enlace 3 - 1

Pin total: -Inf dBm

Enlace 1 - 2

Pin total: $-12 \mathrm{dBm}$

\section{Desalocar}

Conexão 10

Caminho: 124600

-> IDA ->

Enlace 1 - 2

Pin total: -Inf dBm

Enlace 2 - 4

Pin total: -Inf $\mathrm{dBm}$

Enlace 4 - 6

Pin total: -Inf $\mathrm{dBm}$

$<-$ VOLTA <-

Enlace 6 - 4

Pin total: -Inf dBm

Enlace 4 - 2

Pin total: -Inf dBm

Enlace 2 - 1

Pin total: -Inf $\mathrm{dBm}$ 
APÊNDICE

\section{OSNR por conexão}

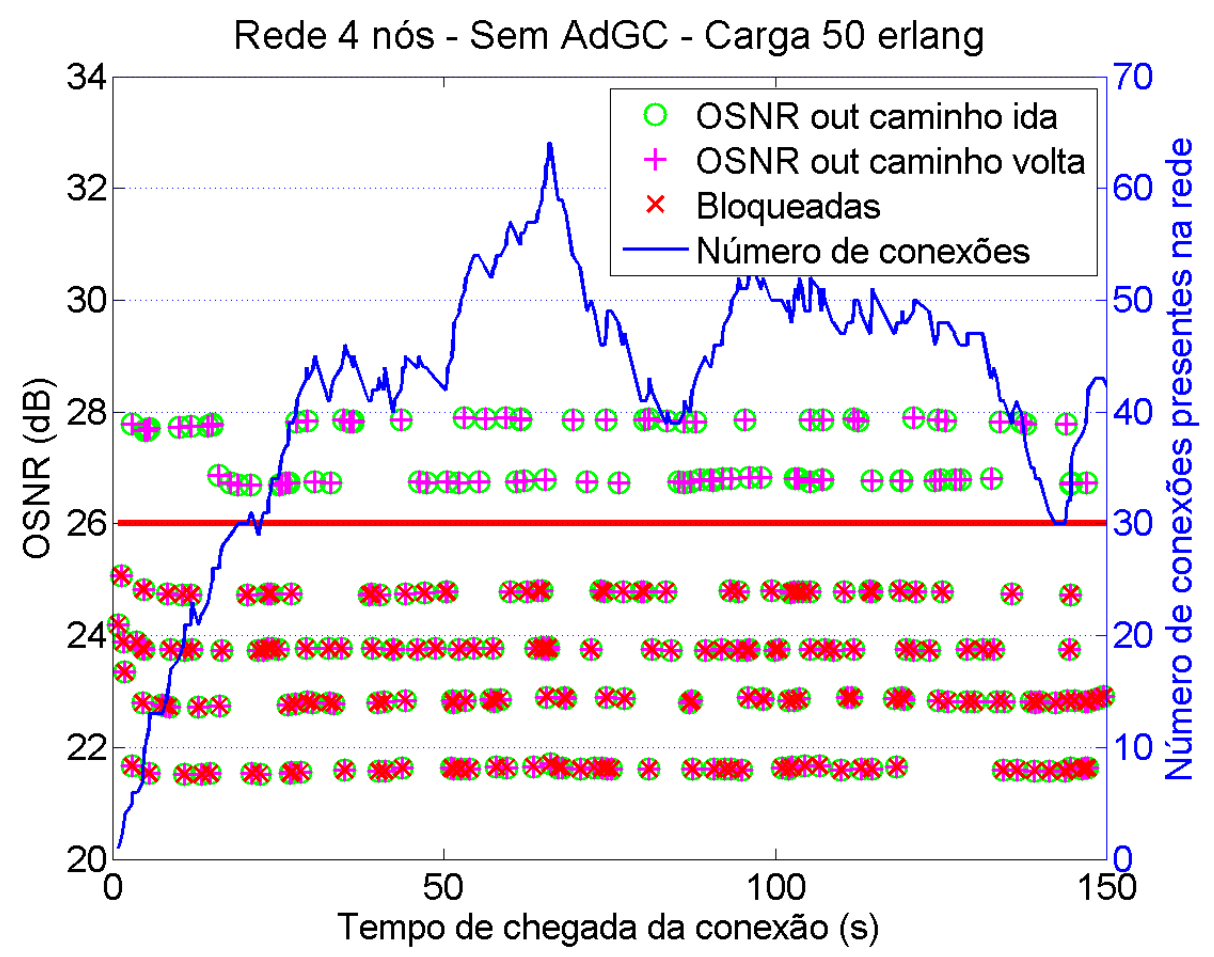

Figura C.1: OSNR na recepção de cada conexão para os caminhos de ida e volta para uma rede de quatro nós sem AdGC e carga de 50 erlangs. Curva em azul corresponde à evolução do número de canais presentes na rede em função do tempo de chegada e a linha em vermelho é o limiar escolhido. 


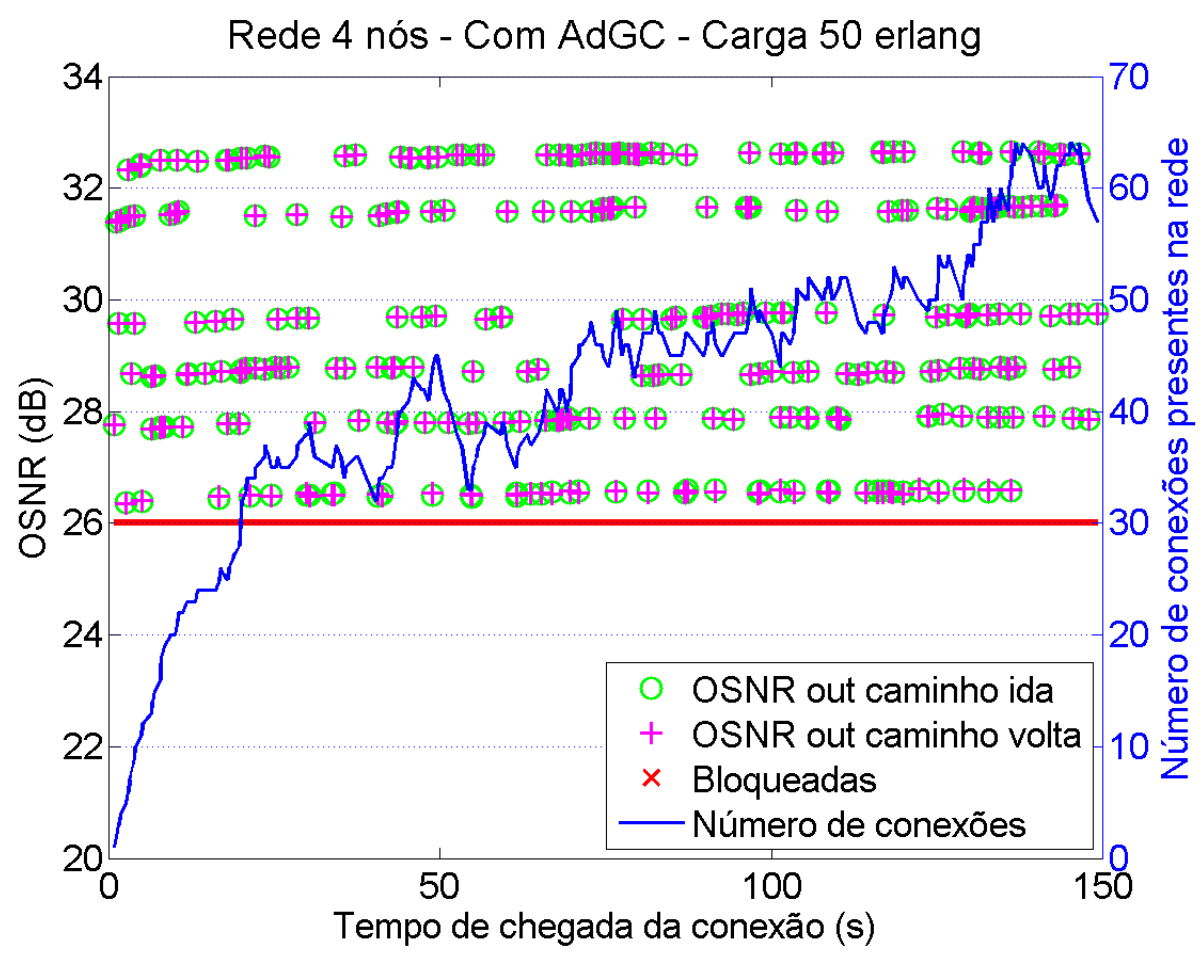

Figura C.2: OSNR na recepção de cada conexão para os caminhos de ida e volta para uma rede de quatro nós com AdGC e carga de 50 erlangs. Curva em azul corresponde à evolução do número de canais presentes na rede em função do tempo de chegada e a linha em vermelho é o limiar escolhido.

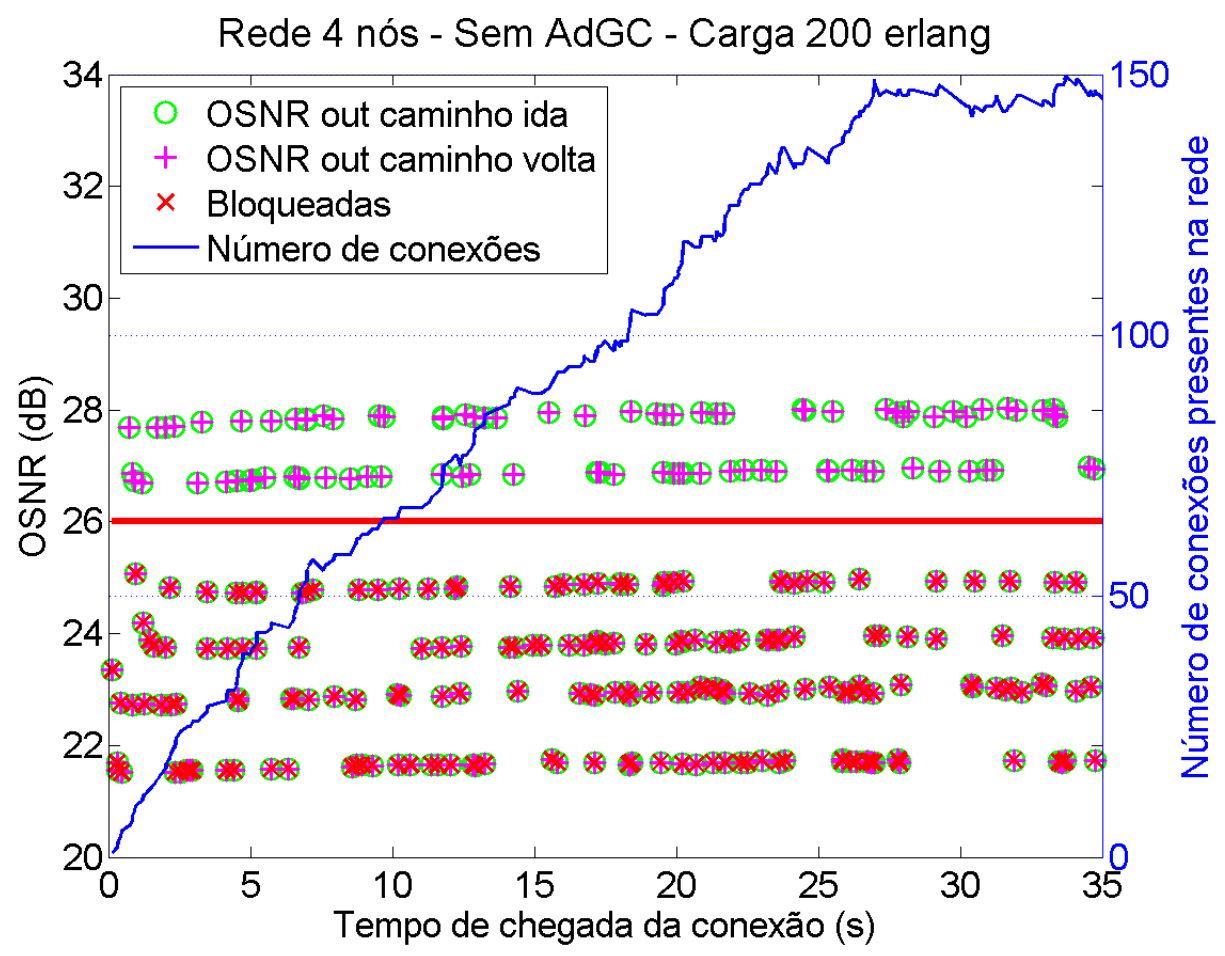

Figura C.3: OSNR na recepção de cada conexão para os caminhos de ida e volta para uma rede de quatro nós sem AdGC e carga de 200 erlangs. Curva em azul corresponde à evolução do número de canais presentes na rede em função do tempo de chegada e a linha em vermelho é o limiar escolhido. 


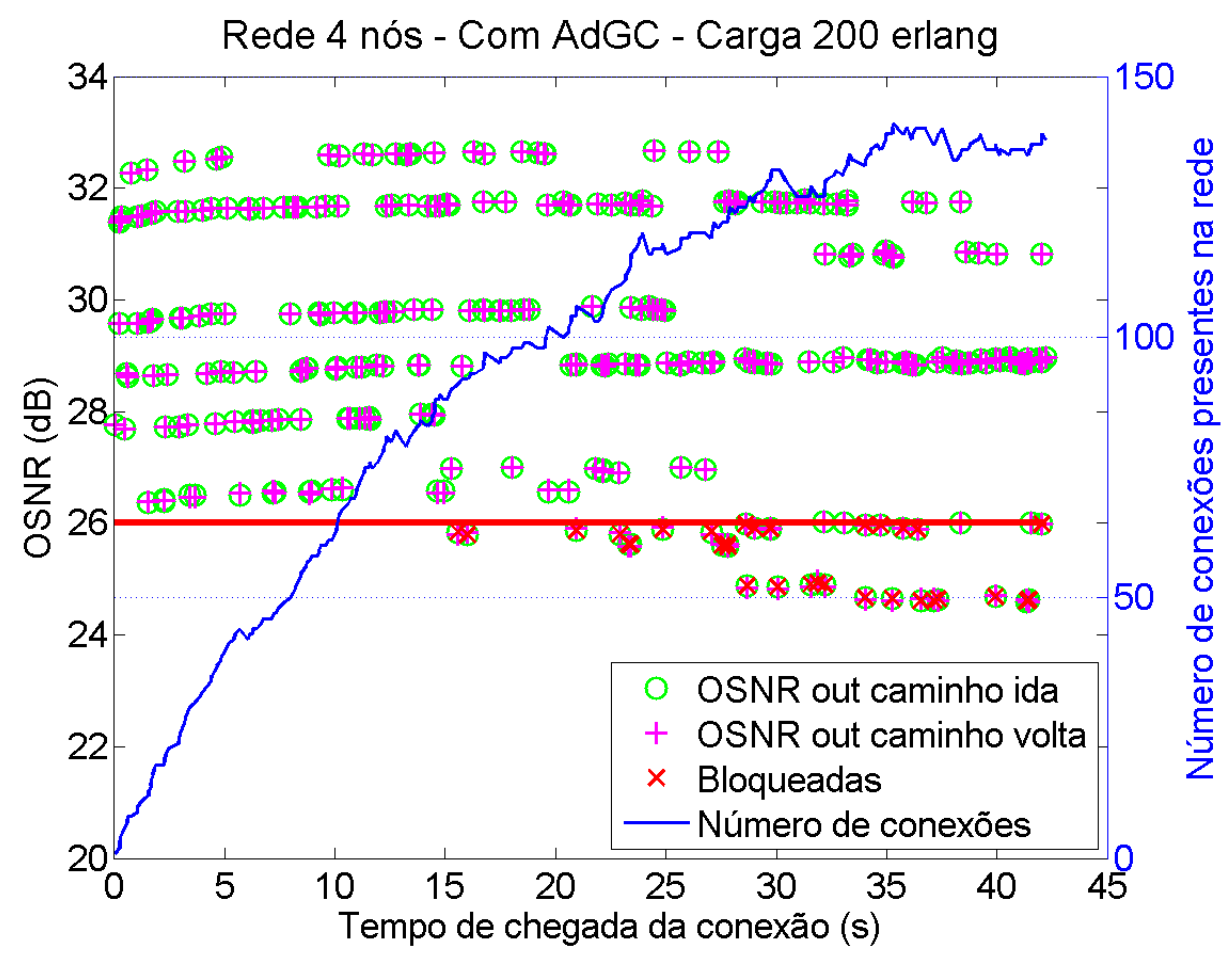

Figura C.4: OSNR na recepção de cada conexão para os caminhos de ida e volta para uma rede de quatro nós com AdGC e carga de 200 erlangs. Curva em azul corresponde à evolução do número de canais presentes na rede em função do tempo de chegada e a linha em vermelho é o limiar escolhido.

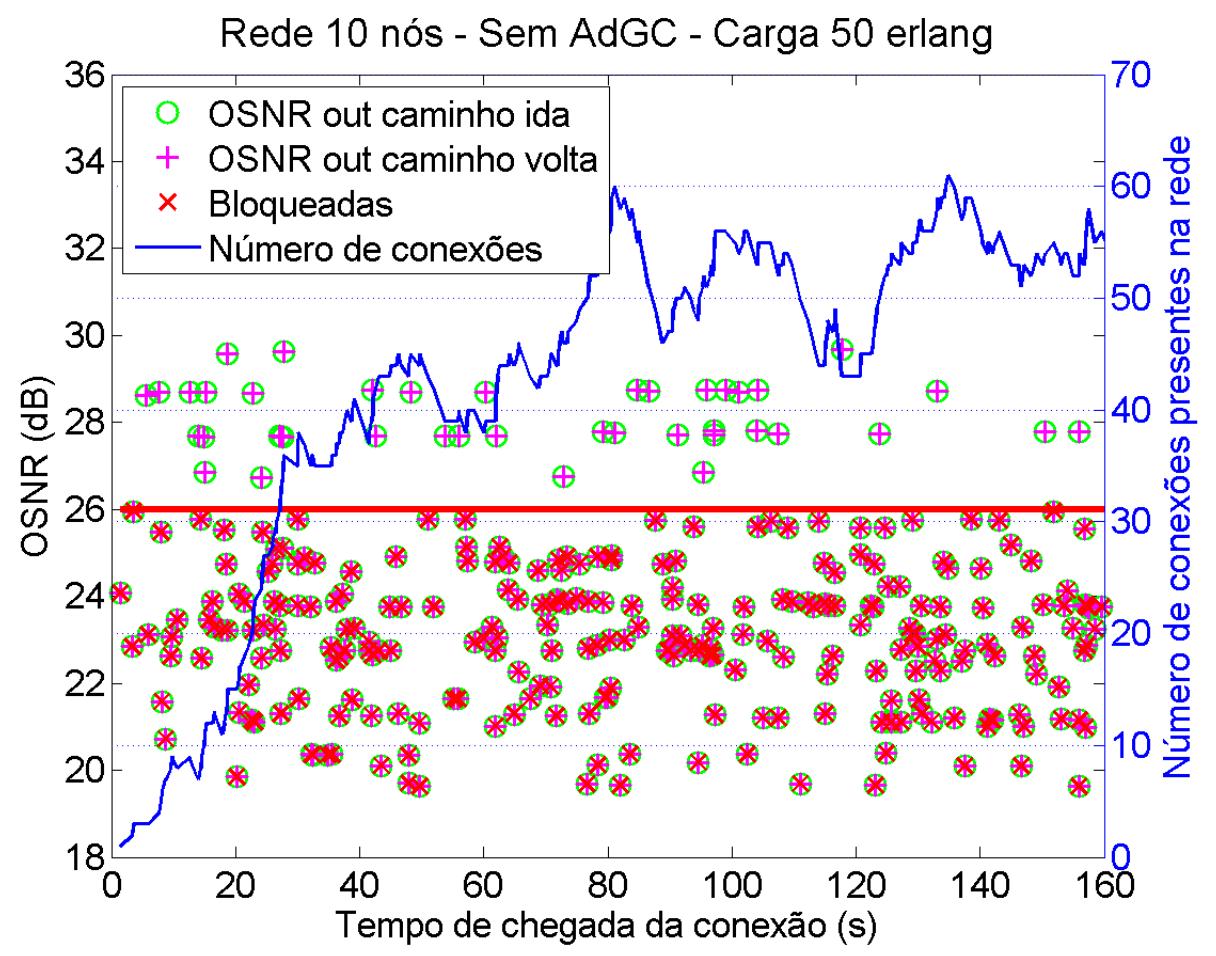

Figura C.5: OSNR na recepção de cada conexão para os caminhos de ida e volta para uma rede de dez nós sem AdGC e carga de 50 erlangs. Curva em azul corresponde à evolução do número de canais presentes na rede em função do tempo de chegada e a linha em vermelho é o limiar escolhido. 


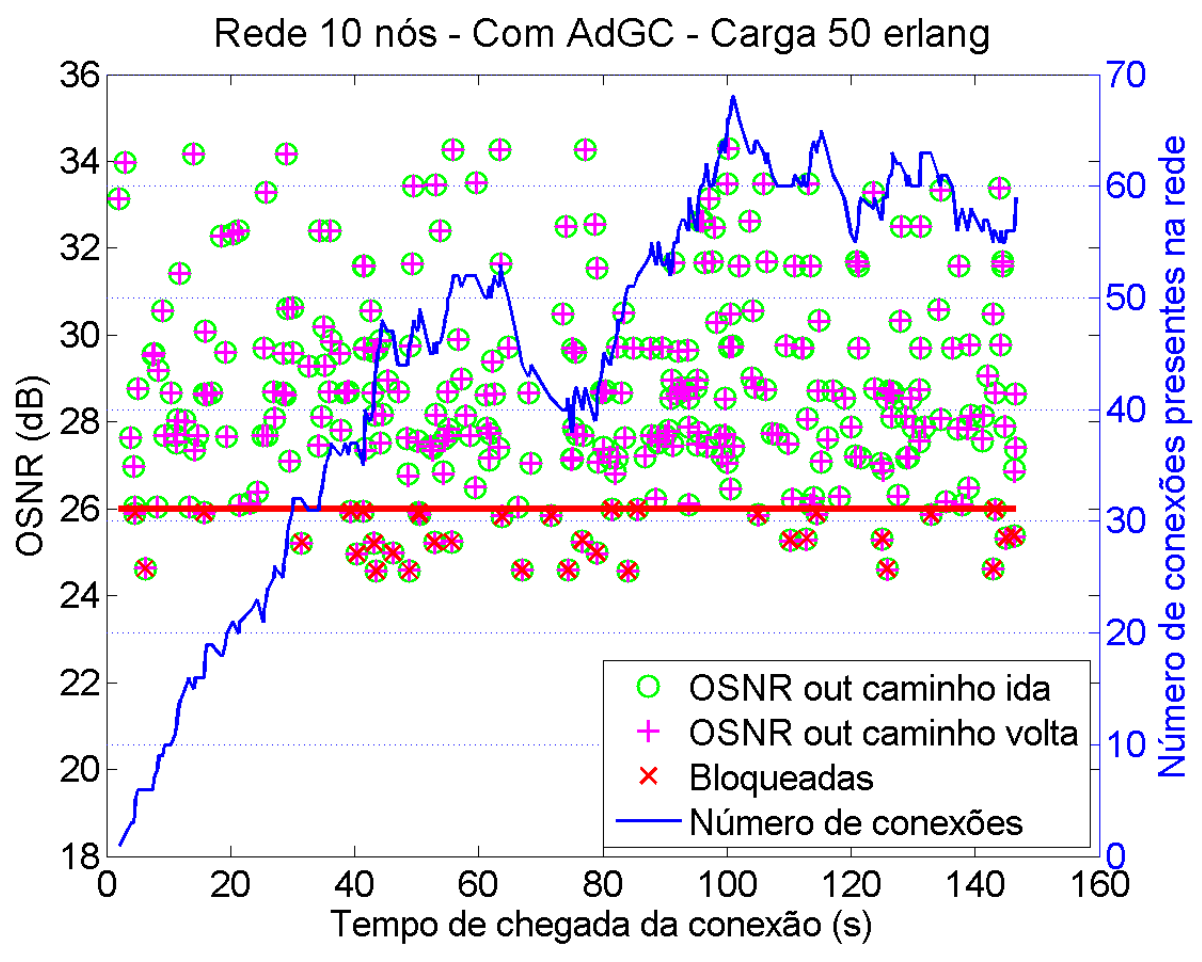

Figura C.6: OSNR na recepção de cada conexão para os caminhos de ida e volta para uma rede de dez nós com AdGC e carga de 50 erlangs. Curva em azul corresponde à evolução do número de canais presentes na rede em função do tempo de chegada e a linha em vermelho é o limiar escolhido.

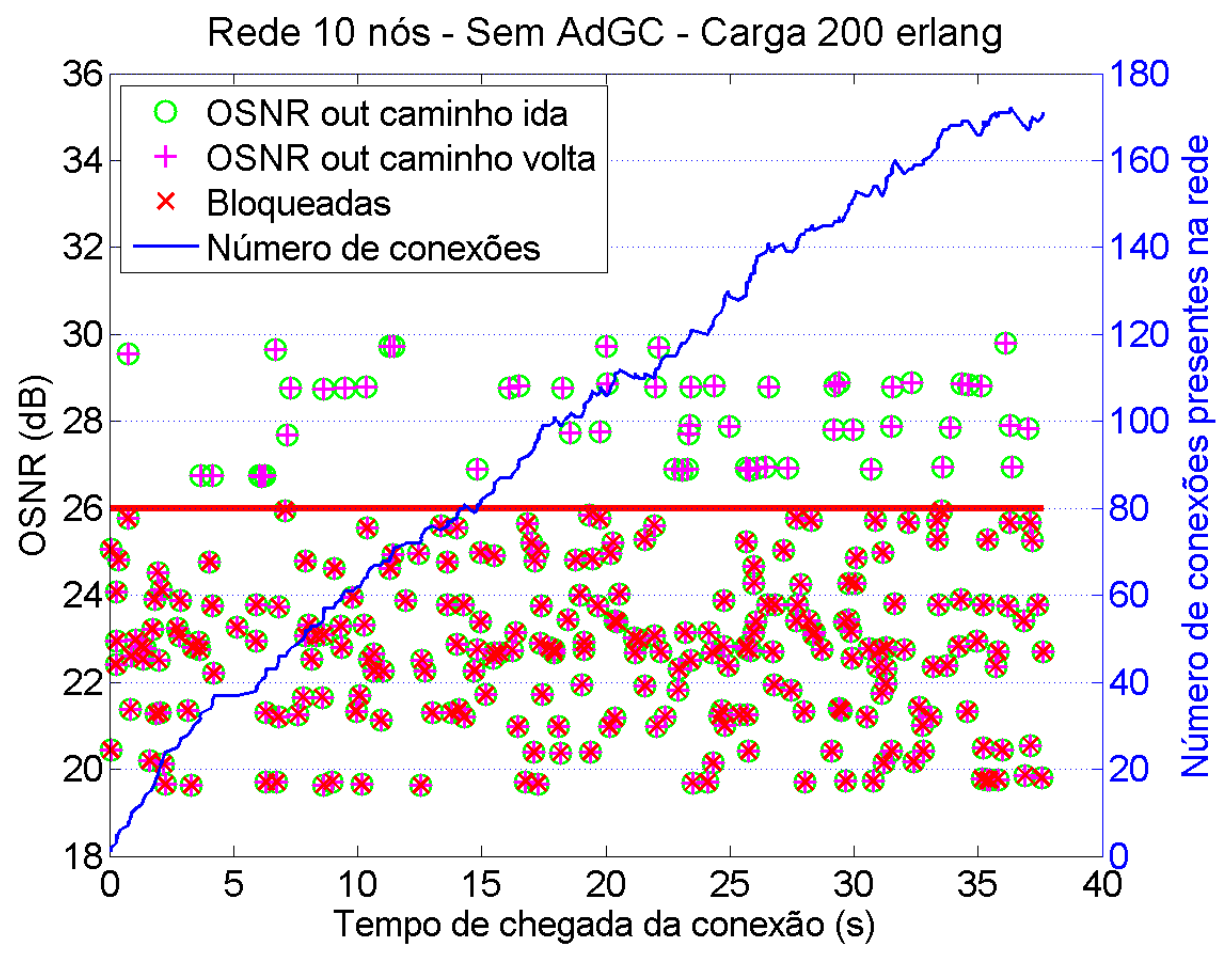

Figura C.7: OSNR na recepção de cada conexão para os caminhos de ida e volta para uma rede de dez nós sem AdGC e carga de 200 erlangs. Curva em azul corresponde à evolução do número de canais presentes na rede em função do tempo de chegada e a linha em vermelho é o limiar escolhido. 


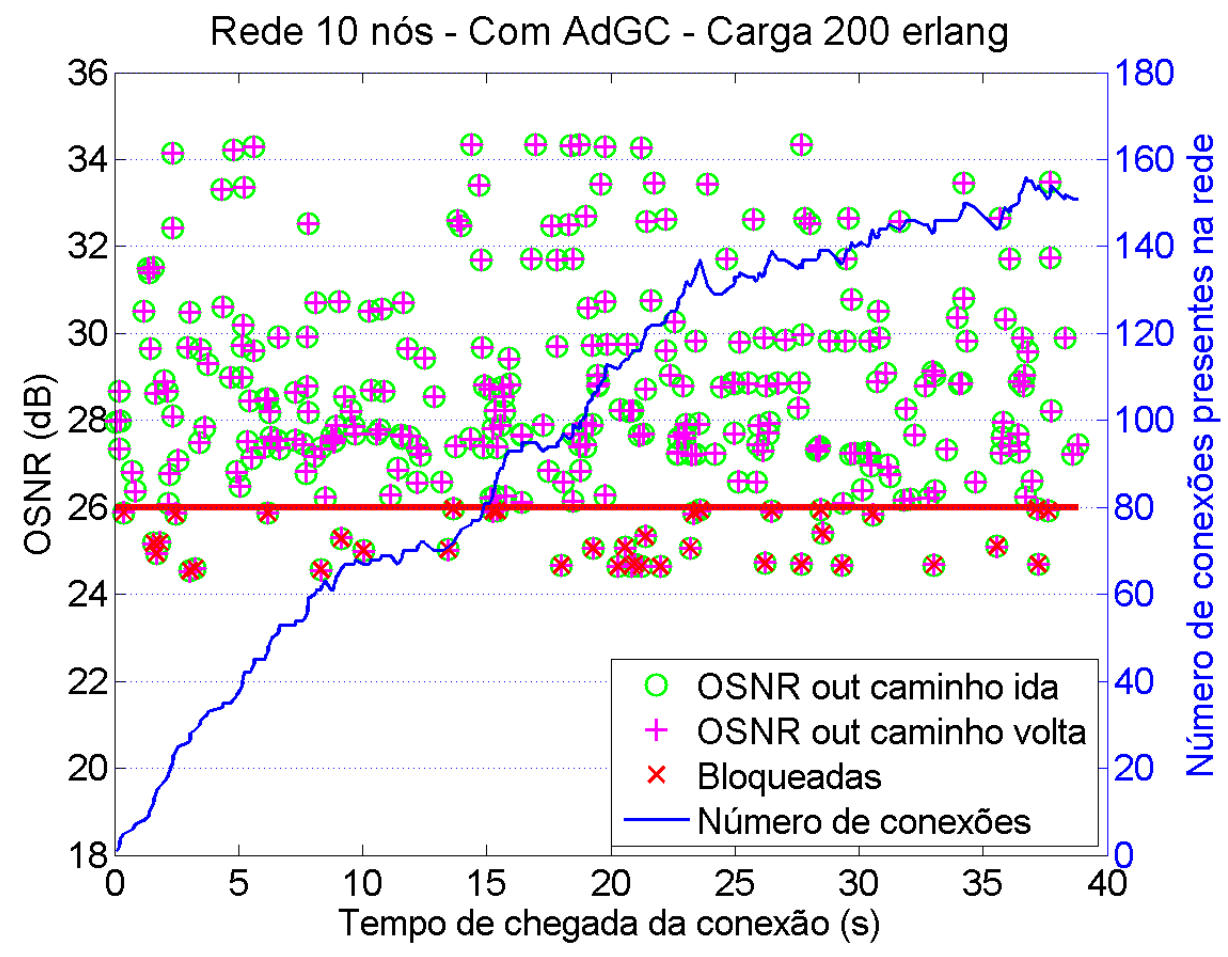

Figura C.8: OSNR na recepção de cada conexão para os caminhos de ida e volta para uma rede de dez nós com AdGC e carga de 200 erlangs. Curva em azul corresponde à evolução do número de canais presentes na rede em função do tempo de chegada e a linha em vermelho é o limiar escolhido. 
APÊNDICE D

\section{Figura de ruído por conexão}

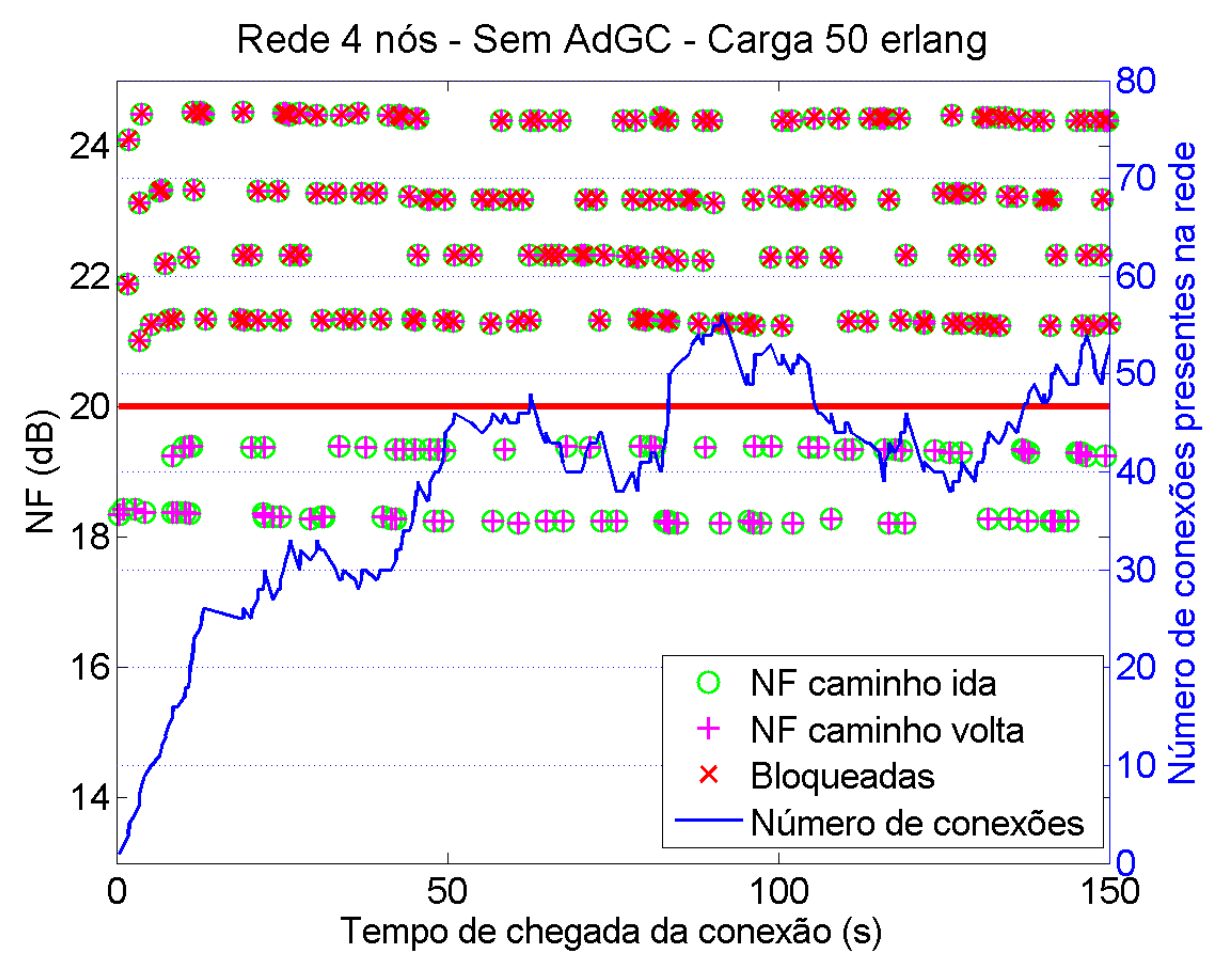

Figura D.1: Figura de ruído de cada conexão para os caminhos de ida e volta para uma rede de quatro nós sem AdGC e carga de 50 erlangs. Curva em azul corresponde à evolução do número de canais presentes na rede em função do tempo de chegada e a linha em vermelho é o limiar escolhido. 


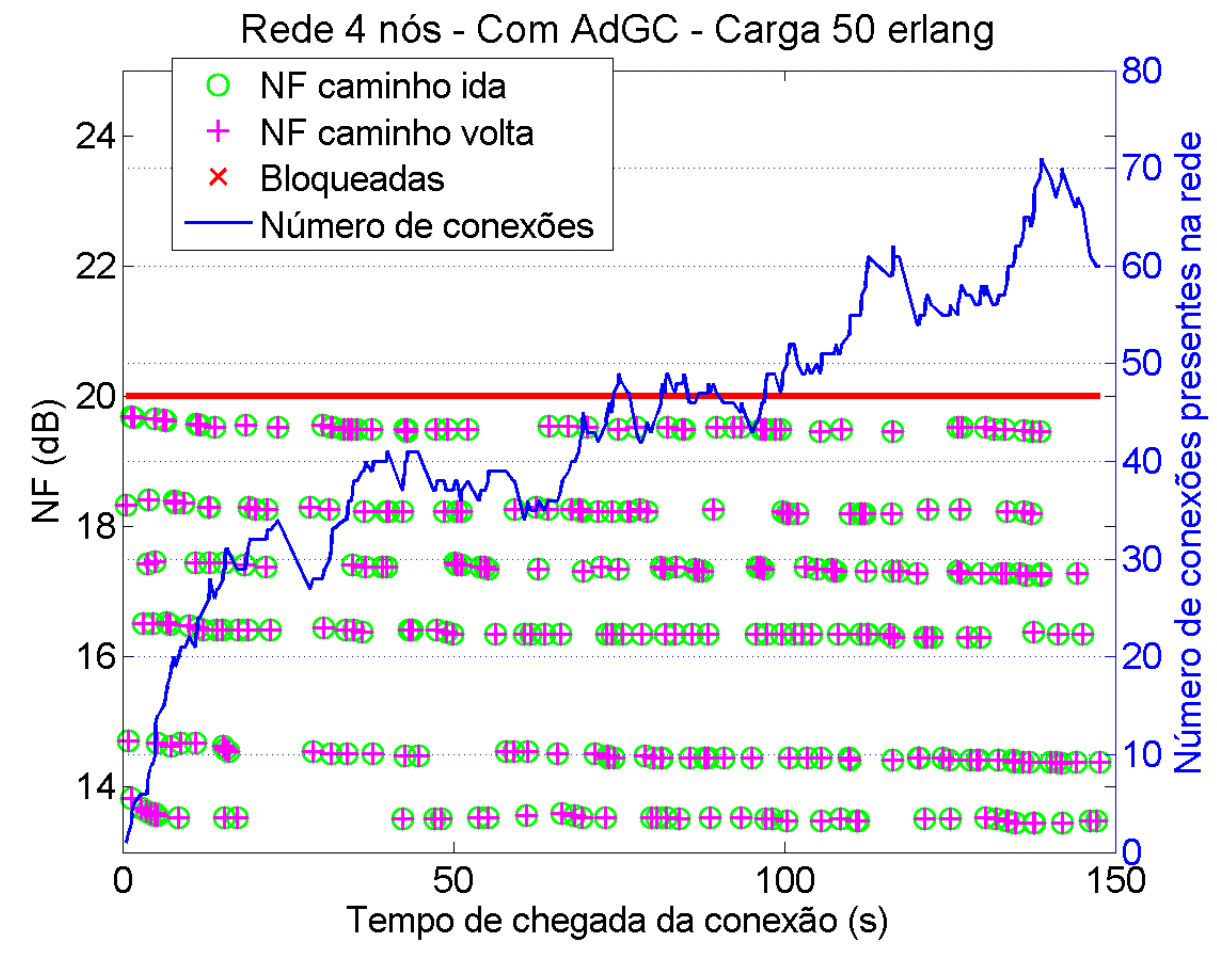

Figura D.2: Figura de ruído de cada conexão para os caminhos de ida e volta para uma rede de quatro nós com AdGC e carga de 50 erlangs. Curva em azul corresponde à evolução do número de canais presentes na rede em função do tempo de chegada e a linha em vermelho é o limiar escolhido.

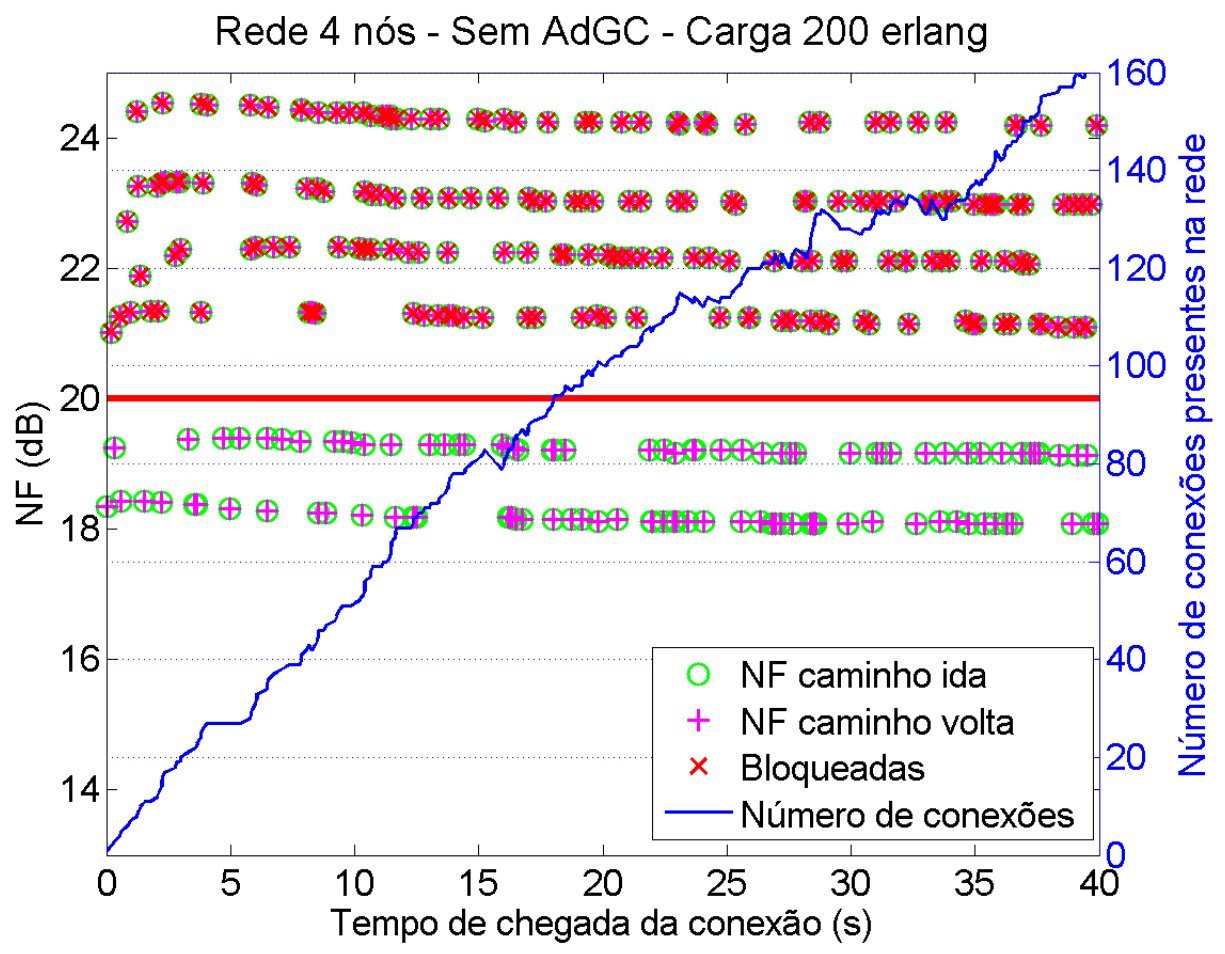

Figura D.3: Figura de ruído de cada conexão para os caminhos de ida e volta para uma rede de quatro nós sem AdGC e carga de 200 erlangs. Curva em azul corresponde à evolução do número de canais presentes na rede em função do tempo de chegada e a linha em vermelho é o limiar escolhido. 


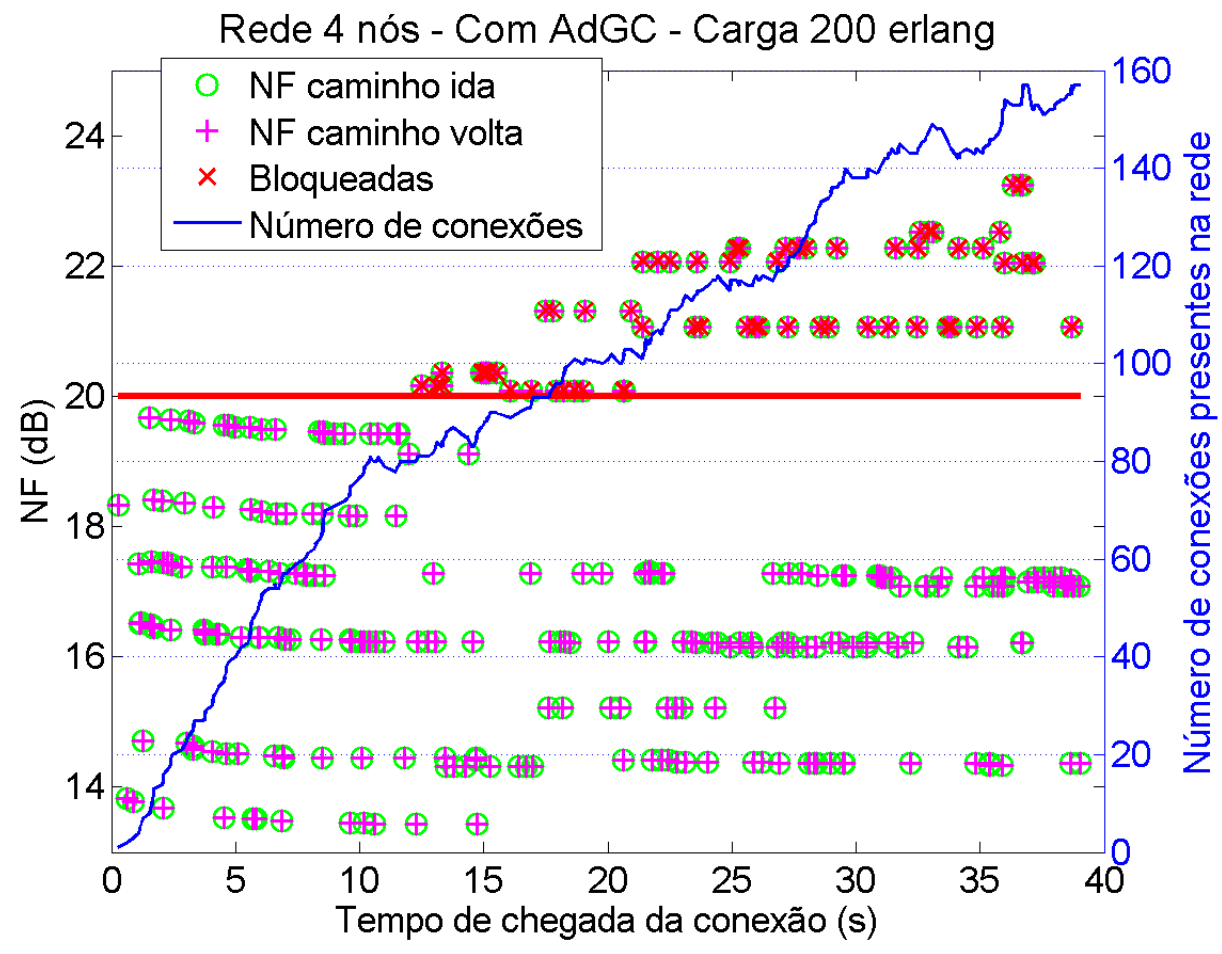

Figura D.4: Figura de ruído de cada conexão para os caminhos de ida e volta para uma rede de quatro nós com AdGC e carga de 200 erlangs. Curva em azul corresponde à evolução do número de canais presentes na rede em função do tempo de chegada e a linha em vermelho é o limiar escolhido.

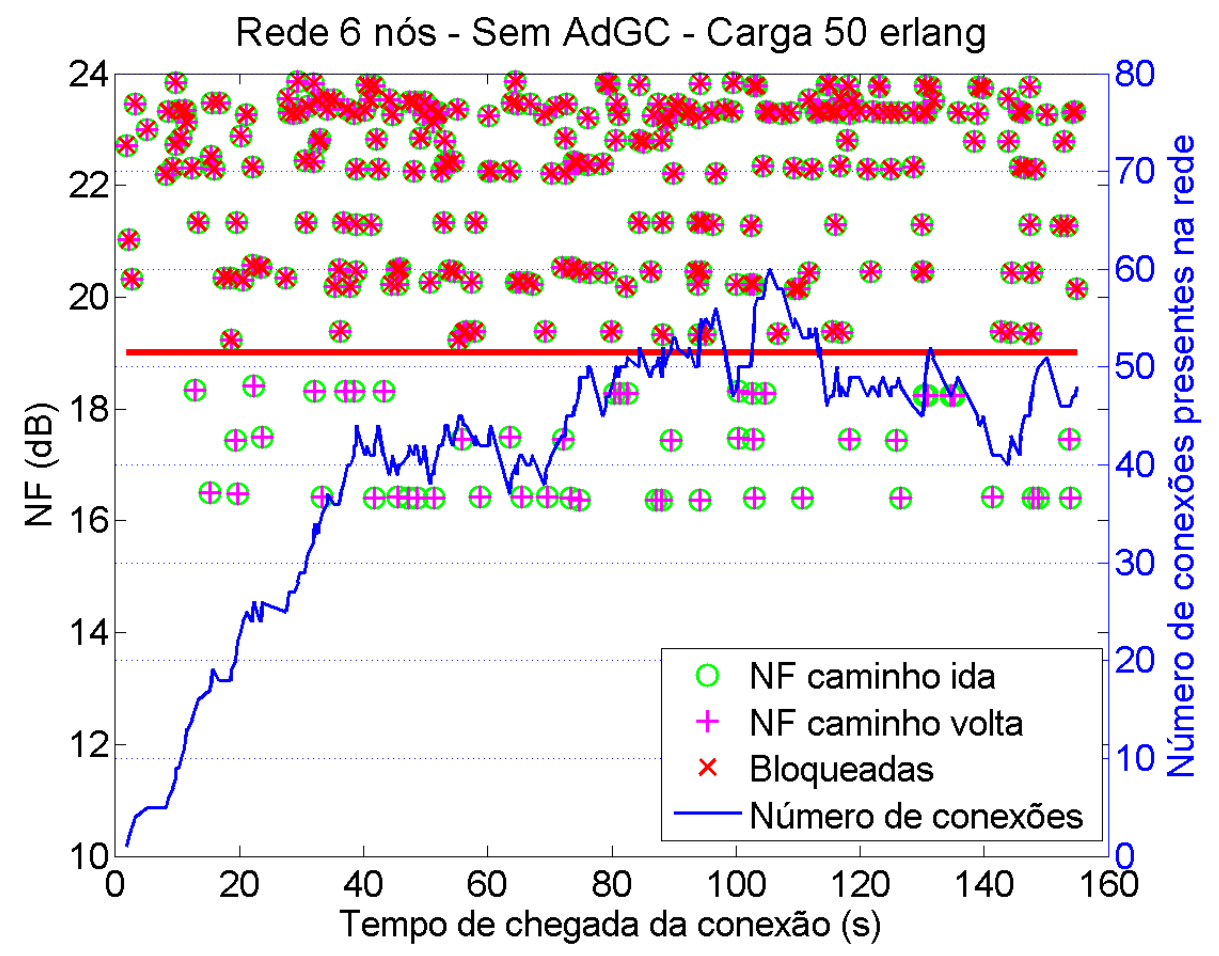

Figura D.5: Figura de ruído de cada conexão na saída dos caminhos de ida e volta para uma rede de seis nós sem AdGC e carga de 50 erlangs. Curva em azul corresponde à evolução do número de canais presentes na rede em função do tempo de chegada e a linha em vermelho é o limiar escolhido. 


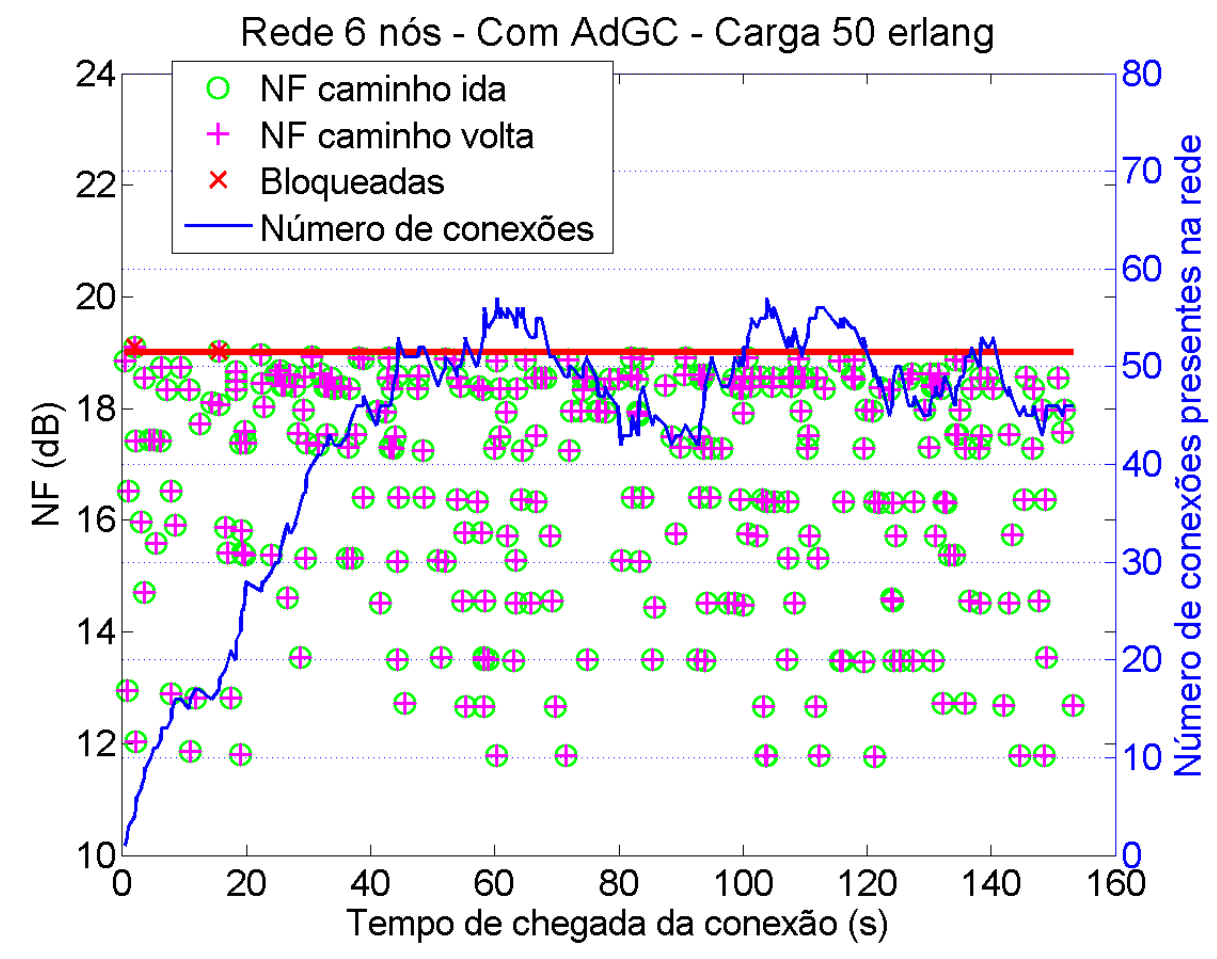

Figura D.6: Figura de ruído de cada conexão na saída dos caminhos de ida e volta para uma rede de seis nós co AdGC e carga de 50 erlangs. Curva em azul corresponde à evolução do número de canais presentes na rede em função do tempo de chegada e a linha em vermelho é o limiar escolhido.

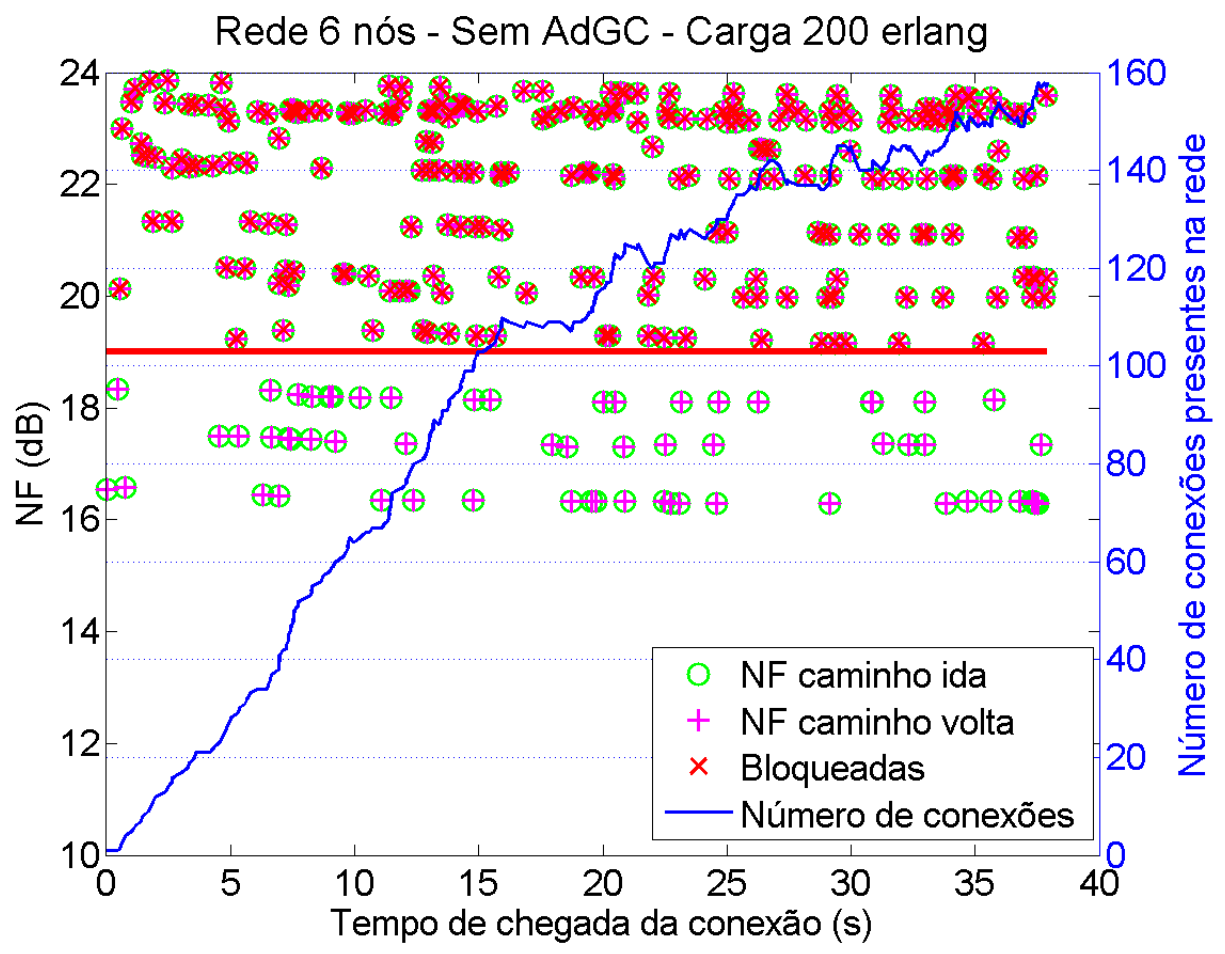

Figura D.7: Figura de ruído de cada conexão na saída dos caminhos de ida e volta para uma rede de seis nós sem AdGC e carga de 200 erlangs. Curva em azul corresponde à evolução do número de canais presentes na rede em função do tempo de chegada e a linha em vermelho é o limiar escolhido. 


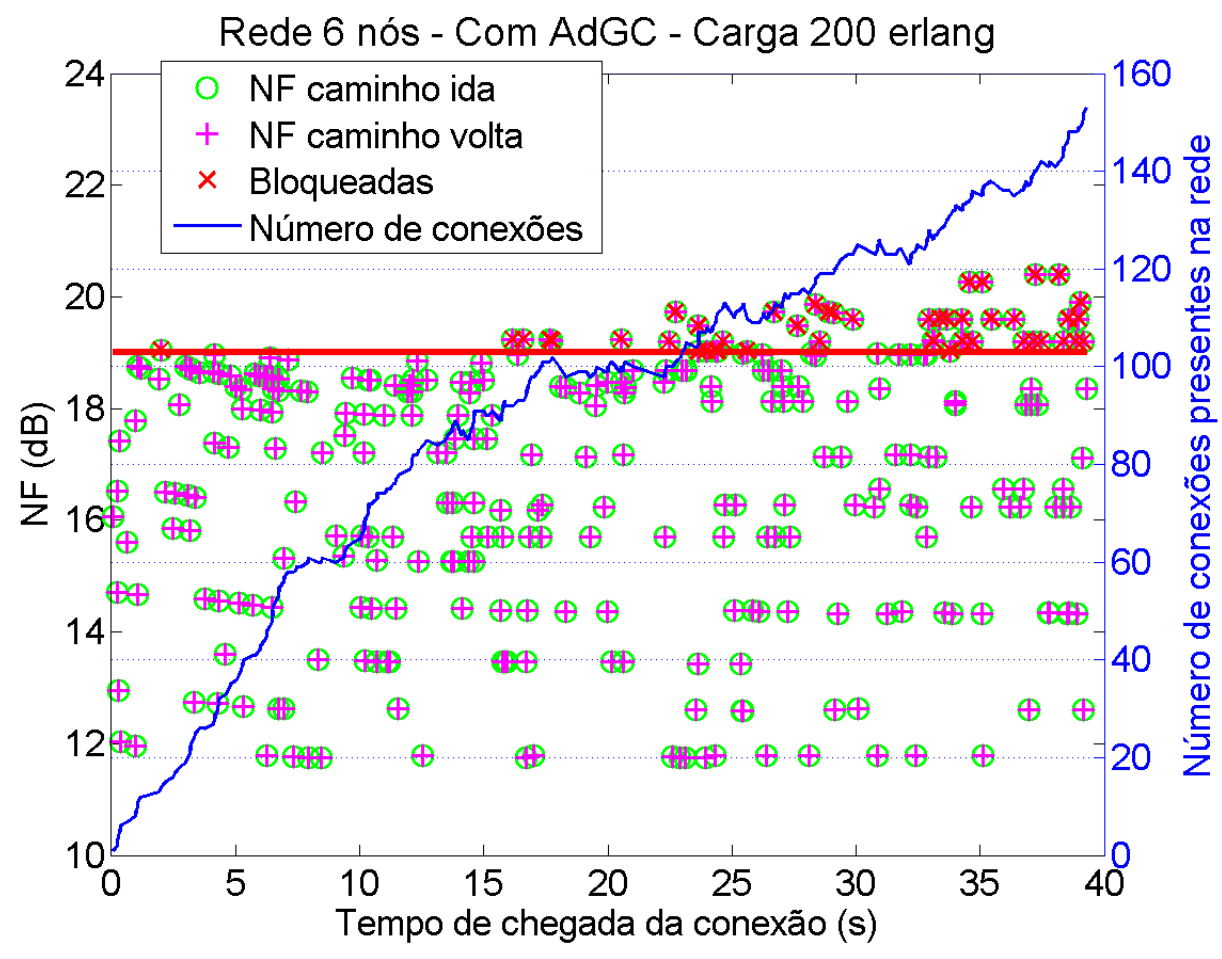

Figura D.8: Figura de ruído de cada conexão na saída dos caminhos de ida e volta para uma rede de seis nós com AdGC e carga de 200 erlangs. Curva em azul corresponde à evolução do número de canais presentes na rede em função do tempo de chegada e a linha em vermelho é o limiar escolhido.

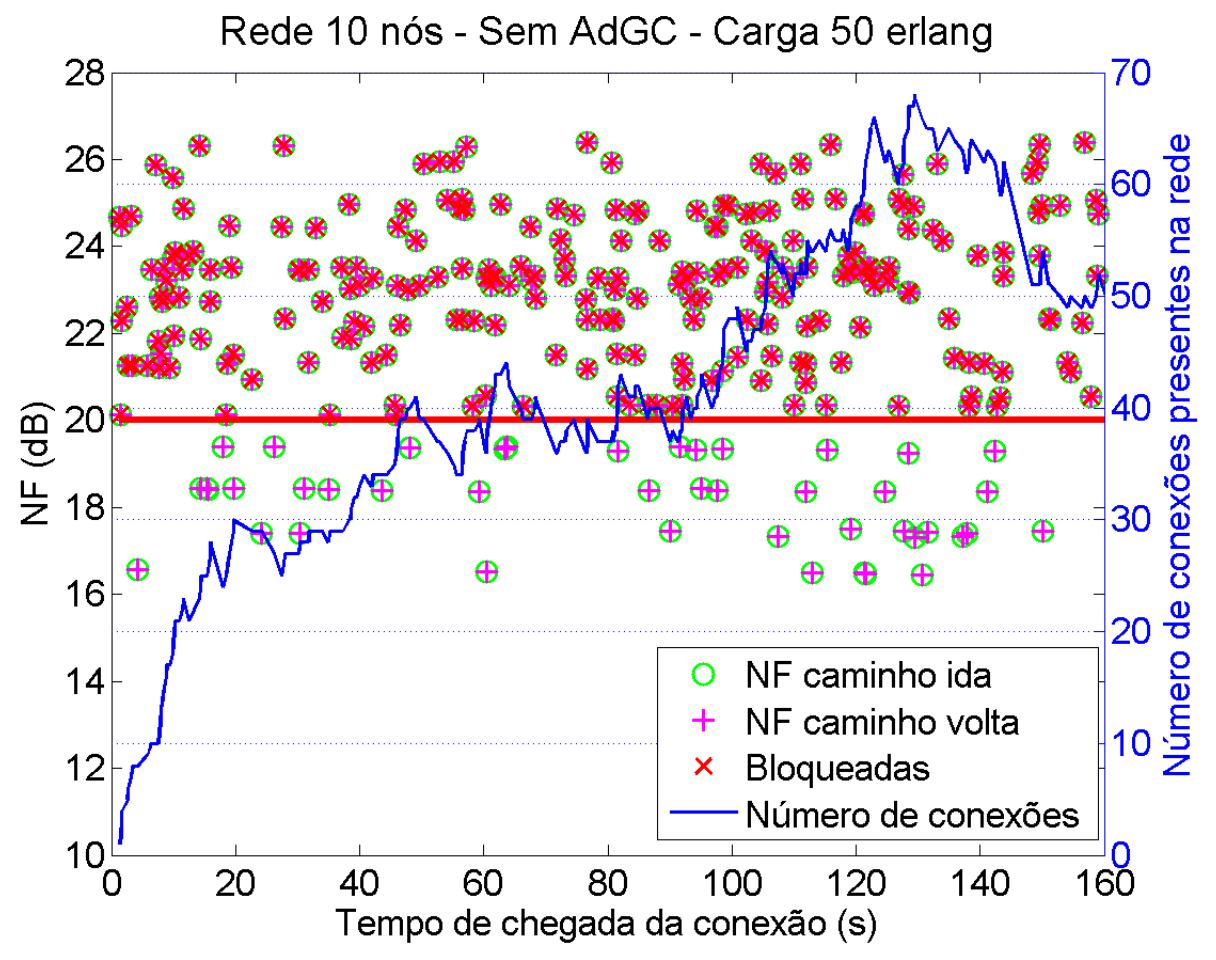

Figura D.9: Figura de ruído de cada conexão para os caminhos de ida e volta para uma rede de dez nós sem AdGC e carga de 50 erlangs. Curva em azul corresponde à evolução do número de canais presentes na rede em função do tempo de chegada e a linha em vermelho é o limiar escolhido. 


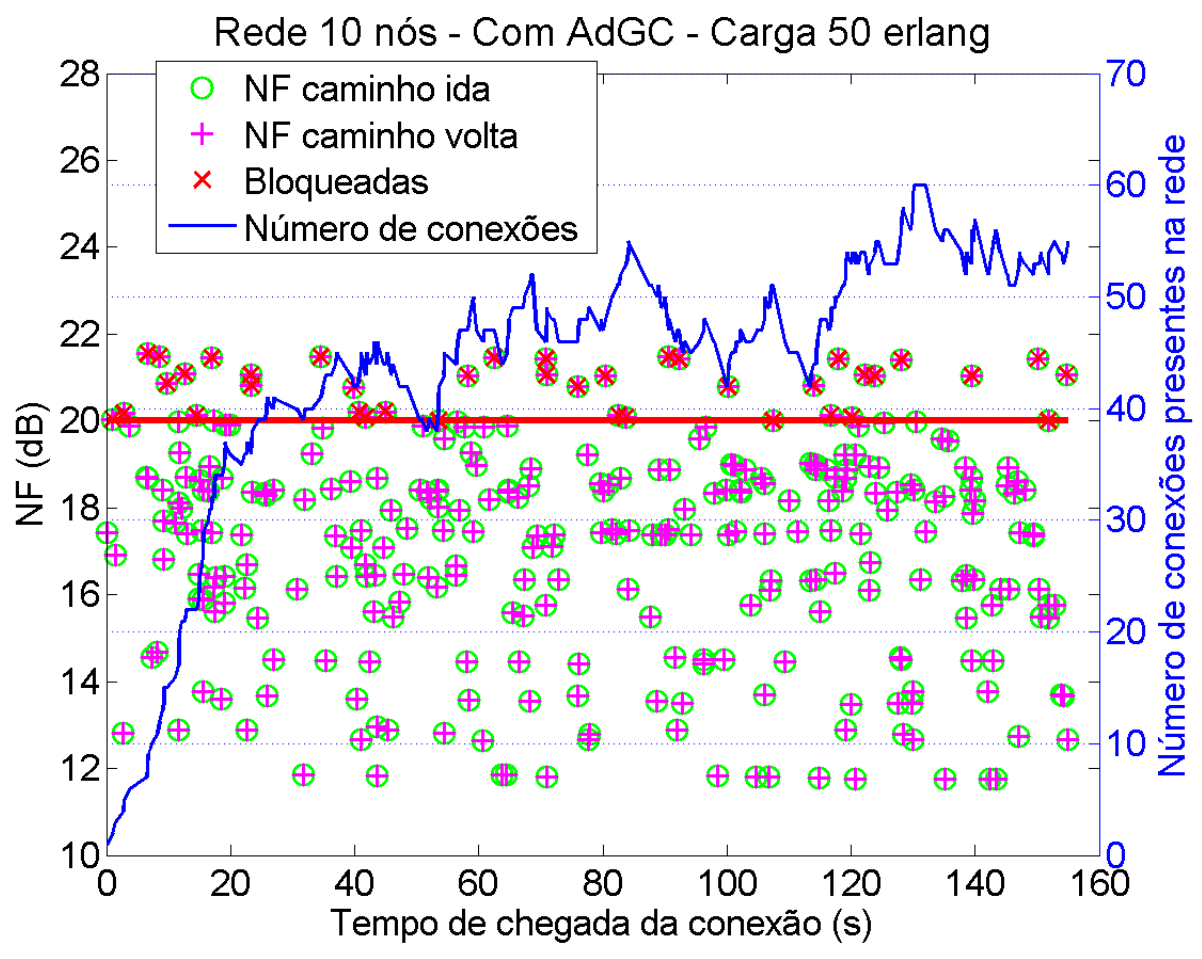

Figura D.10: Figura de ruído de cada conexão para os caminhos de ida e volta para uma rede de dez nós com AdGC e carga de 50 erlangs. Curva em azul corresponde à evolução do número de canais presentes na rede em função do tempo de chegada e a linha em vermelho é o limiar escolhido.

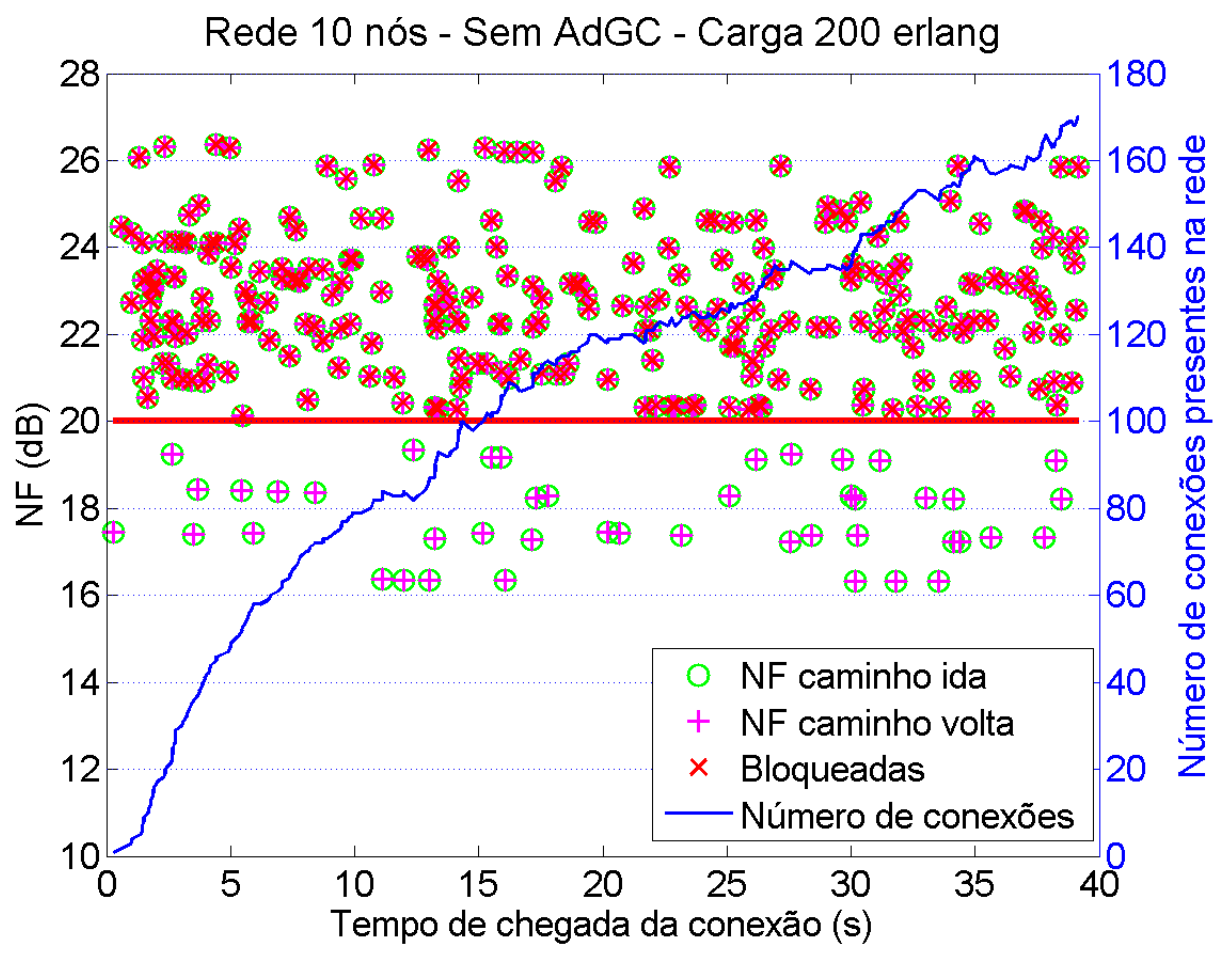

Figura D.11: Figura de ruído de cada conexão para os caminhos de ida e volta para uma rede de dez nós sem AdGC e carga de 200 erlangs. Curva em azul corresponde à evolução do número de canais presentes na rede em função do tempo de chegada e a linha em vermelho é o limiar escolhido. 


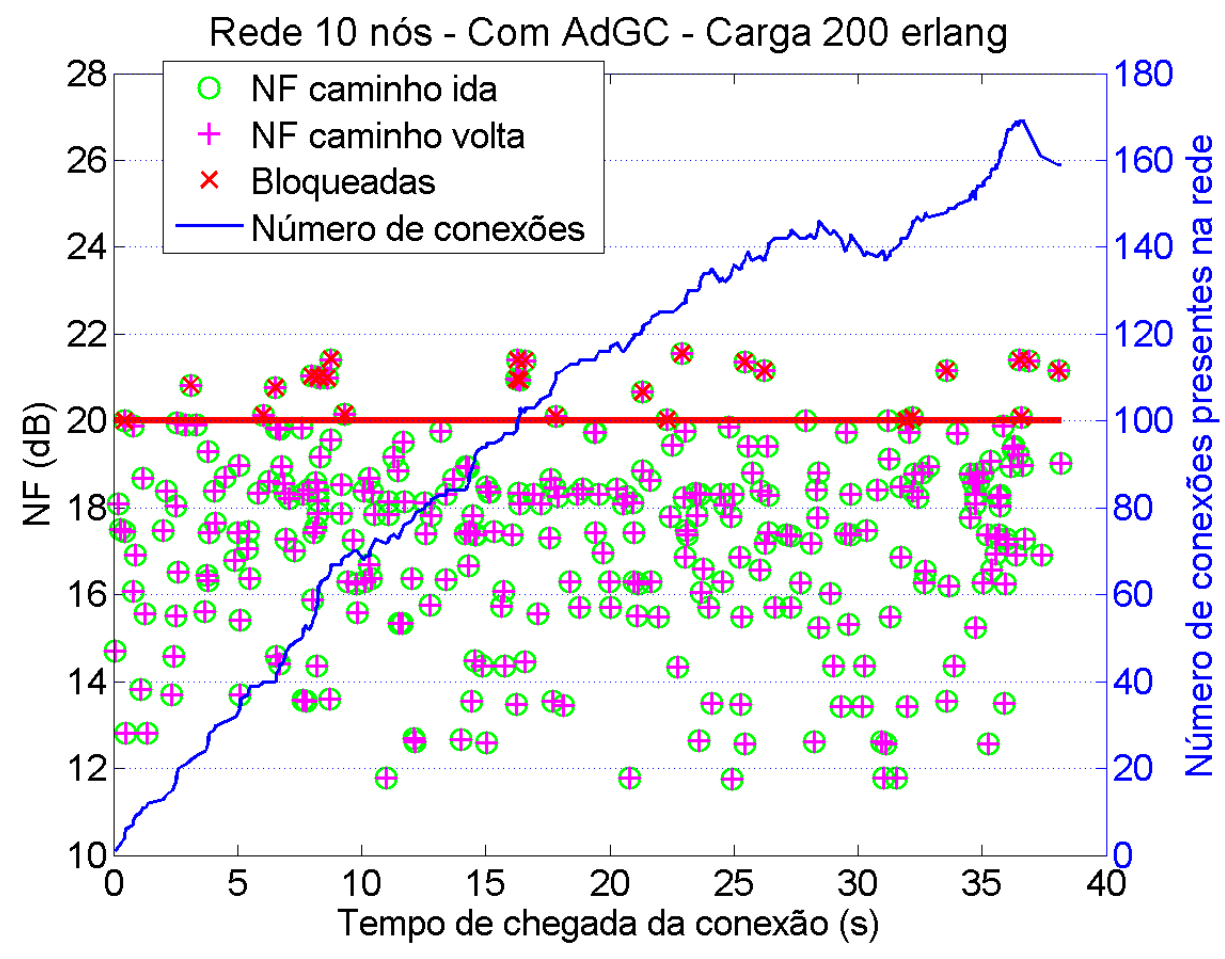

Figura D.12: Figura de ruído de cada conexão para os caminhos de ida e volta para uma rede de dez nós com AdGC e carga de 200 erlangs. Curva em azul corresponde à evolução do número de canais presentes na rede em função do tempo de chegada e a linha em vermelho é o limiar escolhido.

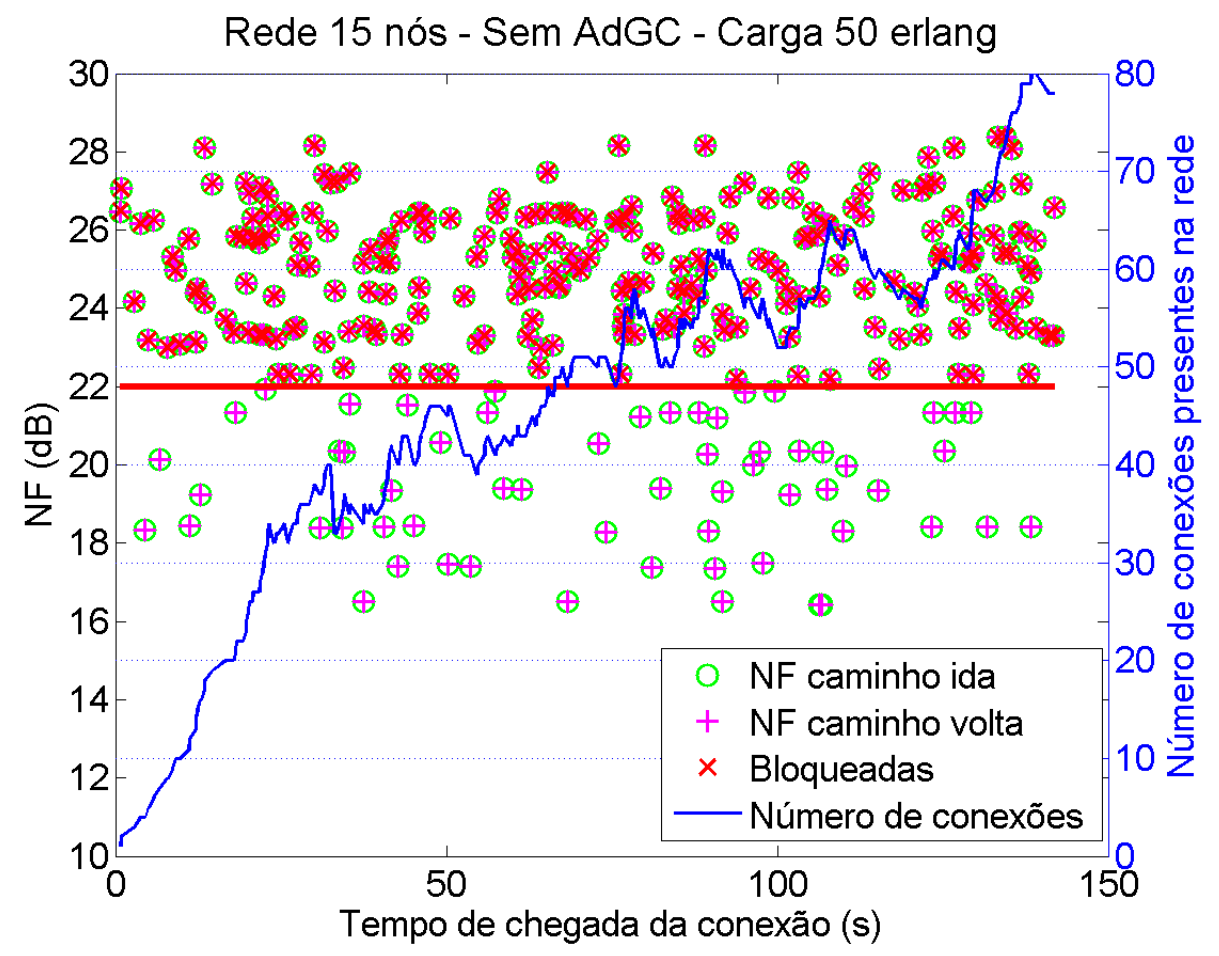

Figura D.13: Figura de ruído de cada conexão na saída dos caminhos de ida e volta para uma rede de quinze nós sem AdGC e carga de 50 erlangs. Curva em azul corresponde à evolução do número de canais presentes na rede em função do tempo de chegada e a linha em vermelho é o limiar escolhido. 


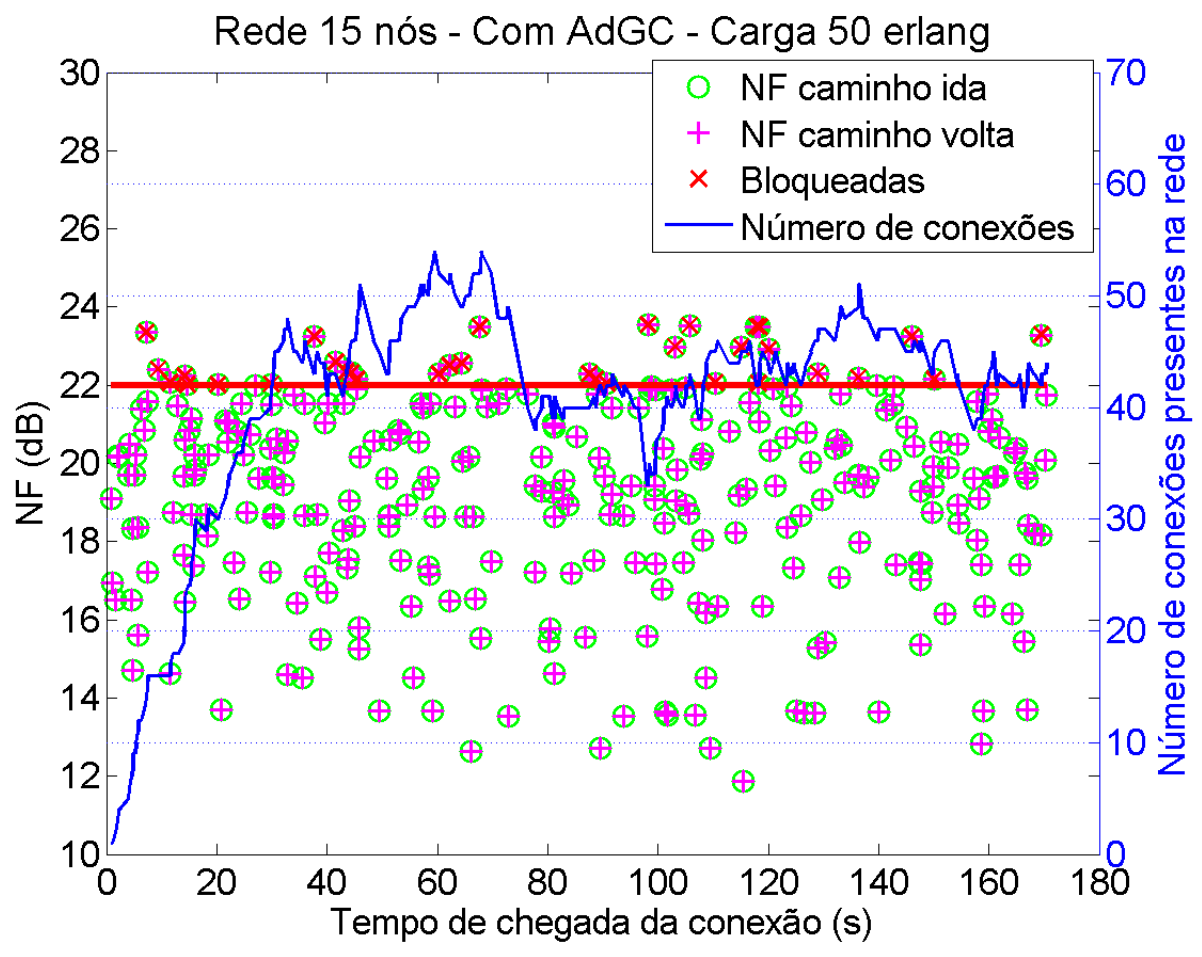

Figura D.14: Figura de ruído de cada conexão na saída dos caminhos de ida e volta para uma rede de quinze nós com AdGC e carga de 50 erlangs. Curva em azul corresponde à evolução do número de canais presentes na rede em função do tempo de chegada e a linha em vermelho é o limiar escolhido.

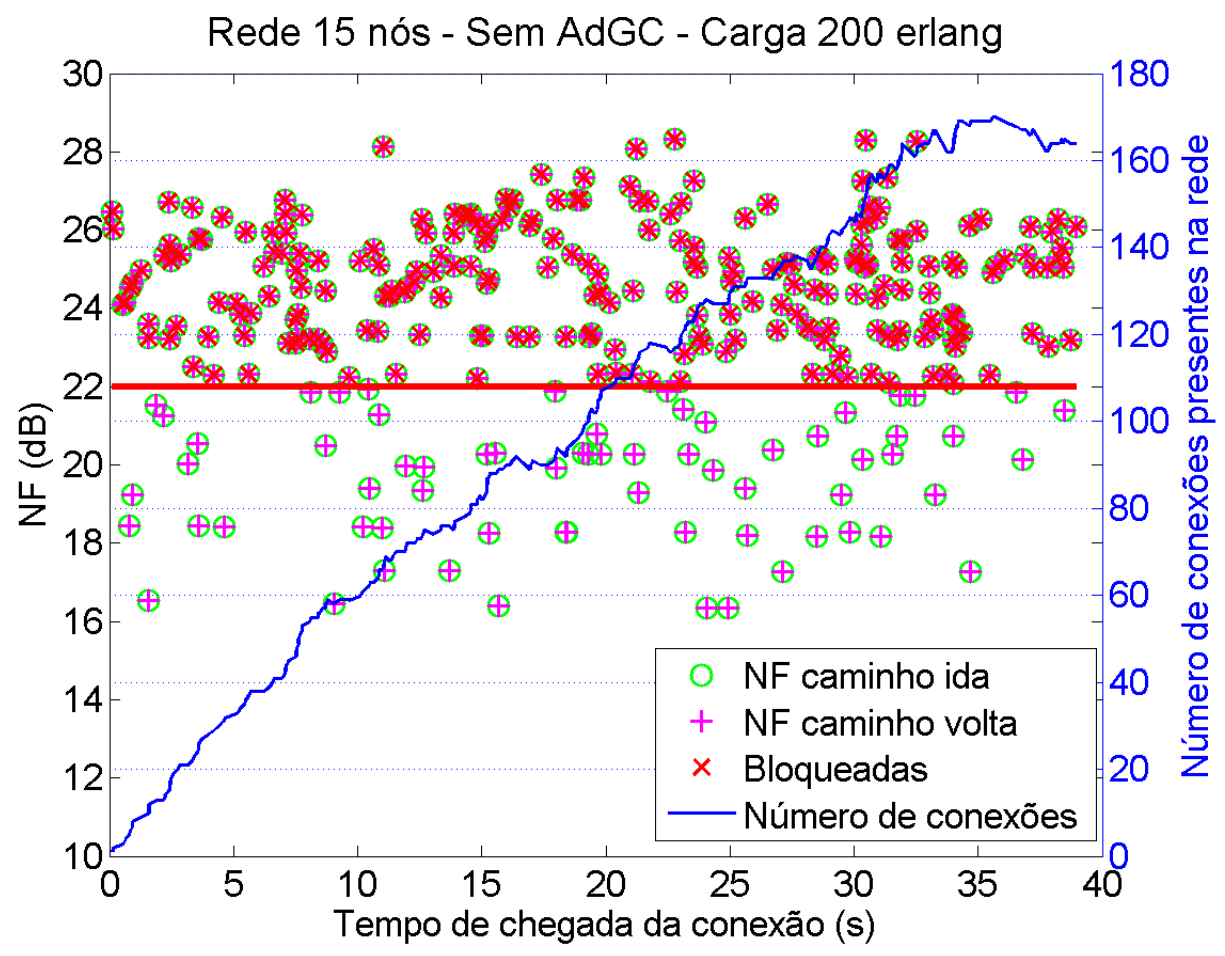

Figura D.15: Figura de ruído de cada conexão na saída dos caminhos de ida e volta para uma rede de quinze nós sem AdGC e carga de 200 erlangs. Curva em azul corresponde à evolução do número de canais presentes na rede em função do tempo de chegada e a linha em vermelho é o limiar escolhido. 


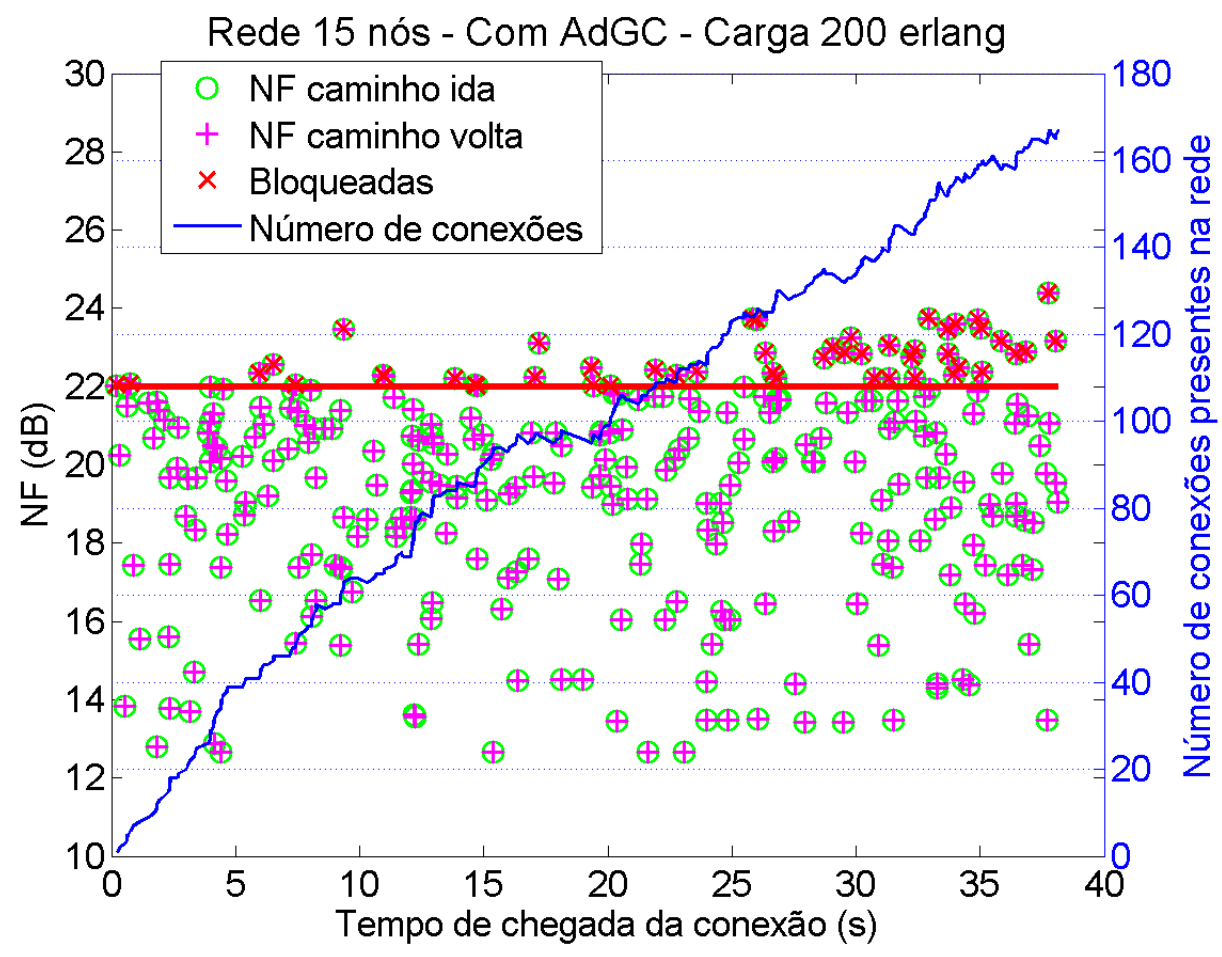

Figura D.16: Figura de ruído de cada conexão na saída dos caminhos de ida e volta para uma rede de quinze nós com AdGC e carga de 200 erlangs. Curva em azul corresponde à evolução do número de canais presentes na rede em função do tempo de chegada e a linha em vermelho é o limiar escolhido. 
APÊNDICE

\section{Probabilidade de bloqueio x carga com restrição de NF}

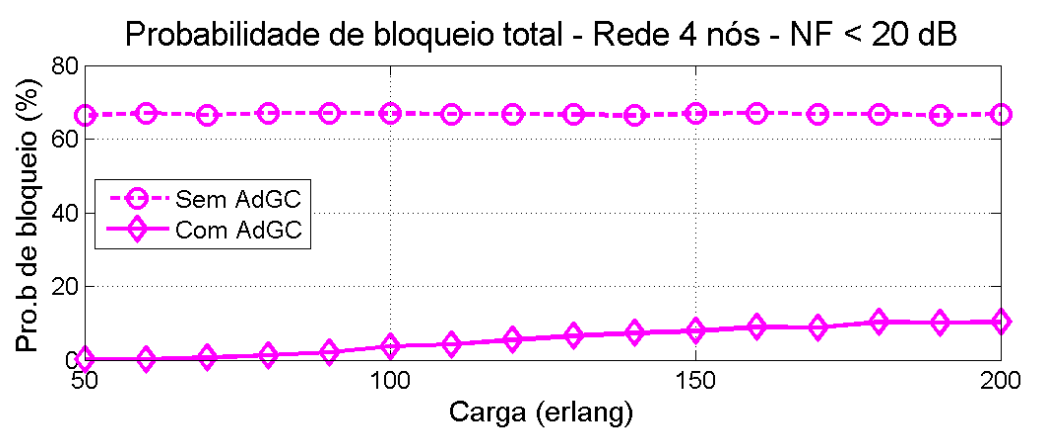

Figura E.1: Probabilidade de bloqueio versus carga para a topologia de quatro nós com restrição de NF (limiar de 20 dB).

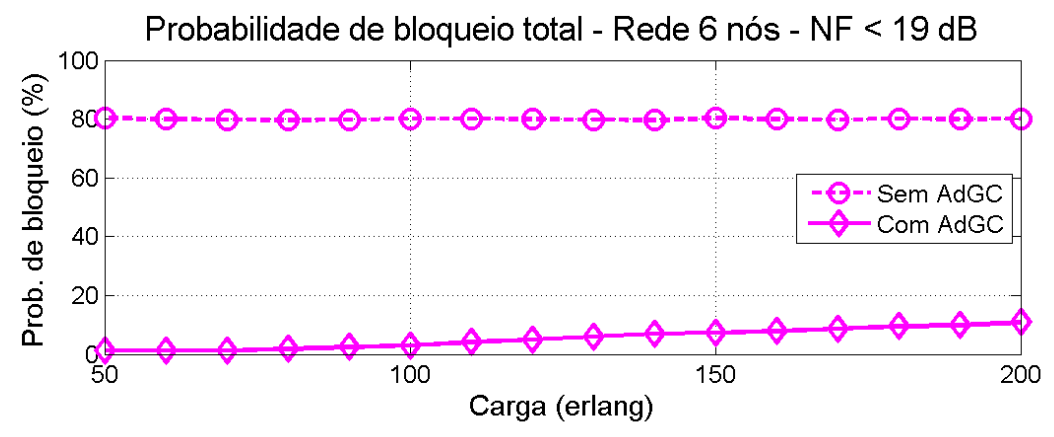

Figura E.2: Probabilidade de bloqueio total versus carga para a topologia de seis nós com restrição de NF (limiar de 19 dB). 


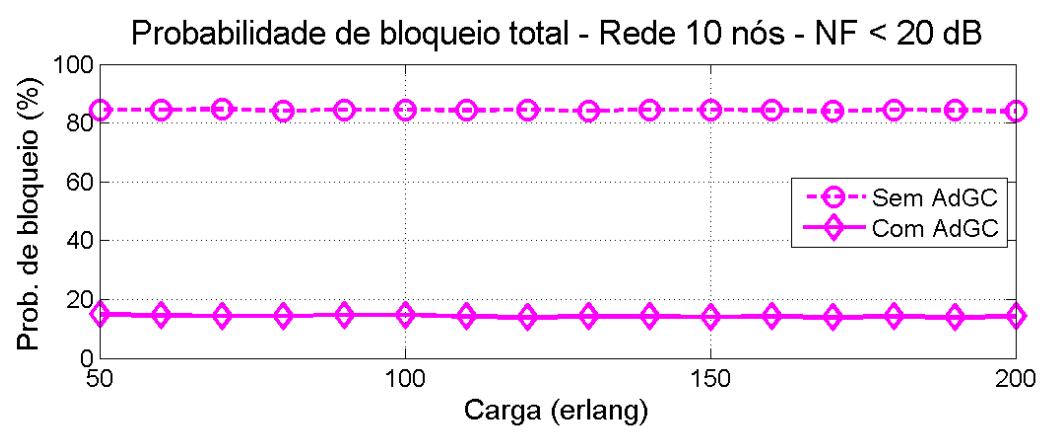

Figura E.3: Probabilidade de bloqueio total versus carga para a topologia de dez nós com restrição de NF (limiar de 20 dB).

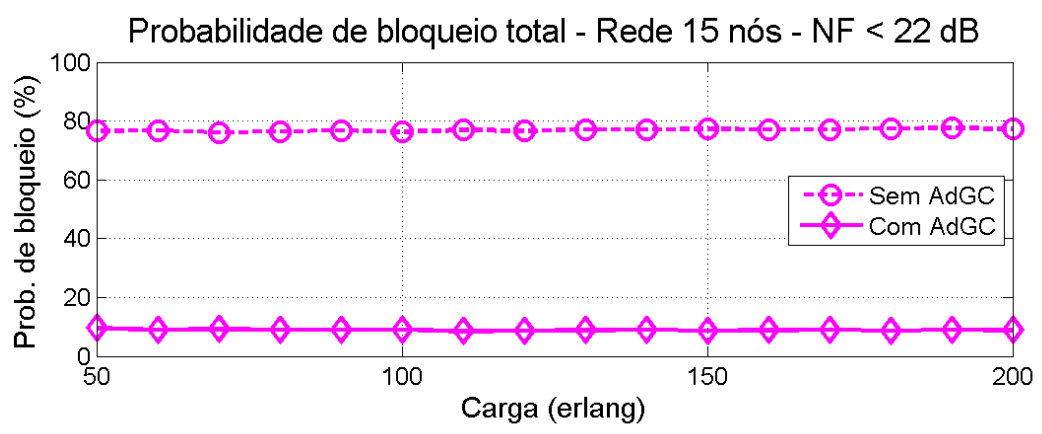

Figura E.4: Probabilidade de bloqueio total versus carga para a topologia de dez nós com restrição de NF (limiar de $22 \mathrm{~dB}$ ). 
APÊNDICE

\section{Probabilidade de bloqueio x carga com restrição de NF para rede com 20 canais}

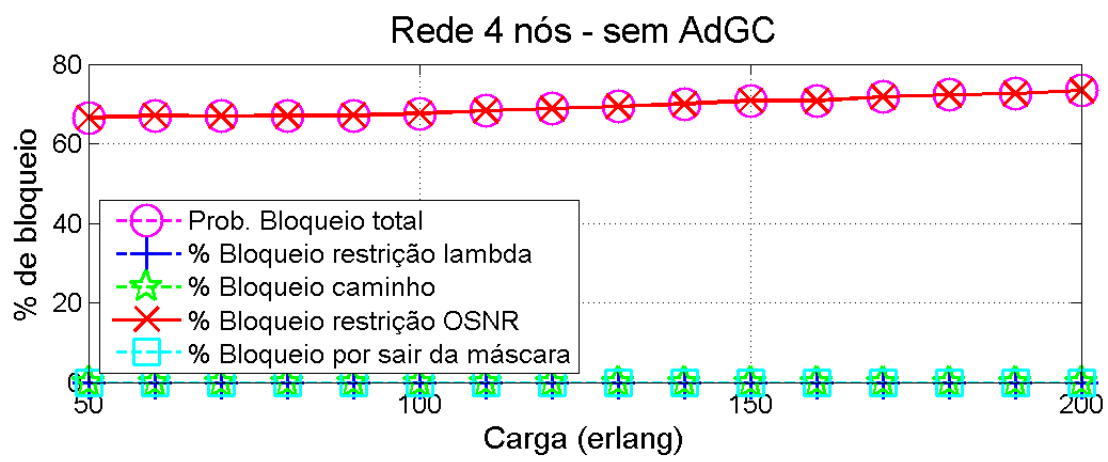

Rede 4 nós - com AdGC

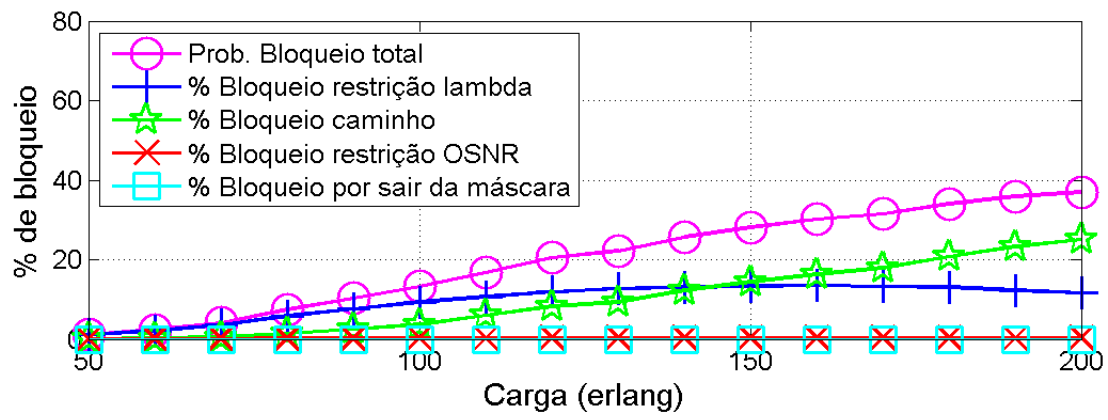

Figura F.1: Probabilidade de bloqueio total versus carga para a topologia de quatro nós com restrição de OSNR (limiar de $26 \mathrm{~dB}$ ) com 20 canais disponíveis na rede. 


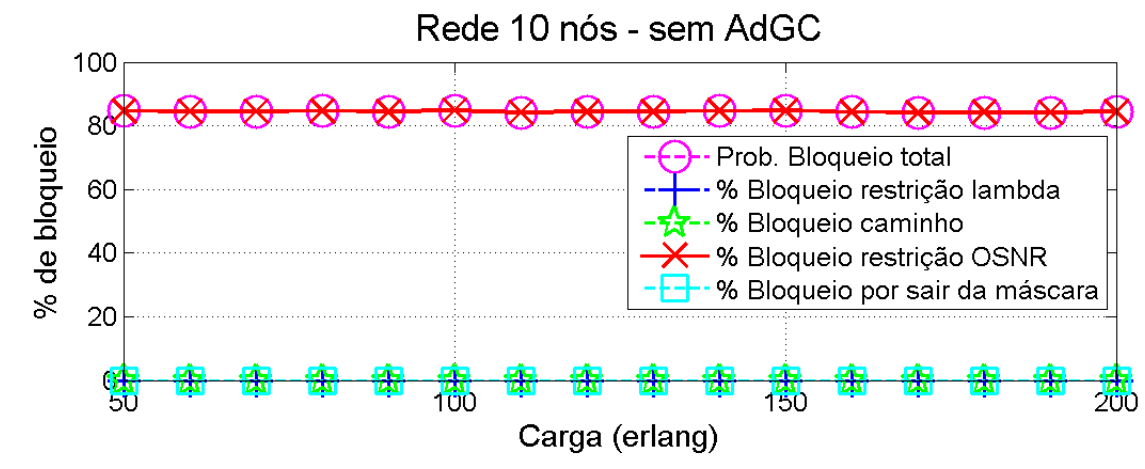

Rede 10 nós - com AdGC

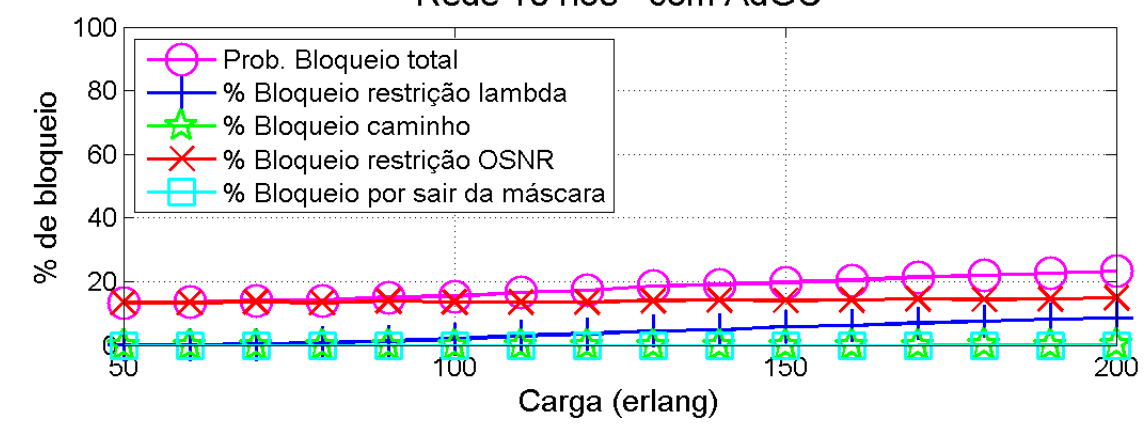

Figura F.2: Probabilidade de bloqueio total versus carga para a topologia de dez nós com restrição de OSNR (limiar de 26 dB) com 20 canais disponíveis na rede.

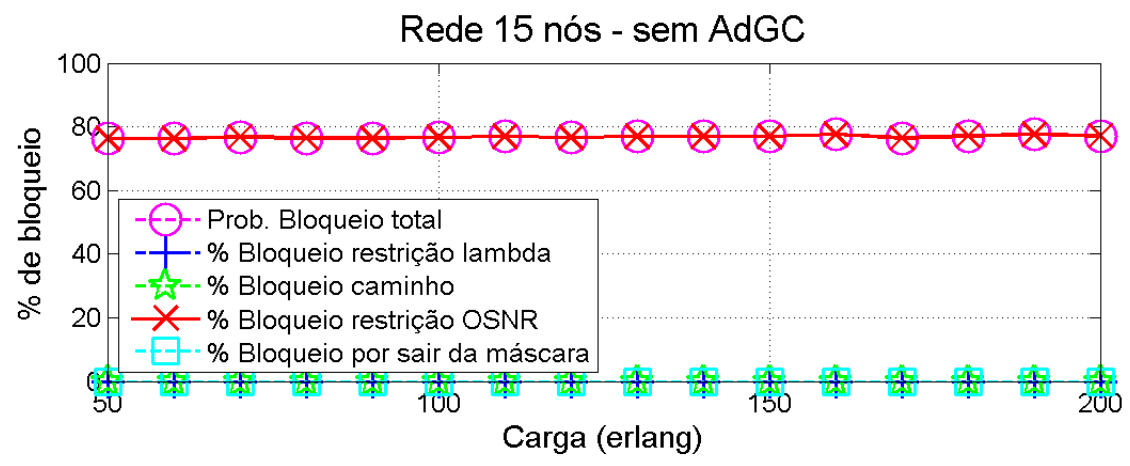

Rede 15 nós - com AdGC

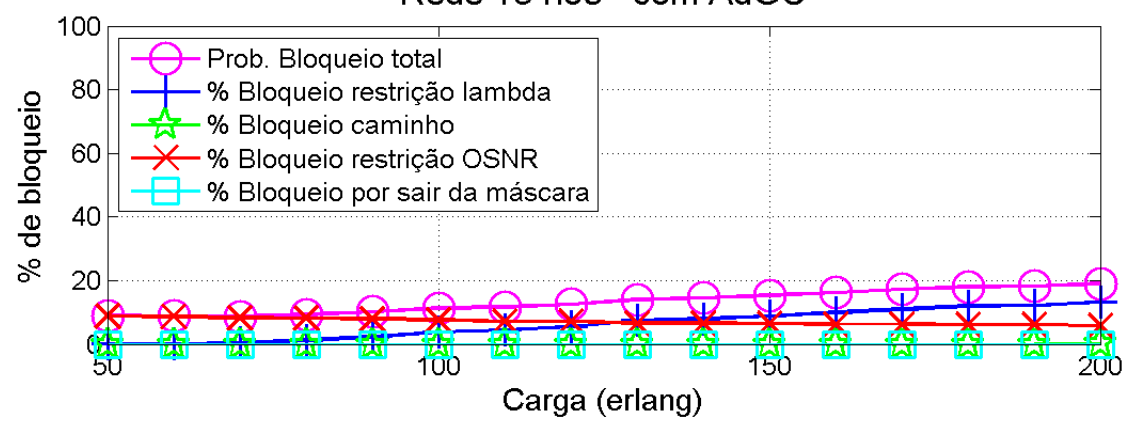

Figura F.3: Probabilidade de bloqueio total versus carga para a topologia de quinze nós com restrição de OSNR (limiar de $24 \mathrm{~dB}$ ) com 20 canais disponíveis na rede. 


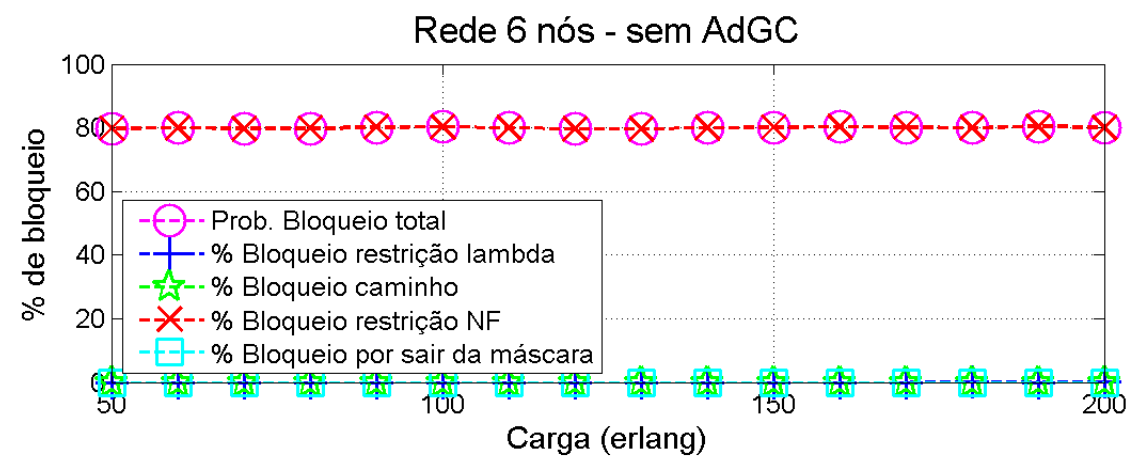

Rede 6 nós - com AdGC

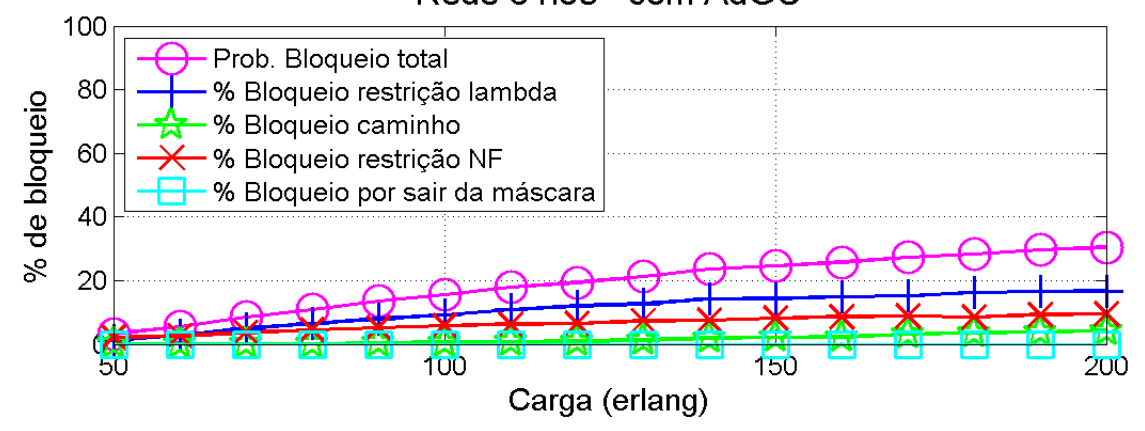

Figura F.4: Probabilidade de bloqueio total versus carga para a topologia de seis nós com restrição de NF (limiar de 19 dB) com 20 canais disponíveis na rede.

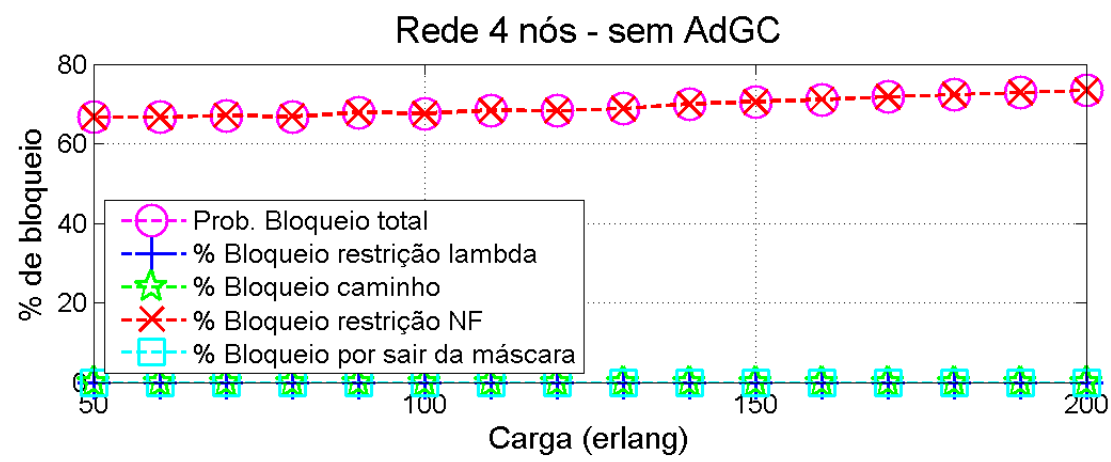

Rede 4 nós - com AdGC

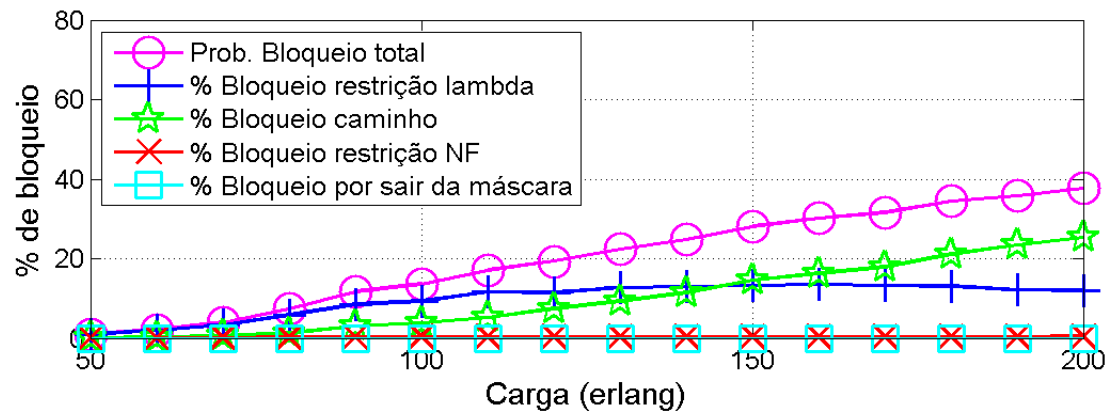

Figura F.5: Probabilidade de bloqueio total versus carga para a topologia de quatro nós com restrição de NF (limiar de 20 dB) com 20 canais disponíveis na rede. 


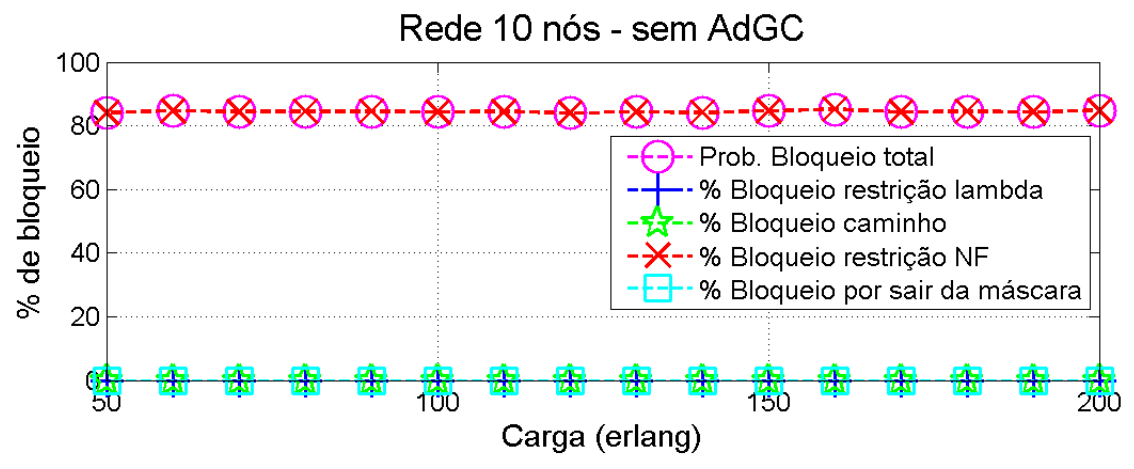

Rede 10 nós - com AdGC

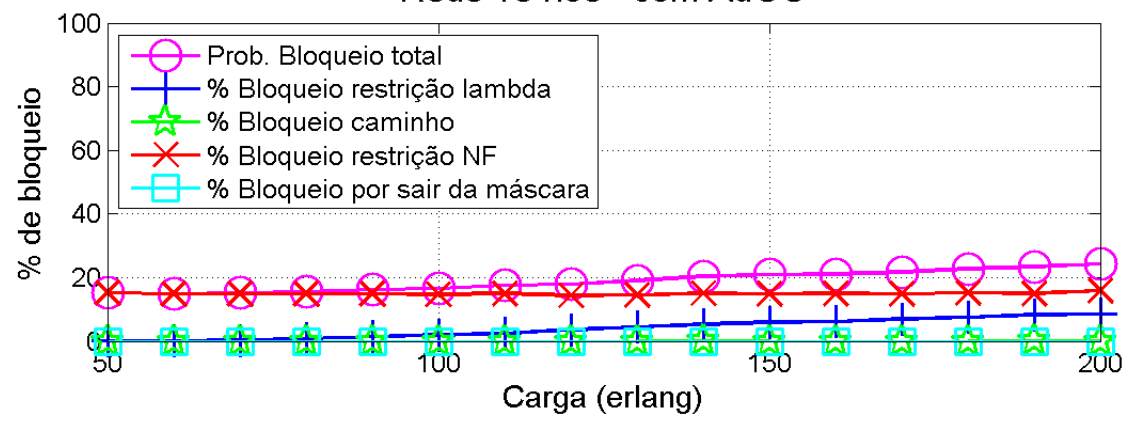

Figura F.6: Probabilidade de bloqueio total versus carga para a topologia de dez nós com restrição de NF (limiar de 20 dB) com 20 canais disponíveis na rede.

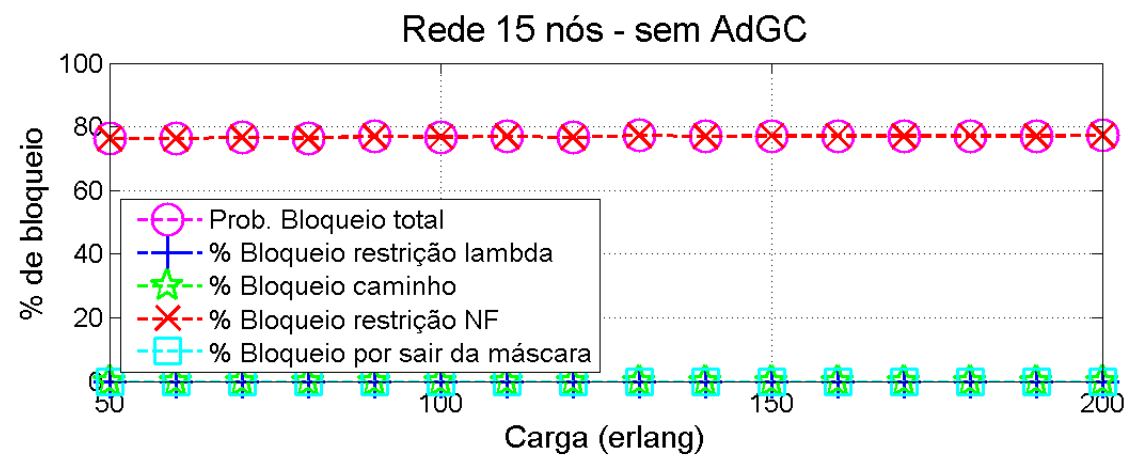

\section{Rede 15 nós - com AdGC}

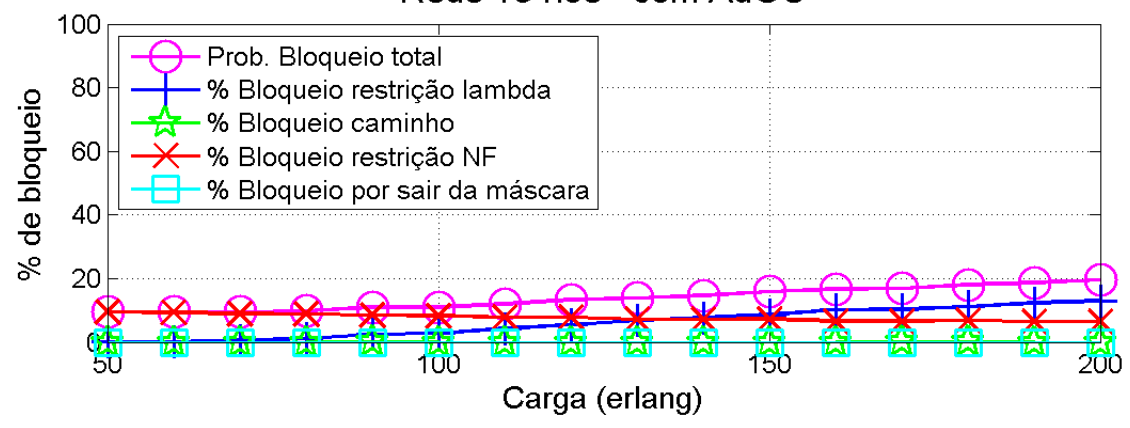

Figura F.7: Probabilidade de bloqueio total versus carga para a topologia de quinze nós com restrição de NF (limiar de $22 \mathrm{~dB}$ ) com 20 canais disponíveis na rede. 
APÊNDICE

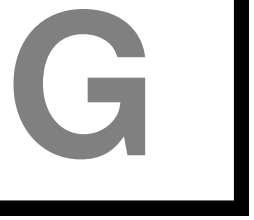

\section{Artigos sobre esta pesquisa}

Como resultado da pesquisa, foram publicados/submetidos três artigos diretamente relacionados ao trabalho:

1. U. de Moura, J. Oliveira, J. Oliveira, and A. Cesar, "EDFA adaptive gain control effect analysis over an amplifer cascade in a DWDM optical system, "in Microwave Optoelectronics Conference (IMOC), 2013.

2. Uiara C. de Moura, Juliano R. F. Oliveira, Eduardo C. Magalhães, Amílcar Careli César, Júlio C. R. F. Oliveira, "Adaptive EDFA Gain Control Scheme for DWDM Optical Networks, "em processo de ressubmissão à IEEE PTL.

3. Uiara Celine de Moura, Juliano R. F. Oliveira, Amílcar Careli César, "Roteamento de Tráfego em Redes WDM Dinâmicas Utilizando Amplificadores Ópticos com Controle Adaptativo de Ganho, "submetido para o MOMAG 2014.

Os seguintes artigos estão indiretamente relacionados com o trabalho:

4. U. C. Moura, J. R. F. Oliveira, R. L. Amgarten, G. E. R. Paiva, and J. C. R. F. Oliveira, "Caracterizador automatizado de máscara de potência de amplificadores ópticos para redes WDM reconfiguráveis, "Anais do SBrT, 2012.

5. J. R. Oliveira, A. Caballero, E. Magalhães, U. Moura, R. Borkowski, G. Curiel, A. Hirata, L. Hecker, E. Porto, D. Zibar, J. M. ao, I. T. Monroy, and J. Oliveira, "Demonstration of edfa cognitive gain control via GMPLS 
for mixed modulation formats in heterogeneous optical networks, "in Optical Fiber Communication Conference/National Fiber Optic Engineers Conference 2013, p. OW1H.2, Optical Society of America, 2013.

6. E. De A Barboza, C. Bastos-Filho, J. Martins-Filho, U. de Moura, and J. de Oliveira, "Self-adaptive erbium-doped fiber amplifiers using machine learning, "in Microwave Optoelectronics Conference (IMOC), 2013. 